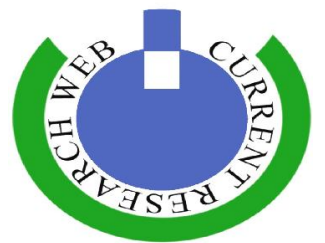

\title{
Climatic changes and their effects on physiological and nutritional status of crop plants: importance and Strategies. A review
}

\author{
${ }^{1}$ Abou Seeda M.A., ${ }^{2}$ Abou El-Nour E.A.A., ${ }^{1}$ Yassen A.A., and ${ }^{1}$ Sahar M. Zaghloul \\ ${ }^{I}$ Plant Nutrition Dept., National Research Centre, 33 El Buhouth St., 12622 Dokki, Giza, Egypt. \\ ${ }^{2}$ Fertilization Tech. Dept., National Research Centre, 33 El Buhouth St., 12622 Dokki, Giza, Egypt. \\ \begin{tabular}{lll}
\hline Received: 09 June $2021 \quad$ Accepted: 05 August 2021 & Published: 10 August 2021
\end{tabular}
}

\begin{abstract}
Climate change represents one of the greatest research challenges currently faced by plant biologists, agronomists and conservation biologists. Greenhouse gas emissions set to continue to rise for the near future. Impact of elevated atmospheric $\mathrm{eCO}_{2}$ and associated shifts in temperature and precipitation are all expected to impact plant ecophysiology, distribution and interactions with other organisms. Climate change such as drought, flood, high temperature, storm etc. are increased dramatically. Climate change has both direct and indirect impacts on agricultural production systems. Direct impacts include effects caused by a modification of physical characteristics e.g. temperature levels and rainfall distribution on specific agricultural production systems. Indirect impacts are those that affect production through changes on other species such as pollinators, pests, disease vectors and invasive species. These indirect effects can play a major role. They are much more difficult to assess and project given the high number of interacting parameters and links, many of which are still unknown. Climate change influences food security in a very complicated manner, it hampers the agricultural yield directly by means of disturbing the agro-ecological environment and indirectly by putting pressure on growth and circulation of income and consequently, increased the necessity of agricultural products. Impacts of climate change on food security have been calculated in several ways. Consequently, due to climate changes, many regions of cultivated land may become unsuitable for cultivation, and other tropical regions may produce more crops. Temperature instability will also provide more favorable environmental conditions for insect, pests of crops to boost their capacity to stay alive in cold temperatures and then emerge in outbreaks in spring. It is very crucial to observe that in case of food accessibility, all recent calculations for food security and safety have concentrated mainly on the effects of climate change in ways that did not measure the probability of substantial alteration in the rate of climate extremes on crop productivity. The atmospheric $\mathrm{eCO}_{2}$ levels have been progressing from the $280 \mathrm{ppm}$, preindustrial reference levels to current global levels exceed now above $400 \mathrm{ppm}$. Although the increasing concentration of atmospheric $\mathrm{eCO}_{2}$ is the main driver of harmful anthropogenic. Climate change, it can also improve crop performance by increasing rates of photosynthesis and water use efficiency (WUE), particularly in $\mathrm{C}_{3}$ plants. The putative positive effect in agriculture is in fact denoted to as the " $\mathrm{CO}_{2}$ fertilization effect" This effect has already been observed in crop plants and vegetables. However, longer treatments with $\mathrm{eCO}_{2}$ might lead to photosynthetic acclimation, due to increased soluble sugars leading to an imbalanced $\mathrm{C}: \mathrm{N}$ ratio, accelerated leaf senescence and/or limited growth rate.
\end{abstract}

Keywords: Climate change, Elevated carbon dioxide, Environmental factors, Crop yield, Mineral, Protein, Soluble sugar antioxidants, Soil fertility, Soil properties

\section{Introduction}

Climate change represents one of the greatest research challenges currently faced by plant biologists, agronomists and conservation biologists. Greenhouse gas emissions set to continue to rise for the near future. Impact of elevated atmospheric e $\mathrm{CO}_{2}$, and associated shifts in temperature and 
precipitation are all expected to impact plant ecophysiology, distribution and interactions with other organisms (Intergovernmental Panel on Climate Change (IPCC), (2014). Agriculture and climate change are internally correlated with each other in various aspects, as climate change is the main cause of biotic and abiotic stresses that have adverse effects on the agriculture of a region. Agriculture is being affected by climate changes in different ways such as, variations in annual rainfall, average temperature, heat waves, modifications in weeds, pests or microbes, global change of atmospheric $\mathrm{eCO}_{2}$ or ozone level, and fluctuations in sea level. Such combination of varying global climate has driven the attention of scientists, as these variations are imparting negative effects on crop production and compromising food security worldwide. According to some predicted reports, agriculture is considered the most endangered activity adversely affected by climate changes. Arunanondchai et al., (2018), reported that natural systems, human health, and agricultural production have been carelessly affected by devastating environmental changes, with the increasing population, there is a corresponding increase in food demand owing to concerns about the stability of the global environment. Several researches, Noya et al. (2018) stated that availability of water, air pollution, and soil fertility have a large influence on agriculture productivity. With abrupt changes in environmental conditions, the harsh impacts on plant productivity are progressing in great intensities owing to direct and indirect effects of abiotic stresses. Vaughan et al., (2018), reported that continuous deforestation and excessive utilization of fossil fuels, may create high concentration of $\mathrm{CO}_{2}$ has escalated from $280 \mu \mathrm{mol} / 1$ to $400 \mu \mathrm{mol}^{-1} 1$ in the atmosphere. Carbon dioxides concentration will gradually increase up to $800 \mu \mathrm{mol} / 1$ at the end of this century. Vaughan et al., (2018), stated that emission of especially $\mathrm{CO}_{2}$, gases, is the main factor for the greenhouse effect and warmer average global temperatures. Number of stress spells their impact on daily life, and damage to agricultural crops FAO (2018), mainly estimate the effects of climate change and environmental variation. Agricultural yield is predominantly suffered due to adverse environmental conditions particularly, in the developing countries. Therefore high temperature and excess of $\mathrm{CO}_{2}$ accumulation forced scientists to devise new strategies to cope with less predictable challenges (Rosenzweig et al., (2014). Accoutrement these disadvantage and guaranteed food security there is a need for production of new climate-smart crop cultivars Wheeler- et al., (2013), reported that plant growth and yield are greatly influenced by abiotic stresses. Under natural climate conditions, plants often experience numerous stresses like water logging, drought, heat, cold, and salinity (Ashraf et al., 2018; Benevenuto et al., 2017). Suzuki et al., (2014) reported that, abiotic factors include UV-B, light intensities, flooding, gas emissions, and physical and chemical factors that induce more stresses. In the $21^{\text {st }}$ average temperature of earth is expected to increase from 2 to $4.5^{\circ} \mathrm{C}$. According to IPCC (2014), the time-span between the $19^{\text {th }}$ and the $21^{\text {st }}$ centuries is considered the period that experienced the most warming (Pachauri et al., 2014). Under extreme rainfall, well cause destructions due to floods whereas the scarcity or the total absence of precipitation for a longer period of time leads to drought stresses (Khan et al., 2016).

The environment of the globe is continuously changing and industrialization is one of the main factors for temperature increase. Due to extreme weather, events the frequency of global warming is expected to increase that ultimately disturb the ecosystem globally (Kanojia, and Dijkwel, 2018). Living organisms e.g. plants, animals, fishes, and humans affected by the extreme environmental conditions. Climate conditions cause a triggered anxiety among everyone therefore; crop yield might be compromised by fluctuations in various environmental factors that can risk food security. Several studies by Lesk, et al., (2016), Altieri, and Nicholls, (2017), reported that developed countries have more vulnerability towards climatic changes by about (8-11\%) than developing states. Climate change and food insecurity are the two major issues of the $21^{\text {st }}$ century. Around 815 million people are affected by malnutrition, hindering sustainable development programs to achieve the universal goal of eliminating hunger by 2030 (Richardson et al., 2018). Food security and agricultural yield are considerably affected by the adverse weather. With elevation in temperature, the production of major crops has been reduced evidently around the world (Ito, et al., 2018). FAOSTAT. (2017), reported that population is supposed to grow to about 9 billion in 2050 and food requirement are expected to escalate by about $85 \%$. Climatic influences are worsened by present cropping schemes with low variation and elevated concentration of inputs, and unstable productivity due to environmental changes in crops (Reckling et al., 2018). The increased frequency of drought and heavy rainfall, temperature fluctuations, salinity, and insect pest attacks are anticipated to decrease crop productivity leading to higher threats of 
starvation (Dhankher, and Foyer, 2018). Crop adaptability has suffered not only because of temperature variations, but also because of rainfall (Kang et al., 2009). Campbell et al., (2016), Fig. (1).

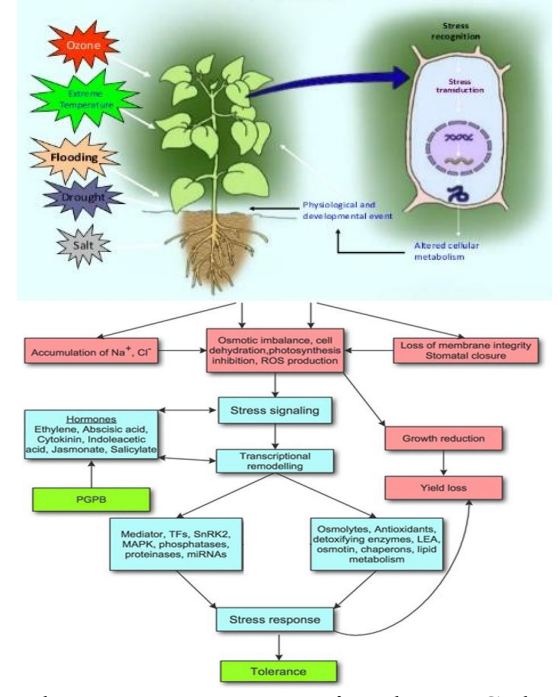

Fig. 1: Overview of salt- and drought-stress responses in plants. Salt and drought affect cell physiology and metabolism and as consequence reduce plant growth. Stress signaling is perceived by the cell and elicits stress-signaling pathways that involve transcriptional remodeling, metabolic changes and altered hormonal activity. Bacterial activity may affect the latter. A positive stress response leads to plant tolerance of the stress while a negative response leads to growth inhibition

Food security and ecosystem resilience are the most concerning subjects worldwide. Climatesmart agriculture is the only way to lower the negative impact of climate variations on crop adaptation, before it might affect global crop production drastically. In this review paper, we summarize the causes of climate change, stresses produced due to climate change, impacts on crops, modern breeding technologies, and biotechnological strategies to cope with climate change, in order to develop climate resilient crops. Revolutions in genetic engineering techniques can also aid in overcoming food security issues against extreme environmental conditions, by producing transgenic plants.

\section{Crop Production and Climate Change}

Plant physiology has been greatly influenced by climate variability by several means. Environmental extremes and climate variability enhanced the chances of numerous stresses on plants Thornton et al., (2014), Climate change affects crop production by means of direct, indirect, and socioeconomic effects as described in Fig. (2) .

\section{Effects of global climate change on agricultural productivity}

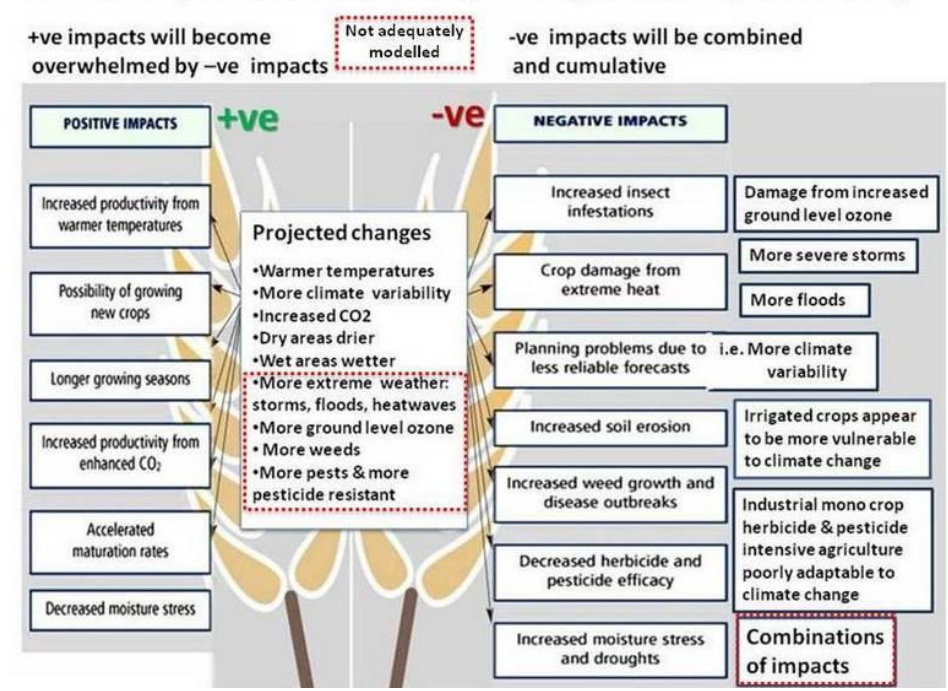

Fig. 2: Diagram illustrates the abiotic stresses that influence crop production 


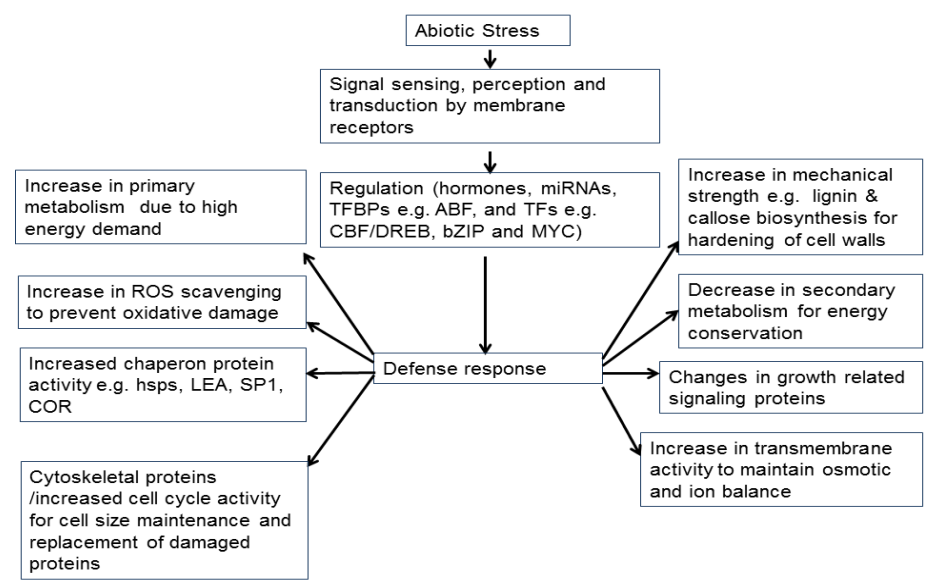

Fig. 3: Illustrates the adverse factors that damage and destroy agricultural crops and you have the impacts that global climate change cause. Most of the lists are factors that cannot be predicted by the computer models the scientists develop and use in assessing the impacts and global warming climate change on agriculture.

Furthermore, climate change such as (drought, flood, high temperature, storm etc.) events are increased dramatically as reported by Food and Agriculture Organization (FAO),2016, reported that climate change has both direct and indirect impacts on agricultural production systems. Direct impacts include effects caused by a modification of physical characteristics such as temperature levels and rainfall distribution on specific agricultural production systems. Indirect effects are those that affect production through changes on other species such as pollinators, pests, disease vectors and invasive species. These indirect effects can play a major role. Much more difficult to assess and project given the high number of interacting parameters and links. Many of which are still unknown Boyer reported in (1982) climate changes have reduced the crop yield up to 70\% (Boyer, 1982). Cultivated areas in the world are affected by climatic changes and only $3.5 \%$ of areas are safe from environmental limitations (Van Velthuizen, 2007). Whereas the outcomes of abiotic stresses on crop yield are hard to calculate accurately, it is believed that abiotic stresses have a substantial influence on crop production depending on the extent of damage to the total area under cultivation Fig. (3).

In future, the productivity of the major crops is estimated to drop in many countries of the world due to global warming, water shortage, and other environmental impacts (Tebaldi and Lobell, 2018; Bonan, et al., 2018). Based on national crop yields and questionnaire surveys, large differences in vulnerabilities to current climate changes were detected across Europe. In Northern Europe, the short duration for crop development and cool temperature are the major concerns, while the temperature extremes and low rainfall limits the crop productivity in Southern Europe, although the most negative effects will be found for the continental climate in the Pannonian zone, which includes Hungary, Serbia.and Romania (Olesen- et al., 2011,2002). It was predicted that the enhancement of greenhouse gas emissions and abrupt climatic changes will occur that may increase the crop yield in North-Western Europe and decrease the crop yield in the Mediterranean area (Olesen et al., 2011). Wheat production is heavily affected by the temperature extremes due to climate change in many countries, and may reduce the crop yield by $6 \%$ for each ${ }^{0} \mathrm{C}$ rise in temperature (Asseng et al., 2015). Drought and high temperatures are key stress factors with high impact on cereal yields Barnabás etal.(2008), Fig.(4) and Rubisco, the central enzyme of photosynthesis, is disrupted if the temperature increases from $35^{\circ} \mathrm{C}$, and stops the photosynthetic process (Griffin et al., 2004). Gong et al., (1997) reported the negative effects of heat stress on antioxidant enzymes in Zea mays. The combined impact of heat and drought stresses on crop yield has been examined in sorghum, maize, and barley. It was revealed that the combined effect of heat and drought stress had more damaging outcomes as compared to individual stress. Wang and Huang (2004) Xu and Zhou (2006) subjected the Leymus chinensis under the combined stresses of drought and heat and found that the function of Photosystem II (PSII) decreased (Xu, et al., 2006). 


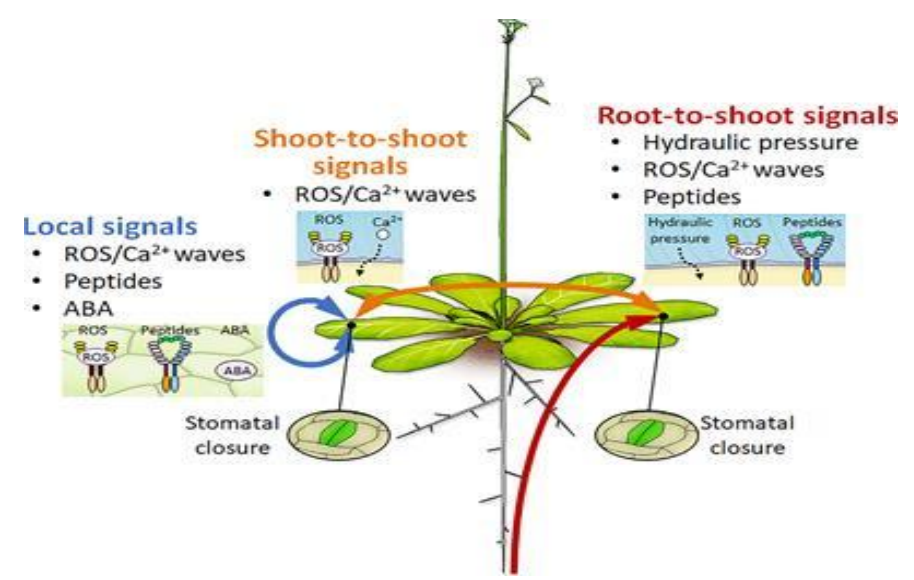

Fig. 4: Conceptual diagram of root-to-shoot, shoot-to-shoot, and local signals in response to drought stress conditions. Mobile signals such as hydraulic pressure, $\mathrm{ROS} / \mathrm{Ca}^{2+}$ waves, peptides, and phytohormones mediate tissue-to-tissue and long-distance communication for the acquisition of drought stress resistance at the whole-plant level. The red line indicates the root-to-shoot signals such as hydraulic pressure, $\mathrm{ROS} / \mathrm{Ca}^{2+}$ waves, and peptides signals under dehydration stress conditions. The orange line indicates the shoot-to-shoot signals of $\mathrm{ROS} / \mathrm{Ca}^{2+}$ waves to mediate stomatal closure under stress conditions. The blue line indicates the local signals of $\mathrm{ROS} / \mathrm{Ca}^{2+}$ waves, peptide, or ABA signals that mediate stomatal control under stress conditions.

Water deficit and temperature extremes owing to climate change; gradually influence the reproductive phase of plant growth. It was described that the flower initiation and inflorescence is badly affected by the water stress particularly, in cereals crops (Winkel et al., 1997). Climate change led to increment in local and global temperatures pose a significant threat to plant growth and crop production (Priya et al., 2019). The Intergovernmental Panel on Climate Change, 2018 reported that if current rates of global warming continue, global temperatures would continue to increase by a further $1.5^{\circ} \mathrm{C}$ between 2030 and 2052. Heat stress can impair all stages of plant growth from germination to reproduction, limiting the productivity of major staple food crops Hussain et al., (2019). For example, heat stress has a negative impact on wheat yields. A 4-6\% reduction in average global yields of wheat is predicted for each $1{ }^{\circ} \mathrm{C}$ increase in global mean temperature (Asseng et al., 2015), Abdelrahman et al., (2020), who place emphasis on the temperature susceptibility of the reproductive and grain-filling stages, and discuss the selection and development of germplasm that can maintain high yields under heat stress, competently review metabolome dynamics in wheat. Plant reproductive organs and processes leading to seed set are extremely vulnerable to increasing temperatures. Lohani et al., (2020) discussed the current knowledge and understanding of the molecular mechanisms that contribute to this temperature sensitivity, they summarized the regulation of male and female reproductive organ development and fertilization, together with heat-induced abnormalities at flowering, (Janni et al., 2020). They evaluate the potential roles of different processes in increasing crop resilience and productivity; describe the importance of genetic mechanisms in the heat stress responses of crop plants. A metabolite profiling analysis of winter wheat genotypes revealed a significant increase in sugars, sugar-alcohols, and phosphate in the more temperature-tolerant genotypes (Impa et al., 2019). Carbon loss caused by high night-time temperatures led to a significant reduction in winter wheat yields (Impa et al., 2019). The study by Sharma et al., (2020) demonstrates that plant growth regulators (PGRs) can afford protection against high-temperature stress (HTS). These authors report that PGR-treated plants were more resilient to heat stress in terms of less damage to membranes, improved photosynthesis and leaf water status, and carbon allocation than the untreated HTS controls (Sharma et al., 2020). Similarly, if the temperature increase of about $30^{\circ} \mathrm{C}$ during floret development it can cause sterility in cereals (Saini and Aspinall, 1982). During the meiotic phase, wheat and rice suffered from the 35-75\% reduction in grain set due to water deficit (Saini, and Aspinall 1981; Sheoran and Saini 1996). In rice, drought stress greatly disturbs the process of fertilization and anthesis. Due to water deficit, the harvest index is reduced to $60 \%$ and decreases the grain set (Garrity and O'Toole, 1994). The cocoa yield has been significantly reduced by the major drought spells in West Africa during the 1980s El Niño years (Ruf et al., (2015). It has been estimated that agricultural production could reduce to $25.7 \%$ by 2080 due to 
climate change and maize will be the most affected crop in Mexico Hellin, et al., (2014). A study based on ECHAM6 climate data were analyzed for North German Plains during two different time durations: 1981-2010 and 2041-2070. The results showed that if the yield for winter wheat is to be sustained, water availability must be guaranteed (Svoboda, et al., 2015).Zhao et al., (2017), they carried out an experiment to analyze the climate change impact on major crop yields and showed considerable yield reductions of $6 \%, 3.2 \%, 3.1 \%$, and $7.4 \%$ in wheat, rice, soybean, and maize, respectively (Zhao et al., 2017; Scheben, etal., 2016). Drought stress influences wheat during all developmental stages, but grain formation and the reproductive stage are the most critical ones (Pradhan, et al., 2012). Wheat yield was decreased from $1 \%$ to $30 \%$ during the mild drought stress at post-anthesis while this reduction increased up to $92 \%$ in case of prolonged mild drought stress at flowering and grain formation (Araus et al., 2002; De Oliveira et al., 2013).

Drought stress has greatly reduced the yield of important grain legumes. Mash bean (Vigna mungo L.) Yield has been decreased by drought stress from 31\% to $57 \%$ during the flowering stage while a $26 \%$ reduction caused by drought stress during the reproductive phase (Baroowa and Gogoi, 2014). Maleki et al., (2013) reported that the soybean yield has been largely affected by drought stress and a $42 \%$ reduction was observed during the grain filling stage of soybean (Maleki et al., 2013). Schlenker and Roberts (2009) described that maize yield was increased at an optimum temperature of $29^{\circ} \mathrm{C}$ but a further increase in temperature hampered the yield of maize (Lobell, et al., 2011). Every $1^{\circ} \mathrm{C}$ rise in temperature was found to negatively influence the maize yield (Schlenker and Roberts, 2009). Similar results reported by, Lobell, et al., (2011), that yield in maize decreased by $8.3 \%$ with every $1^{\circ} \mathrm{C}$ rise in temperature from the optimum growth temperature. Brown et al., (2009) reported that wheat yield decreased by about $10 \%$ with every $1^{\circ} \mathrm{C}$ increase in temperature (Lobell and Field, 2007). In another report it was reported that a 3-4\% reduction in wheat yield takes place for every $1^{\circ} \mathrm{C}$ increase in temperature (Ray etal., 2015). Easterling et al., (2007) described that a $2^{\circ} \mathrm{C}$ increase in temperature cause $7 \%$ reduction in yield while a further increase in temperature to $4{ }^{\circ} \mathrm{C}$ decreased the yield by up to $34 \%$ in wheat. Similarly, rice yield decreased by $2.6 \%$ for every $1{ }^{\circ} \mathrm{C}$ rise in temperature (Easterlinget al., 2007). In sorghum, yield was reduced by $7.8 \%$ due to a $1^{\circ} \mathrm{C}$ increase in temperature (Kjellstrom et al., 2018). In sorghum, water shortage is another big issue reported in most of the world's top producer countries (Otto et al., 2017). Schlenker and Roberts (2009) revealed that the threshold temperature for soybean is $30^{\circ} \mathrm{C}$; a rise in temperature to the optimum level increased soybean yield but after that level, further rise in temperature reduced the yield abruptly (Schlenker and Roberts, 2009). Eastburn et al., (2010) reported that the rise in ozone and $\mathrm{CO}_{2}$ concentration in the atmosphere influenced the disease type, and with a continuous rise in temperature, disease susceptibility in soybean was enhanced Eastburn etal (2010). Kitano revealed this rising concern in the growing quantity of research papers focused on abiotic problems after the crucial review on systems biology (Kitano 2002). The amount of research studies has increased dramatically related to biotic and abiotic stresses in plants by applying different strategies Fig. (5).

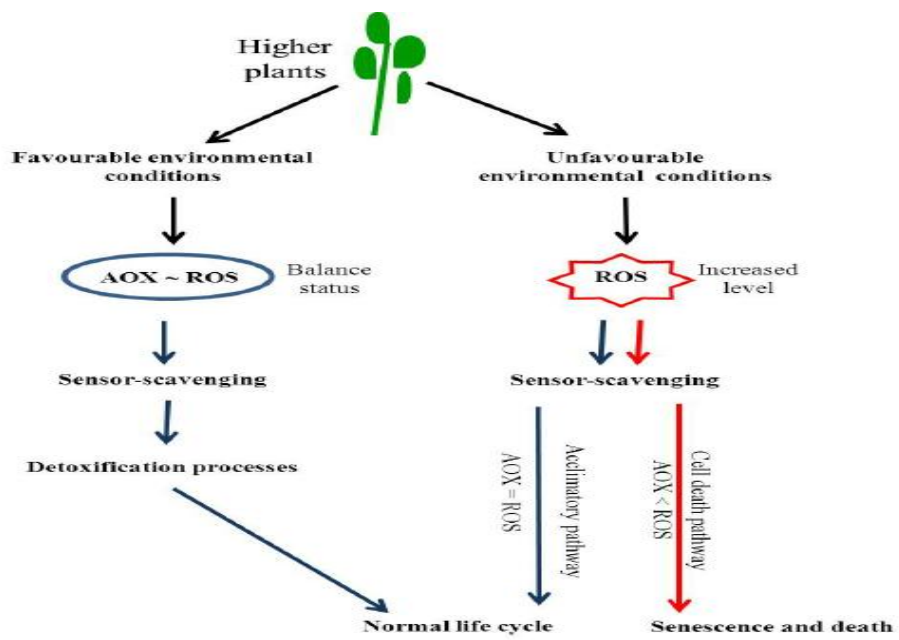

Fig. 5: Represents diagram of antioxidants and redox signaling in plants 
Climate change influences food security in a very complicated manner. It hampers the agricultural yield directly by means of disturbing the agro-ecological environment and indirectly by putting pressure on growth and circulation of income and consequently, increased the necessity of agricultural products. Impacts of climate change on food security have been calculated in several ways Intergovernmental Panel on Climate Change (IPCC), (2007). These advances have to be established to tackle amplified rate of climate changes, for example, drought and temperature extremes in the Mediterranean zone or massive rainfall spells and in temperate areas increase the risk of flooding (Schmidhuber, and Tubiello, 2007). Nevertheless, in the case of arid and semiarid regions, it may cause a reduction in livestock growth and enhance their death rates (Intergovernmental Panel on Climate Change (IPCC), 2000). The extensive rate of evapotranspiration and less moisture in the soil are predicted in drier regions by various climate models Intergovernmental Panel on Climate Change (IPCC), (2007).

Consequently, due to climate changes, many regions of cultivated land may become unsuitable for cultivation, and other tropical regions may produce more crops. Temperature instability will also provide more favorable environmental conditions for insect pests of crops to boost their capacity to stay alive in cold temperatures and then emerge in outbreaks in spring. It is very crucial to observe that in case of food accessibility, all recent calculations for food security and safety have concentrated mainly on the effects of climate changes in ways that did not measure the probability of substantial alteration in the rate of climate extremes on crop productivity. They have also not considered the situations of sudden changes in socio-economic status and climate, so all these factors have been putting negative impacts on global food security and safety (Schmidhuber, and Tubiello, 2007). Around the globe, food security is remarkably significant for human beings. Because of climate change, food quality, supply and safety are still the biggest problems for researchers. Future studies on food security will need to incorporate climate change, crop productivity, water supply, and population to estimate food security conditions entirely and scientifically (Kang et al., 2009).

\section{Climate Changes as a Global Problem}

\subsection{Impact on soils}

Climate change has become a major scientific and political issue during the last decade. There are well-marked cold and hot cycles in the history of earth's climate, however, these changes have been observed relatively rapid in the last 150-200 years around the world. Fauchereau et al., (2003) reported that soil seems to be more important for modern human societies than ever before to meet the global demands for food and fiber for increasing population from limited soil resources. Climate change is threatening food security globally. Countries like India are more vulnerable in view of the tropical climate and poor coping capacity of the small and marginal farmers. Climate change is projected to have significant impacts on agriculture through direct and indirect effects on crops, soils, livestock and pests. However, climate change is a slow process involving relatively small changes in temperature and precipitation over long period, nevertheless these slow changes in climate influence the various soil processes particularly, those related to soil fertility Fig. (6).

The effects of climate change on soils are expected mainly through alteration in soil moisture conditions and increase in soil temperature and $\mathrm{CO}_{2}$ levels because of climate change. The global climate change is projected to have variable effects on soil processes and properties important for restoring soil fertility and productivity. The major effect of climate change is expected through elevation in $\mathrm{CO}_{2}$ and increase in temperature.

\subsection{Soil formation and development}

Soil formation is controlled by numerous factors including climatic factors such as temperature and precipitation. These parameters of climate influence the soil formation directly by providing biomass and conditions for weathering. Main parameters of climate that directly influence on soil formation are sum of active temperatures and precipitation-evaporation ratio Fig. (7). They determine values of energy consumption for soil formation and water balances in soil, mechanism of organicmineral interactions, transformation of organic and mineral substances and flows of soil solutions. Stable progressive climate warming lead to irreversible changes in mineral matrix of soils. Changes in external factors of soil formation (temperatures and precipitation) will lead to transformation of internal factors (energy, hydrological, biological). The climate change will increase energy of destruction of soil 
minerals resulting in simplification of mineral matrix due to accumulation of minerals tolerant to weathering Fig. (7).

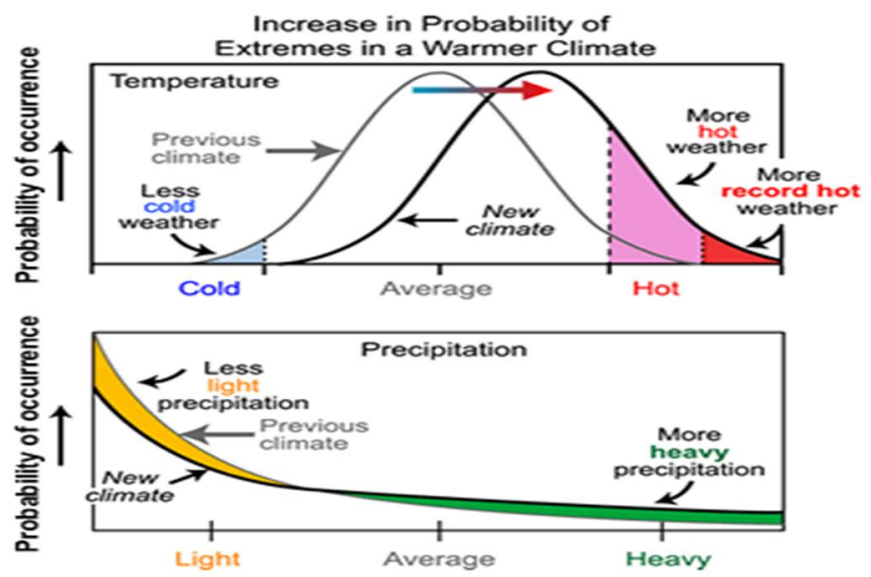

Fig. 6: Illustrates small changes in the global average temperature also mean heat waves get hotter and droughts get drier, the pine forests became sagebrush desert. Such changes in precipitation could be just as important, or even more important, than temperature increases for many parts of Earth.

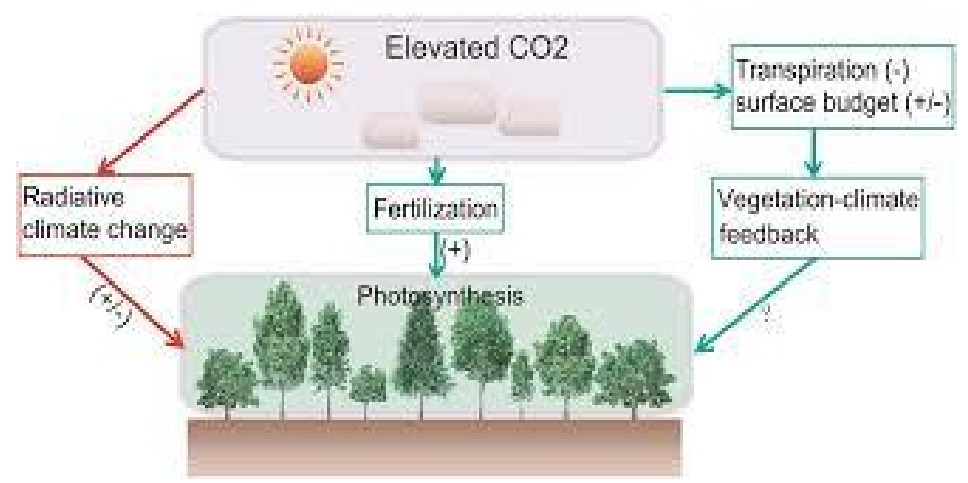

Fig. 7: Schematic diagram of $\mathrm{CO}_{2}$ 's three-pathway influence on terrestrial gross primary productivity (GPP).

The rising atmospheric $\mathrm{CO}_{2}$ concentration will facilitate plant uptake of $\mathrm{CO}_{2}$ through photosynthesis (fertilization effect). $\mathrm{CO}_{2}$ also influences plant photosynthesis indirectly through its climate forcing effect. Its impact on climate through trapping long wave radiation (radiative climate change) can increase Earth's mean surface temperature and thus influence plant photosynthesis. The response of plants to rising $\mathrm{CO}_{2}$ can cause an increase in foliage cover and decreases leaf transpiration by reducing stomatal conductance per unit leaf area, which also influence climate system (vegetation-climate feedback) and thus influence plant photosynthesis indirectly.

Gross primary productivity (GPP) plays a crucial role in driving the land carbon cycle. Processbased and data driven models have been used to evaluate how global GPP responds to climate change and rising $\mathrm{CO}_{2}$ concentrations (Beer et al., 2010; Jung et al., 2011; Piao et al., 2013). Models and field experiments agree on the fact that elevated $\mathrm{CO} 2$ increases carboxylation rates and GPP (hereafter fertilization effect) in absence of nutrient limitations and decreases leaf-scale stomatal conductance (Medlyn et al., 2015). The radiative forcing of elevated $\mathrm{eCO}_{2}$ also causes climate change, which can increase or reduce GPP depending on regional temperature and water limitations, with water limitations being today prominent over most of ecosystems (Beer et al., 2010). Therefore, there are large uncertainties about the magnitude and regional patterns of the net GPP response to the joint perturbation of $\mathrm{eCO}_{2}$ concentration and climate change (Beer et al.,2010). Most studies of GPP trends with processbased land carbon models have been conducted by using so-called off-line simulations where atmospheric forcing conditions are imposed to an ecosystem model, but there is no feedback from the 
land surface to the atmosphere (Piao et al., 2013; Beer et al., 2010). Coupled climate-carbon cycle models include both impacts of $\mathrm{CO}_{2}$ through climate change and vegetation fertilization, but previous simulations did not fully separate the two mechanisms (Friedlingstein et al., 2006; Arora et al., 2013; Matthews et al., 2007). In a coupled climate-carbon models, climate change affects GPP differently across regions and time of the year, depending upon local temperature or water limitations (Matthews et al., 2007; Cox et al., 2000). In addition, vegetation-climate feedback occurs when plants close their stomates and decreased transpiration under elevated $\mathrm{CO}_{2}$. This anti-transparent effect of $\mathrm{eCO}_{2}$ leads to more soil moisture being available for plants in the dry season and changes the partition of net radiation between latent heat (evapotranspiration) and sensible heat. Increases in vegetation cover and leaf area index due to $\mathrm{CO}_{2}$ fertilization can, however, offset the effect of leaf-level stomatal closure by increasing the surface of leaves available for transpiration (Ukkola et al., 2015; Donohue et al., 2013). Previous research on carbon-climate feedback under $\mathrm{eCO}_{2}$ mainly focused on the $\mathrm{eCO}_{2}$-fertilization (a negative feedback on climate change through increased carbon sinks caused by higher GPP) and on $\mathrm{eCO}_{2}$ induced climate change. Vegetation-climate feedback under $\mathrm{eCO}_{2}$ have been shown to decrease atmospheric humidity Cao et al., (2010) and precipitation Andrews et al., (2011); Boucher et al., (2009), which warms land surface temperature and in turn impacts GPP. But the effect of climate change from $\mathrm{eCO}_{2}$ through vegetation-climate feedback on GPP has not been separated from the $\mathrm{CO}_{2}$-fertilization effect in previous studies. Here we use the terms $\mathrm{eCO}_{2}-\mathrm{VCF}$ to denote climate change caused by vegetation-climate feedback under $\mathrm{eCO}_{2}$ and eCO2-FERT for the $\mathrm{CO}_{2}$ fertilization effects on GPP.

It will lead loss of soil function for fertility maintenance and greater dependence of on mineral fertilizers. Soil development is broadly controlled by three main factors i.e. climate, parent material and vegetation type. The effects of climate change on soil development are expected mainly through alteration in soil moisture conditions and increase in soil temperature and $\mathrm{CO}_{2}$ levels. Climate change will influence soil moisture levels by direct climatic effects (precipitation, temperature effects on evaporation), climate induced changes in vegetation, plant growth rates, rates of soil water extraction by plants and the effect of enhanced $\mathrm{CO}_{2}$ levels on plant transpiration. Changes in soil water fluxes may also feed back to the climate itself and even may contribute to drought conditions by decreasing available moisture, altering circulation patterns and increasing air temperatures. Among various factors controlling the process of soil development, climate plays a major role in weathering of rocks and minerals. The variables of climate change particularly temperature and rainfall dictates various stages of weathering of rocks and minerals (parent material) resulting in chemical and mineralogical changes in soil forming rocks. Water is very essential for chemical weathering to take place and hence, an increase in rainfall accelerates weathering. The same types of primary minerals give rise to different secondary minerals when the conditions of weathering differ. Thus, similar rock types undergoing weathering in different climatic conditions could give rise to distinct soil profiles.

\subsection{Plant nutrients availability, transformation and acquisition}

Plant availability of nutrients in the soil is a function of soil chemical properties as well as location of the ion relative to the root surface and the length of the pathway the nutrient must travel in the soil to reach the root surface Fig. (8). Increases in air temperature and changes in precipitation have significant impacts on root zone temperature and moisture regimes. It is well known that soil moisture and temperature are primary determinants of nutrient availability and root growth and development and that carbon allocation to roots governs nutrient acquisition, it is reasonable to expect that process outcomes will be reflective of the changed climate.

The nature and extent of the change in these two parameters will be site- and soils specific. It has been suggested that climate change impacts on nutrient use efficiency is be primarily affected through direct impacts on root surface area and influx rate (Brouder and Volenec, 2008). Plants accumulate nutrients from the soil solution pool, and nutrients must be in solution to be mobile in the soil biological transformation between organic and inorganic pools is strongly influenced by moisture and temperature, and thus, global climate change may strongly influence solution concentrations of $\mathrm{N}$ as well as Pendall et al., (2004) who suggested that increased $\mathrm{CO}_{2}$ may not exert a significant direct effect on $\mathrm{N}$ mineralization per use but associated warming can cause increased $\mathrm{N}$ mineralization, leading to increased solution-phase N (Abou Seeda et al., 2020). Rates of adsorption/ desorption reactions will accelerate with increased temperature, and changes in soil moisture may further modify reactions by altering the ionic strength of the soil solution. 


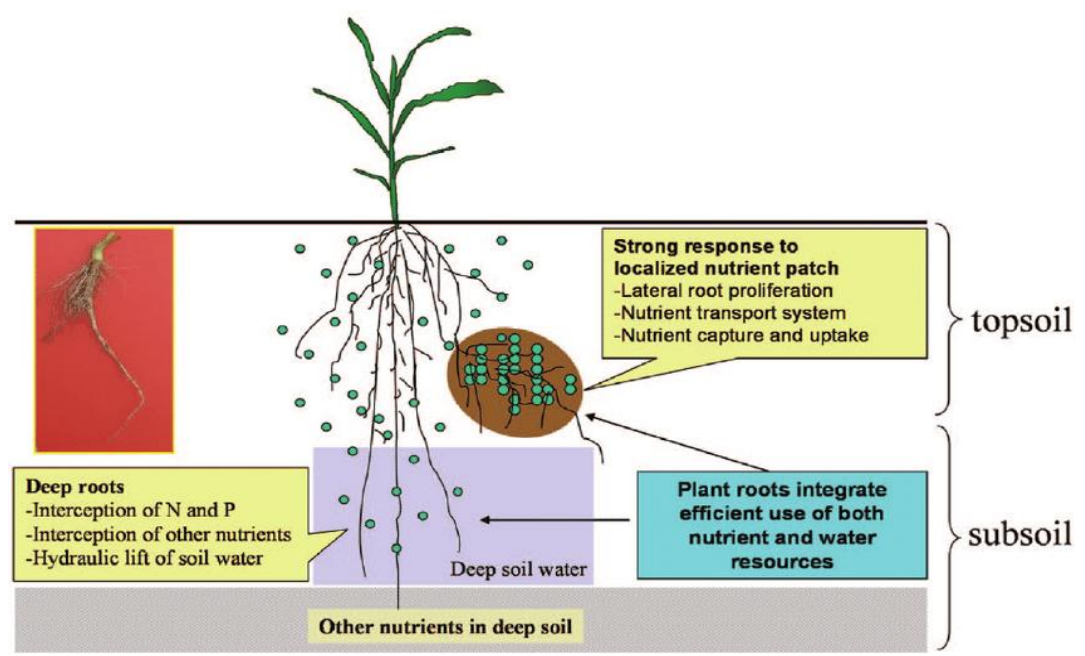

Fig. 8: Represents root architecture with strong responses to localized nutrient patches and deep rooting properties for efficient nutrient and water acquisition. After Mi et al.,2010).

\subsection{Adaptation and mitigation strategies}

Agriculture can adapt to climate change by adopting farm management practices that minimize the adverse effects of increasing or decreasing rainfall and temperatures or other extreme weather conditions. Many management level adaptation options are available to attenuate the effects of climate change on crop production, including zero tillage, retaining crop residues, extending fallows, increasing the diversity of production, altering amounts and timing of external inputs, as well as broader agronomic management strategies. Agriculture can contribute to climate change mitigation through farm management practices that reduce greenhouse gas emissions and enhance soil carbon sequestration. Emissions of carbon dioxide can be reduced through reduced biomass burning and more efficient energy use. Emissions of methane reduced through improved farm management practices that include improved management of livestock waste and water in rice paddies. Nitrous oxide emissions reduced through improved management of $\mathrm{N}$ fertilizers including appropriate type, rate and method of application and soil management. Various farm management practices can enhance soil carbon stocks and encourage soil functional stability. Conservation agriculture technologies, soil conservation measures and nutrient replenishment strategies can restore soil organic matter by providing a protective soil cover and an environment conducive to vigorous plant growth. In some cases, however, a change in the agricultural production system may be required. Continuous cereal cropping is being replaced by ley farming or by the introduction of agro forestry systems. The global soil carbon pool exceeds biomass pools by a factor of four or five, without taking into account that recent soil degradation has led to losses of between 30 percent and $75 \%$ of their antecedent soil organic carbon. Globally, therefore, a soil carbon increase offers great mitigation potential. Carbon sequestration refers to the storage of carbon in a stable solid form. It occurs through direct and indirect fixation of atmospheric $\mathrm{CO}_{2}$. Direct soil carbon sequestration occurs by inorganic chemical reactions that convert $\mathrm{CO}_{2}$ into soil inorganic carbon compounds such as calcium and magnesium carbonates. Direct plant carbon sequestration occurs as plants photosynthesize atmospheric $\mathrm{CO}_{2}$ into plant biomass. Subsequently, some of this plant biomass is indirectly sequestered as soil organic carbon (SOC) during decomposition processes. The amount of carbon sequestered at a site reflects the long-term balance between carbon uptake and release mechanisms. Many agronomic, forestry, and conservation practices, including best management practices, leads to a beneficial net gain in carbon fixation in soil.

It is generally accepted that increases in $\mathrm{CO}_{2}$ concentration quantitatively and qualitatively alter the release of root-derived compounds. Plants under elevated $\mathrm{CO}_{2}$ decrease their allocation of N-rich metabolites and increase the allocation of $\mathrm{C}$ rich metabolites to root exudates. Tarnawski and Aragno (2006) stated that such phenomena gradually increase in microbial activity and consequently the $\mathrm{CO}_{2}$ production, which has is a potential negative effect on the accumulation of organic $\mathrm{C}$ in soils and thus on potential sequestration of soils Fig. (9). 


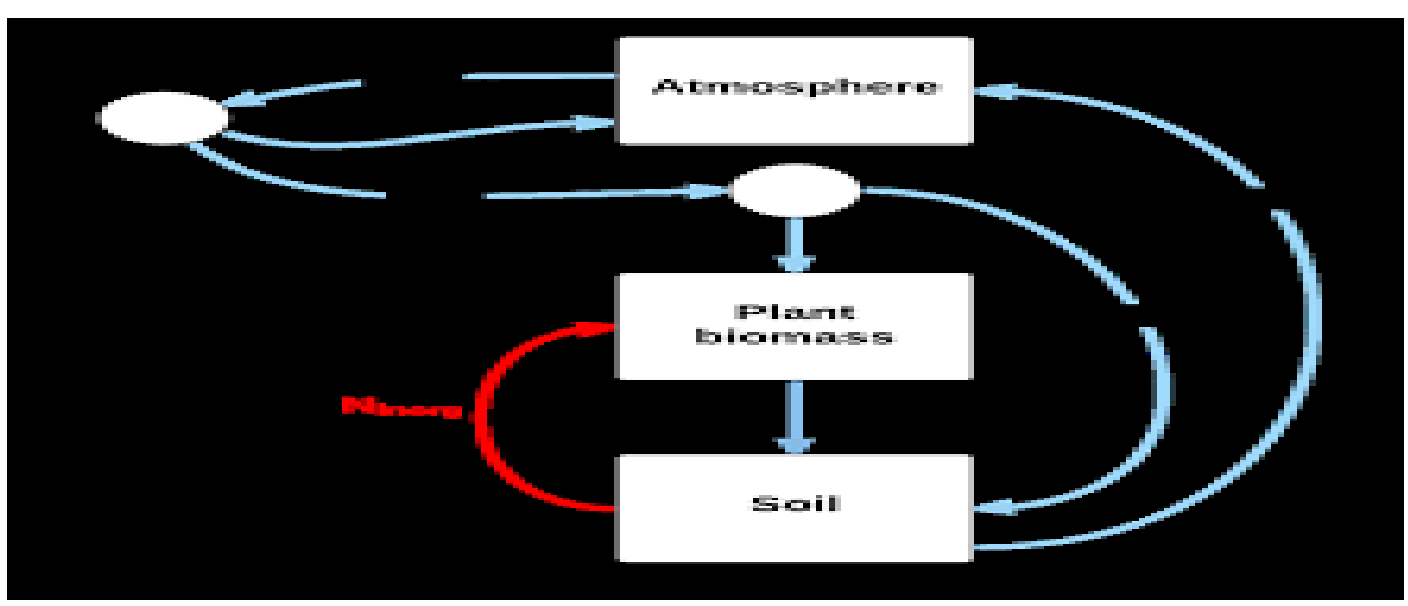

Fig. 9: Representation of the $\mathrm{C}$ cycle, including pools (squares), the fluxes of $\mathrm{C}$ between pools (blue arrows), and its interaction with the $\mathrm{N}$ cycle (red arrow). Circles represent the division of a flux in to two different sub fluxes. Plants absorb $\mathrm{CO}_{2}$ from the atmosphere via photosynthesis. Part of the photosynthetically fixed C (gross primary production, GPP) goes back to the atmosphere ( $\mathrm{Ra}$, autotrophic respiration). The remaining utilizable $\mathrm{C}$ (net primary production, NPP; NPP = GPP - Ra) can be allocated to biomass productivity (BP, growth), and to Cex (C export, exudation into the soil and allocation to mycorrhizal fungi and root symbionts). When plants die, the $\mathrm{C}$ in plant biomass is transferred into the soil $\mathrm{C}$ pool. Soil microorganisms, fuelled by the Cex released belowground, can decompose the available soil organic matter (SOM): a process in which $\mathrm{N}$ is transformed from organic to inorganic form (mineralization), and hence it can become available to plants to support their growth. The decomposition of SOM emits $\mathrm{CO}_{2}$ back to the atmosphere (Rh, heterotrophic respiration). After César Terrer-Moreno (2017).

It was stated that the concentration has a significant negative feedback on global change processes and will reduce the sequestration potential of soils. Several studies using $\mathrm{C}$ isotope tracers have demonstrated that the production of $\mathrm{CO}_{2}$ in the rhizosphere by roots and microorganisms is significantly stimulated by elevated $\mathrm{CO}_{2}$ plant growth conditions. The stimulation of $\mathrm{CO}_{2}$ respiration in the rhizosphere may be much higher than the enhancement of root biomass. Cheng et al., (1998), demonstrated that although plants produced only $15-26 \%$ more biomass under elevated $\mathrm{CO}_{2}$, rhizosphere respired $\mathrm{C}$ increased by $56-74 \%$ as compared to ambient $\mathrm{CO}_{2}$ treatments.

Agro-ecosystems can play an important role in mitigating $\mathrm{CO}_{2}$ emissions through biotic $\mathrm{C}$ sequestration in soils and vegetation. Because of historic losses of $\mathrm{C}$ from soils, estimated to be 41 to $55 \mathrm{Gt}$, the soils now offer an opportunity for carbon storage. The carbon sequestration potential of a soil depends on climate, the type of vegetation it supports, the nature of parent material, the depth of profile, soil drainage, the edaphic environment, soil organic matter (SOM) content and its decomposability and land management practices. Improved management of a,gro-ecosystems can significantly enhance $\mathrm{C}$ sequestration in soils. Management practices or technologies that increase carbon input to the soil and reduce $\mathrm{C}$ loss or both lead to net carbon sequestration in soils. Increased $\mathrm{C}$ input in agro-ecosystems can be achieved in a number of ways such as selection of high biomass producing crops, residue recycling or residue retention by lessened tillage intensity, application of organic materials e.g. animal manure, compost, sludge, green manure, adoption of agro forestry systems, intensification of agriculture through improved nutrient and water management practices, reducing summer or winter fallow, changing from monoculture to rotation cropping, and switching from annual crops to perennial vegetation. Soil carbon loss could be decreased by adopting conservation agriculture and minimizing soil disturbance, checking erosion through reduced tillage intensity, and using low quality organic inputs. Technological options that have been found to be efficient for soil $\mathrm{C}$ sequestration in Indian agro-ecosystems include integrated nutrient management and maturing, crop residue incorporation, mulch farming and/conservation agriculture, agro-forestry systems, grazing management, choice of cropping system and intensification of agriculture. Integrated nutrient management involving addition of organic manures/composts along with inorganic fertilizers results in improved soil aggregation (Benbi and Senapati, 2009). 


\section{Climatic changes on mineral accumulation and importance}

The atmospheric $\mathrm{CO}_{2}$ levels have been progressing from the $280 \mathrm{ppm}$ preindustrial reference levels, Ainsworth and Long (2005); Myers et al., (2017) to current global levels which are now above $400 \mathrm{ppm}, \mathrm{IPCC}$ (2018). Although the increasing concentration of atmospheric $\mathrm{CO}_{2}$ is the main driver of harmful anthropogenic climate changes, it can also improve crop performance by increasing rates of photosynthesis and water-use efficiency, particularly, in $\mathrm{C}_{3}$ plants. The putative positive effect in agriculture is in fact denoted to as the " $\mathrm{CO}_{2}$ fertilization effect" Ainsworth and Long (2005); Bowes (1993); Bunce (2015); Dietterich et al., (2015); Högy and Fangmeier (2008); Loladze (2014); Long et al., 2004; Myers et al., (2017); Ziska and Bunce (2007). This effect has already been observed in crop plants and vegetables, including wheat Dong et al., (2018c); Fernando et al., (2012a); Han et al., (2015); Högy and Fangmeier 2008), maize Zong and Shangguan (2014), rice (Guo et al., 2015; Pang et al., (2006); Yang et al., (2007), barley Haase et al., (2008); Mitterbauer et al., (2017), bean (Bunce (2008); Ma et al., (2017), soybean Bunce (2015); Kumagai et al., (2015), cowpea Dey et al., (2017), potato Kumari and Agrawal (2014), lettuce, carrot, parsley Dong et al., (2018b); Long et al., (2004); Mortensen (1994) and tomato Jin et al., (2009) among others. However, longer treatments with $\mathrm{eCO}_{2}$ might lead to photosynthetic acclimation, due to increased soluble sugars leading to an imbalanced C: $\mathrm{N}$ ratio, accelerated leaf senescence and/or limited growth rate Fig. (10), Ainsworth and Long (2005); Ainsworth et al., (2004); Kaplan et al., (2012); Ludewig and Sonnewald (2000). Future models of climate change for the period of 2000-2100 predicted an overall decrease of the growing season length and crop transpiration, and increase in water-use efficiency, biomass production, and yields, but with considerable variation among crop models (Ahmed et al., 2017; Bassu et al.,2014).
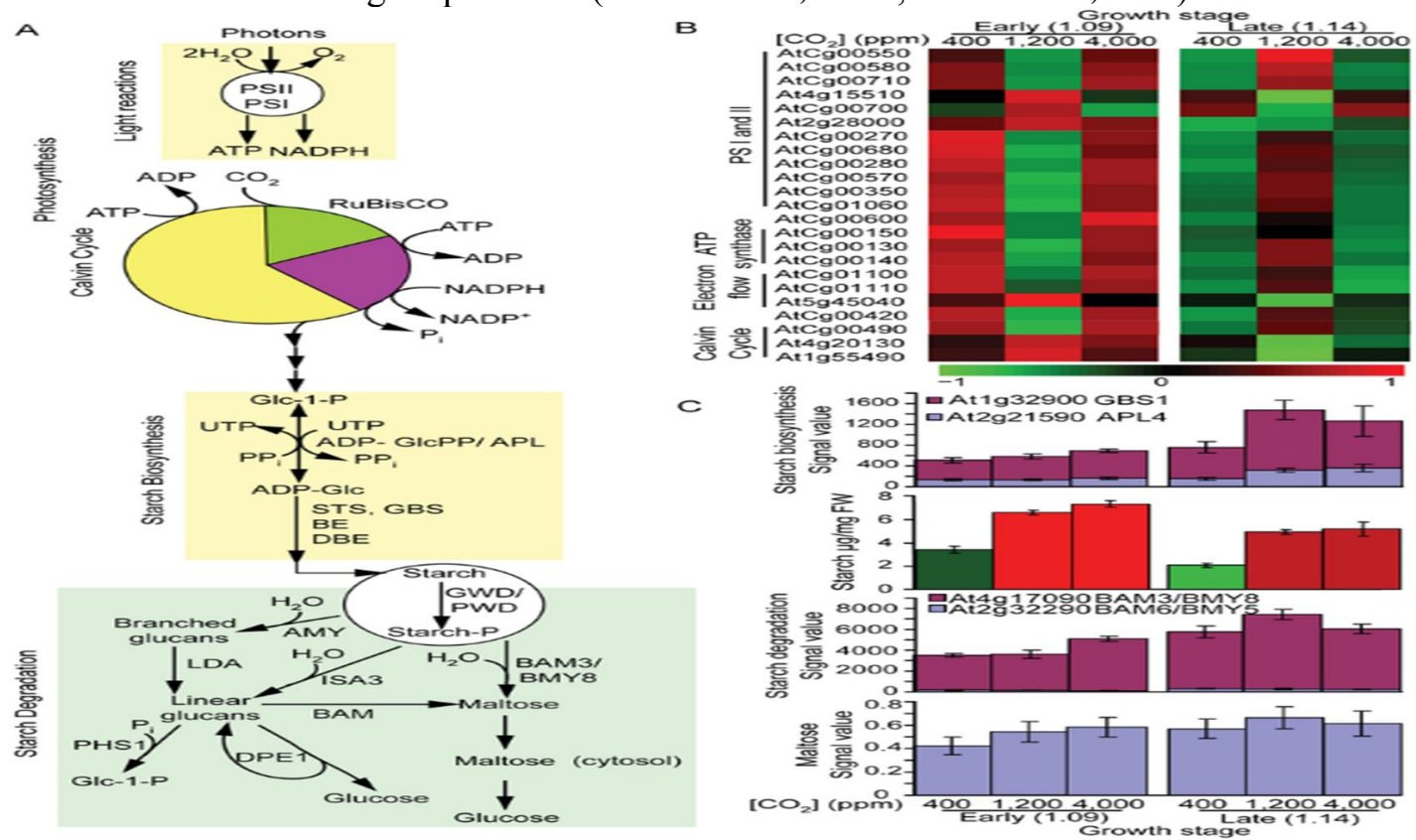

Fig. 10: Illustrates influence of $\left[\mathrm{CO}_{2}\right]$ and development on photosynthesis and starch metabolism. A) Photosynthesis and starch biosynthesis and degradation pathways. B) Heat maps of the transcript profiles of photosynthesis. For each gene, its expression level was normalized across all samples so that the mean expression is 0 and the variance is 1 . Higher levels are represented with color red of increasing intensity, and lower levels are represented with green of increasing intensity. The increased or reduced expression is relative to the mean expression. All transcript levels shown was statistically significant ( $p$-value $\leq 0.001$ ) with 2 fold or more increase or decrease at any one treatment. C) Starch biosynthesis, starch content, starch degradation and maltose content $(n=3$ biological replicates $\times 3$ analytical replicates). Starch levels were significantly higher in elevated and $\mathrm{SE}\left[\mathrm{CO}_{2}\right]$ treatments (students t-test $\mathrm{p}$-value $<0.05$ ) than the control.

Despite all the compelling evidence, there is still insufficient knowledge on the role of $\mathrm{eCO}_{2}$ in shifting the nutritional composition of crops and on the direct consequences to humans Dong et al., (2018b); Duval et al., (2012); Fernando et al., (2012a); Guo et al., (2015); Högy and Fangmeier (2008); Jablonski et al., (2002); Li et al., (2018b); Loladze (2002); Myers et al., (2014). Loladze (2014) describing a 
significant reduction in overall mineral concentration $(\sim 8 \%)$ in $\mathrm{C}_{3}$ plants, including foliar and edible tissues using a meta-analysis of FACE and non-FACE studies, Fig. (11).

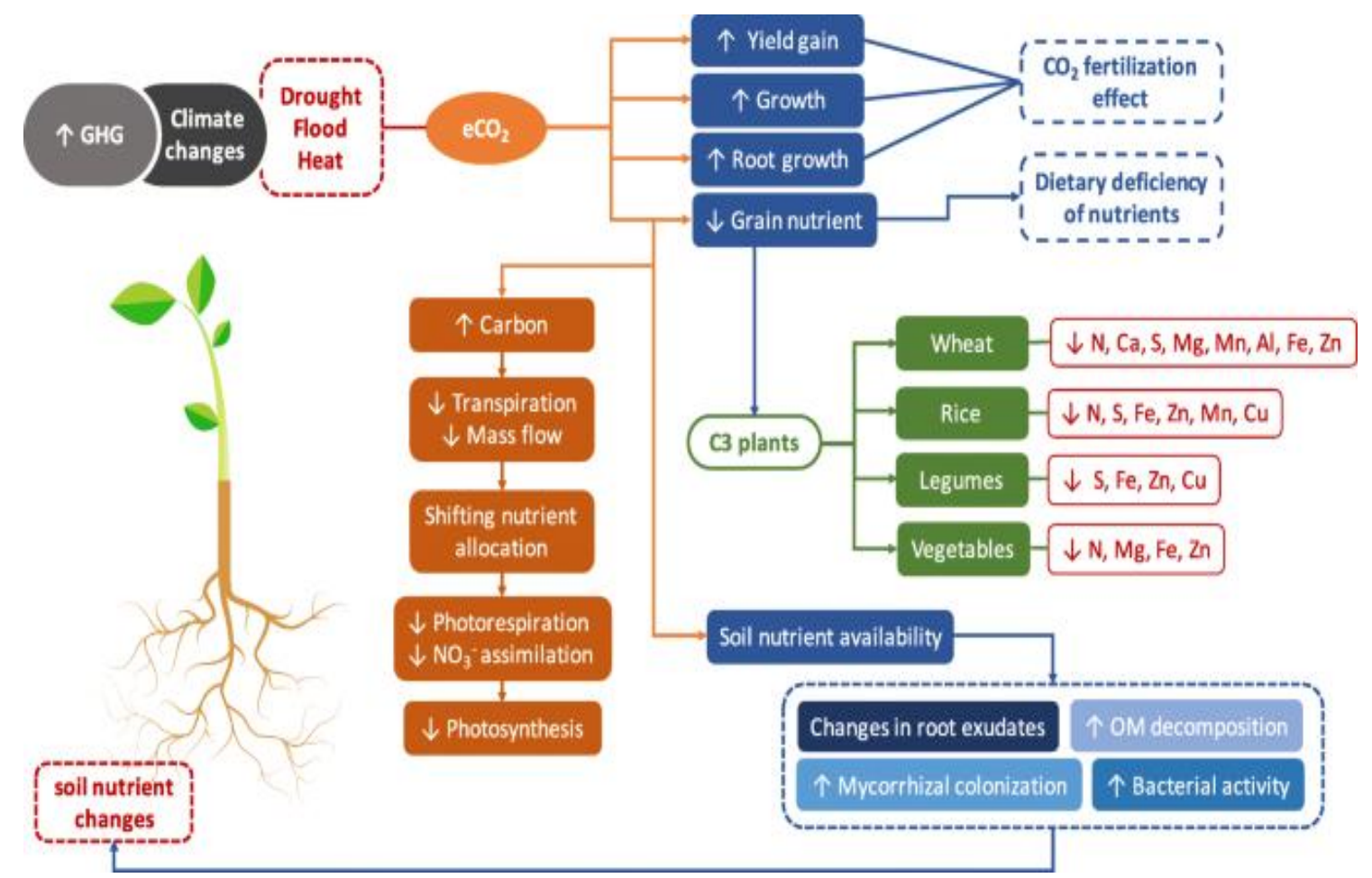

Fig. 11: Schematic illustration of the influence of climatic changes, driven by increased greenhouse gas (GHG) emissions, on grain mineral concentrations and their bioavailability in soil. The effects of $\mathrm{CO}_{2}$ on nutrient concentrations in edible tissues of $\mathrm{C} 3$ plants are reflected in FACE and non-FACE studies. The mechanisms proposed as responsible for changing the plant mineral concentration are: "carbohydrate dilution" in which there is an increase in carbon (C) assimilation relative to the mineral concentration, decrease in transpiration rates that reduces mass flow of nutrients, and shifting nutrient allocation by altered biochemical processes between tissues can affect nutrient uptake. In addition, down-regulation of photosynthesis and increased photorespiration has been also expected to elucidate the variations in mineral concentrations. The $\mathrm{CO}_{2}$ concentration has also a direct effect on the bioavailability of nutrients in soils and, consequently, affecting the quantity of existing microorganisms. Possibly, due to changes in soil $\mathrm{pH}, \mathrm{e}_{2}$ improves the exudation processes affecting nutrient availability. Furthermore, the role of e $\mathrm{CO}_{2}$ increasing mycorrhizal colonization and organic matter (OM) decomposition in the soil, facilitating the availability of several nutrients

Carbon dioxide concentration has also a direct effect on the bioavailability of nutrients in soils, and consequently, affecting the number and diversity of existing microorganisms. A positive effect on soil nutrient bioavailability was described under $\mathrm{CO}_{2}$ enrichment conditions (Jablonski et al., 2002; Kimball et al., 2002). However, the increase in plant growth with $\mathrm{eCO}_{2}$ may have a disadvantage in terms of competition for micronutrient acquisition with microorganisms prevailing in the soil (Guo et al., 2015). Abbas et al., (2009) showed that $\mathrm{eCO}_{2}$ promoted increases in $\mathrm{P}, \mathrm{K}, \mathrm{Fe}, \mathrm{Mn}$ and $\mathrm{Zn}$ in the soil. Possibly, $\mathrm{eCO}_{2}$-induced changes in soil $\mathrm{pH}$ improves some exudation processes that affects the availability of nutrients in the soil. Similarly, it was described that $\mathrm{eCO}_{2}$ responses averaged across two $\mathrm{N}$ treatments increased the concentrations of $\mathrm{Ca}, \mathrm{Mg}, \mathrm{Fe}, \mathrm{Zn}$ and $\mathrm{Mn}$ at the soil surface by 15.6, 9.5, 23.4, 138.2 and 16.9\%, respectively (Guo et al., 2015; Abou Seeda etal., 2020). In another study, Jin et al., (2019) described the interaction of long-term $\mathrm{CO}_{2}$ conditions with different soil types (chromosol, vertosol, and calcarosol) on grain nutrient concentrations of wheat, field pea, and canola. At $\mathrm{eCO}_{2}$, the concentrations of $\mathrm{N}, \mathrm{P}$, and $\mathrm{Zn}$ decreased by 6,5 , and $10 \%$, respectively, regardless of soil, crop and year. In addition, the concentrations of $\mathrm{K}, \mathrm{Fe}, \mathrm{Mn}$ and $\mathrm{Cu}$ were not affected by $\mathrm{CO}_{2}$ enrichment in any crop grown in the soils tested. Furthermore, e $\mathrm{CO}_{2}$ may increase mycorrhizal colonization and protect 
plants against some stresses, having led to improved P nutrition, particularly on legumes Jakobsen et al., (2016) and increased soil organic carbon decomposition (Abou Seeda et al., 2020). Cheng et al., (2012) facilitating the availability of some nutrients. In sum, a clear understanding of the nutrientrelated processes that are impacted by climate change will increase our ability to predict responses for diverse crops and could benefit farmers in agronomic management to adapt crops to higher $\mathrm{CO}_{2}$. One important final consideration under $\mathrm{eCO}_{2}$ is the overall effect of lower mineral concentrations while in promoting higher yields. For some situations it has been suggested that regardless of the decrease in grain nutrient concentrations at $\mathrm{eCO}_{2}$, overall availability of $\mathrm{Fe}, \mathrm{Zn}, \mathrm{Mn}, \mathrm{B}, \mathrm{Cu}, \mathrm{Ca}, \mathrm{N}$, and other macronutrients on a land area basis would actually be enhanced, due to grain yield increase at $\mathrm{eCO}_{2}$ conditions (Asif et al., 2017a; Fernando et al., 2012b). Elevated atmospheric gradually decreased N, $\mathrm{Mg}, \mathrm{Fe}$, and $\mathrm{Zn}$ concentrations, and not affected $\mathrm{P}, \mathrm{K}, \mathrm{S}, \mathrm{Cu}$, and $\mathrm{Mn}$ concentrations in the edible part of vegetables (Dong et al., 2018b Abou Seeda et al., 2020). Strong evidence that $\mathrm{Zn}$ deficiency is a significant global health problem affecting $17 \%$ of the world's population, and that increasing $\mathrm{CO}_{2}$ levels lower the concentration of $\mathrm{Zn}$ in significant food crops (Myers et al., 2017; Myers et al., 2015; Myers et al., 2014). In a meta-analysis with previously published data from FACE and growth chamber experiments, Myers et al., (2014) found a significant reduction in $\mathrm{Zn}$ concentration in wheat $(-9.1 \%)$, rice $(-3.1 \%)$, barley $(-13.6 \%)$, field peas $(-6.8 \%)$, and soybean $(-5.0 \%)$ grown at e $\mathrm{CO}_{2}$. Similarly, e $\mathrm{CO}_{2}$ decreased by $9.4 \%$ the $\mathrm{Zn}$ concentration in vegetables as described by (Dong et al.,2018b). Thus, due to increased concentrations of atmospheric $\mathrm{CO}_{2}$ it was anticipated that 138 million of people will be placed at new risk of Zn deficiency by a year of 2050, and the most affected populations live in Africa and South Asia, with a particular incidence in India with 48 million people at risk (Myers et al., 2015). The mechanisms responsible for the overall decline of plant mineral concentrations are not completely deciphered. Despite the "carbohydrate dilution" being a likely cause, it cannot elucidate all the mineral reductions because of the heterogenous response of each mineral tested for a given crop or for different species (Loladze 2002; Poorter et al., 1997). Moreover, decreases in transpiration rates reduces mass flow of nutrients, and shifting nutrient allocation driven by altered biochemical processes between tissues can both change nutrient uptake (McGrath and Lobell, 2013).

However, a trade-off effect must be considered because per serving size, the actual tissues can affect nutrient uptake. In addition, down-regulation of photosynthesis and increased photorespiration have been also expected to elucidate the variations in mineral concentrations. The $\mathrm{CO}_{2}$ concentration has also a direct effect on the bioavailability of nutrients in soils and, consequently, affecting the quantity of existing microorganisms. Possibly, due to changes in soil $\mathrm{pH}, \mathrm{eCO}_{2}$ improves the exudation processes affecting nutrient availability. Furthermore, the role of $\mathrm{eCO}_{2}$ increasing mycorrhizal colonization and organic matter (OM) decomposition in the soil, facilitating the availability of several nutrients amount of minerals provided will still be lower, albeit the higher overall grain yields, which may not be sustainable in the long run due to COacclimatization effects and faster depletion of mineral nutrients from the soil.

\subsection{The influence of $\mathrm{eCO}_{2}$ on protein accumulation}

Elevated $\mathrm{CO}_{2}$ has generally been shown to decrease the concentration of protein in grains of many crops species Dong et al., (2018b); Högy and Fangmeier (2008); Medek et al., (2017); Myers et al., (2017), (2014), directly affecting human nutrition (Toreti et al., 2019). Consequently, millions of people may face protein deficiency since a great part of worldwide population depends on plant proteins (Medek et al., 2017). Medek et al., (2017) confirmed that when grown under $\mathrm{eCO}_{2}$ conditions expected by the middle of this century $(500-700 \mathrm{ppm})$, a lower protein concentration was found in $\mathrm{C} 3$ grains (wheat, rice and barley with $-7.8,-7.6$, and $-14.1 \%$, respectively), potato (-6.4\%), vegetables $(-17.3 \%)$, and fruit (-23.0\%). The $\mathrm{eCO}_{2}$ was also responsible for a slight decrease in protein in legume species ($3.5 \%$ ), and no significant effects were found in oil crops and $\mathrm{C} 4$ plants. Accordingly, they anticipated a decrease in protein intake under $\mathrm{eCO}_{2}$ conditions by $>5 \%$ in 18 countries predominantly throughout Middle East and India. Moreover, it was highlighted that almost $12 \%$ of the world's population is currently at risk of protein deficiency. In the case of constant atmospheric $\mathrm{CO}_{2}$, they predict that globally, $15 \%$ (1.4 billion people) of world population would be at risk of protein deficiency by 2050 due mainly to demographic changes. However, with projections of $\mathrm{CO}_{2}$ levels above $500 \mathrm{ppm}$ by 2050 , it was expected that an additional 148.4 million people would be at risk of protein deficiency compared to the $2050 \mathrm{aCO}_{2}$ scenarios. 
Decreasing of micronutrients concentration in food crops will put at risk the populations of the developing world. Iron concentration was also significantly reduced in soybean seeds at fresh edible stage (R6), while $\mathrm{Zn}$ and Mn concentrations varied among cultivars Li et al., (2018b). Fig. (12).

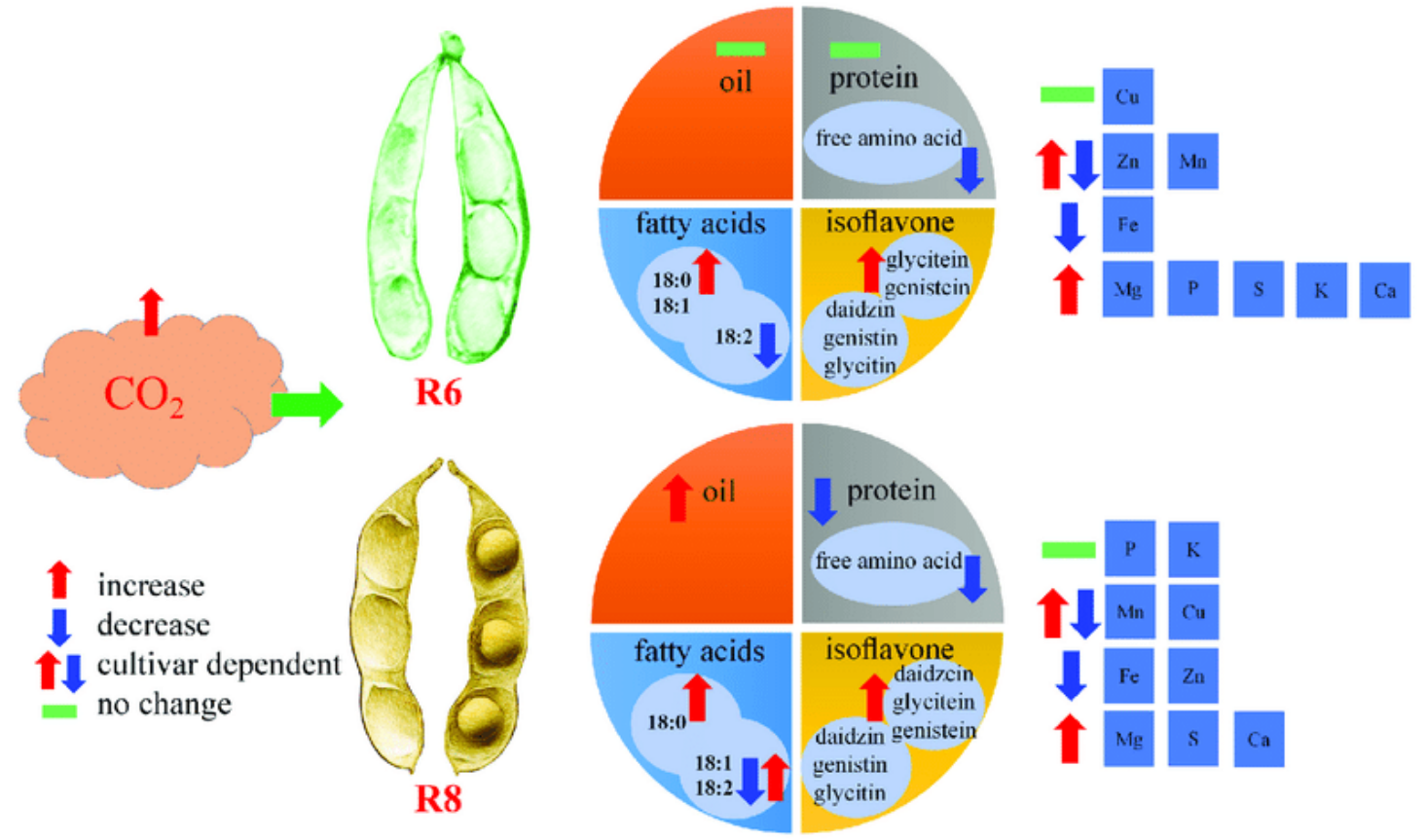

Fig. 12: Diagram illustrating the impact of elevated $\mathrm{CO}_{2}$ on seed quality of soybean at the fresh edible (R6) and mature stages (R8). After Li, Yansheng et al., (2018)

Li, Yansheng et al., (2018), stated that protein concentration in soybean seeds was significantly decreased under e $\mathrm{CO}_{2}$; however, oil concentration showed the opposite trend at $\mathrm{R} 8$. The free amino acids concentration were significantly decreased under $\mathrm{eCO}_{2}$, irrespective of the growth stage. Elevated $\mathrm{CO}_{2}$ resulted in an increase in oleic acid concentration (18:1) of all cultivars at R6. Total is flavone concentrations were significantly increased at R6 and R8. The concentrations of Fe were significantly decreased at $\mathrm{R} 6$ and $\mathrm{R} 8$ under $\mathrm{eCO}_{2}$, while the changes in $\mathrm{Zn}$ and $\mathrm{Mn}$ concentrations varied among cultivars Fig. (12). These results suggest that $\mathrm{eCO}_{2}$ may promote fat content by enhancing oleic acid levels (18:1) but decrease the content of proteins and relevant amino acids.

\subsection{Modification of root architecture, and its important}

Root architecture modification and down regulation of photosynthesis. Taub and Wang (2008), and also inhibition of nitrate assimilation by decreased photorespiration Bloom et al., (2002) have been proposed to elucidate the variations in mineral concentrations. The $\mathrm{CO}_{2}$ concentration has also a direct effect on the bioavailability of nutrients in soils, and consequently affecting the number and diversity of existing microorganisms. A positive effect on soil nutrient bioavailability was described under $\mathrm{CO}_{2}$ enrichment conditions (Jablonski et al., 2002; Kimball et al., 2002). However, the increase in plant growth with $\mathrm{eCO}_{2}$ may have a disadvantage in terms of competition for micronutrient acquisition with microorganisms prevailing in the soil (Guo et al.,2015). Abbas et al., (2009) showed that $\mathrm{eCO}_{2}$ promoted increases in $\mathrm{P}, \mathrm{K}, \mathrm{Fe}, \mathrm{Mn}$ and $\mathrm{Zn}$ in the soil. Possibly, $\mathrm{eCO}_{2}$-induced changes in soil $\mathrm{pH}$ improves some exudation processes that affect the availability of nutrients in the soil. Similarly, it was described that $\mathrm{eCO}_{2}$ responses averaged across two $\mathrm{N}$ treatments increased the concentrations of $\mathrm{Ca}$, $\mathrm{Mg}, \mathrm{Fe}, \mathrm{Zn}$ and $\mathrm{Mn}$ at the soil surface by $15.6,9.5,23.4,138.2$ and $16.9 \%$, respectively (Guo et al., 2015). In another study, Jin et al., (2019) described the interaction of long-term $\mathrm{CO}_{2}$ conditions with different soil types (Verti and calcareous soils) on grain nutrient concentrations of wheat, field pea, and canola. At $\mathrm{eCO}_{2}$, the concentrations of N, P, and $\mathrm{Zn}$ decreased by 6,5 , and $10 \%$, respectively, regardless of soil, crop and year. In addition, the concentrations of $\mathrm{K}, \mathrm{Fe}, \mathrm{Mn}$ and $\mathrm{Cu}$ were not affected by $\mathrm{CO}_{2}$ enrichment in any crop grown in the soils tested. 
The effects of elevated atmospheric $\mathrm{CO}_{2}$ concentration on soil microbial community structure are often characterized by an increased mycorrhizal colonization due to the increased plant demand for nutrients, coupled with increased $\mathrm{C}$ assimilation rates $\mathrm{CO}_{2}$ enrichment should increase mycorrhizal biomass because plant demands for $\mathrm{N}$ and $\mathrm{P}$ will increase concurrently with $\mathrm{C}$ assimilation rates, and plants will allocate more photosynthates belowground to the roots and mycorrhizal fungi to help satisfy this increased nutrient demand. Greater fine root mass and mycorrhizal infection promote enhanced $\mathrm{P}$ uptake in mycorrhizal plants grown under elevated $\mathrm{CO}_{2}$ concentrations. It seems reasonable to expect that at elevated $\mathrm{CO}_{2}$ levels, mycorrhizal biomass will increase as $\mathrm{C}$ becomes relatively less limiting and soil nutrients become more limiting to plant growth (Drigo et al., 2008).

The response of soil microorganisms to changes in plant production under elevated $\mathrm{CO}_{2}$ is highly variable due to very different patterns of plant $\mathrm{C}$ allocation in different plant-soil systems. Microbial biomass, gross $\mathrm{N}$ mineralization, microbial immobilization, and net $\mathrm{N}$ mineralization under elevated $\mathrm{CO}_{2}$ show a high degree of variability. However, rates of soil and microbial respiration are generally more rapid under elevated $\mathrm{CO}_{2}$, indicating that enhanced plant growth under elevated $\mathrm{CO}_{2}$ increases the amount of $\mathrm{C}$ entering the soil, thereby stimulating soil microbial activity. Soil microorganisms are often $\mathrm{C}$-limited and therefore, increased $\mathrm{C}$ availability stimulates microbial growth and activity. It is generally assumed that the $\mathrm{CO}_{2}$ induced increases in soil $\mathrm{C}$ availability will increase fungal biomass more than bacterial biomass. It is because of increased concentrations of dissolved organic $\mathrm{C}$ in the rhizosphere and to increases in soil water dissolved organic N. Given the important roles played by fungi in organic matter degradation, nutrient cycling, plant nutrition, and soil aggregate formation, shifts in fungal communities might have a strong impact on soil functioning. Furthermore, lower $\mathrm{N}$ availability at elevated $\mathrm{CO}_{2}$ may, in part, explain these increases in fungi, as fungi tend to have a higher $\mathrm{C} / \mathrm{N}$ ratio than bacteria and so have a lower demand for nitrogen than bacteria have. Hu et al., (2001) Bacteria and fungi, the initial consumers of soil organic matter, are themselves substrates for a multitude of tiny predators and grazers, including protozoa, nematodes, and arthropods, which comprise the soil food web. Therefore, an increase in bacterial growth due to an increasing $\mathrm{C}$ allocation at elevated atmospheric $\mathrm{CO}_{2}$ levels may be followed by an increase in grazing, resulting in a higher turnover of the microbial biomass. Increased grazing thus, results in faster recycling of nutrients from the microbial biomass, which would increase the flux of nutrients to the plant. Furthermore, $\mathrm{eCO}_{2}$ may increase mycorrhizal colonization and protect plants against some stresses, having led to improved $\mathrm{P}$ nutrition, particularly on legumes Jakobsen et al., (2016) and increased soil organic carbon decomposition Cheng et al., (2012) facilitating the availability of some nutrients. Climate change will increase our ability to predict responses for diverse crops and could benefit farmers in agronomic management to adapt crops to higher $\mathrm{CO}_{2}$. Decreasing $\mathrm{CO}_{2}$ gradually stimulated the concentration micronutrients and furthermore promoting higher yields. For some situations it has been suggested that regardless of the decrease in grain nutrient concentrations at $\mathrm{eCO}_{2}$, overall availability of $\mathrm{Fe}, \mathrm{Zn}, \mathrm{Mn}, \mathrm{B}, \mathrm{Cu}, \mathrm{Ca}, \mathrm{N}$, and other macronutrients on a land area basis would actually be enhanced, due to grain yield increase at $\mathrm{eCO}_{2}$ conditions (Asif et al., 2017a; Fernando et al., 2012b).

Micronutrients play a decisive role in maintaining health, because they have an essential role in cognitive growth and development Abou Seeda et al., (2020), in reproductive functions and cell metabolism, and in immune system responses of humans (Nakandalage and Seneweera, 2018). Limitation of $\mathrm{Fe}$ adversely disturbs growth, immune function and is the most common and widespread nutritional disorder in the world causing anemia (Murgia et al., 2012; Abou Seeda et al., 2020). Current studies show that Fe deficit in the first year of life is responsible for permanent effects on brain development, structure and function (Beard, 2008). Furthermore, $0,2 \%$ of deaths in children under 5 years of age can be attributed to Fe deficiency (Murgia et al., 2012).

Various biological functions have been attributed to $\mathrm{Zn}$, since it cooperates with many enzymes and other proteins and performs critical structural, functional and regulatory roles in the body (Krężel and Maret 2016; Abou Seeda et al., 2020). A large consumption of cereal-based foods is considered the main driver to $\mathrm{Zn}$ deficiency, since cereals have low concentration and bioavailability of $\mathrm{Zn}$ and cannot meet the human demand for $\mathrm{Zn}$ (Cakmak and Kutman, 2018). Nowadays, wheat, rice and corn account for about $60 \%$ of the world's daily energy consumption, and bread wheat alone is the staple food for about $35 \%$ of the world's population (Poursarebani et al., 2014). Countries with a high incidence of Zn and $\mathrm{Fe}$-deficiencies, rice and wheat deliver over $70 \%$ of the daily calorie intake in rural areas (Cakmak et al., 2010; Cakmak and Kutman, 2018). The goal of biofortification is to solve some of these problems 
by increasing the concentration of micronutrients in the edible parts of crops that improving their bioavailability and absorption in the human body after digestion (Carvalho and Vasconcelos 2013; Thornton, et al., 2014; Vasconcelos et al., 2017; Bouis and Saltzman, 2017). Plants require 14 mineral nutrients to achieve for optimal development and growth (Marschner, 2012; Abou Seeda et al., 2020). These elements are structural components of numerous macromolecules including nucleic acids, phospholipids, certain amino acids, and several coenzymes and play a central role in plant cellular metabolism (Grusak, 2001). In addition, they are beneficial in chlorophyll biosynthesis, redox reactions, plasma membrane integrity and contribute to the osmotic potential of cells (Nakandalage and Seneweera, 2018). Micronutrient insufficiencies affect plant growth and yield by limiting the biosynthesis or expression of important mechanisms of energy capture and/or metabolism (Grusak, 2001). Therefore, an increase in the vulnerability to abiotic stresses is usually encountered in plants that experienced micronutrient deficiency (Bencke-Malato et al., 2019; Hajiboland, 2012; Jin et al., 2009).

\section{Factors Affecting Mobility and Bioavailability of Phosphorous \\ 5.1. Plant phosphorous requests extending $\mathrm{CO}_{2}$ elevated}

Phosphorus is a unique nutrient among the essential plant nutrients with respect to increasing atmospheric $\mathrm{CO}_{2}$ concentrations. It plays an essential role in plant metabolism as it is involved in conserving and transferring energy in cell metabolism Raghothama, (1999); Abel et al., (2002); Lambers et al., (2006), Abou Seeda et al., (2020), and is an indispensable structural component of nucleic acids, coenzymes, nucleotides, phosphoproteins, phospholiqids and sugar phosphates (Schachtman et al., 1998; Veneklaas et al., 2012). The growth increases from elevated $\mathrm{CO}_{2}$ are likely to require more $\mathrm{P}$, which is taken up from the available P pool in soil (Edwards et al., 2005; Gentile et al., 2012; Jin et al., 2012). Several studies have reported that both the magnitude and the direction of the growth response of plants to elevated $\mathrm{CO}_{2}$ depend on $\mathrm{P}$ availability (Bassiri Rad et al., 2001; Jin et al., 2013). However, only a small proportion of total soil $\mathrm{P}$ in generally.

These strategies facilitate the mobilization of $\mathrm{P}$ from these non-labile pools, and thereby $\mathrm{P}$ availability has been enhanced over a large time scale in weathered soils with the evolution of these strategies (Lambers et al., 2008; Abou Seeda et al., 2020). These evolved strategies induce feedback processes between plants and soils, which are relevant to the photosynthetically fixed $\mathrm{C}$ and its allocation (Buendi'a et al., 2014). Increased C fixation and more belowground investments promote Penhancing processes in the soil (De Lucia et al., 1997; Allen et al., 2003). Thus, an important consideration here is that elevated $\mathrm{CO}_{2}$ will generally increase the $\mathrm{C}$ allocations to roots and the increase in root C will stimulate root growth (Rogers et al., 1992 1994; Li et al., 2012) and increase exudate secretions from the roots. This, in turn, will influence conditions in the rhizosphere, which is the interface between plant roots and soil (Paterson et al., 1997; Haase et al., 2008; Drigo et al., 2013). The changes in rhizosphere environment are likely to affect $\mathrm{P}$ acquisition by plants. Questions therefore arise as to whether plant $\mathrm{P}$ demand on the one hand and $\mathrm{P}$ acquisition on the other will be affected more by the increase of atmospheric $\mathrm{CO}_{2}$ concentrations. Understanding this supply-demand balance for labile soil $\mathrm{P}$ will be important for developing $\mathrm{P}$ management strategies in agricultural systems to cope with increasing atmospheric $\mathrm{CO}_{2}$ concentrations. Elevated $\mathrm{CO}_{2}$ is likely to affect the internal $\mathrm{P}$ requirement of plants because elevated $\mathrm{CO}_{2}$ alters $\mathrm{P}$ utilization within plant tissues (Niu et al., 2013a).

\subsection{Their impact on plant strategies to achieve phosphorous}

Current crop production in P-deficient soils is heavily reliant on the application of $\mathrm{P}$ fertilizers. However, more intensive fertilization with phosphorous is likely to become problematic in the long term, to provide for the increasing $\mathrm{P}$ demands of crops under elevated $\mathrm{CO}_{2}$, because reserves of phosphate ore deposits are finite (Lynch, 2011). There are also concerns about the environmental impact resulting from intensive $\mathrm{P}$ fertilization. Thus, it is increasingly important to improve plant $\mathrm{P}$ acquisition and P-use efficiency under elevated $\mathrm{CO}_{2}$. Elevated $\mathrm{CO}_{2}$ is likely to affect the $\mathrm{P}$ acquisition strategies in several ways. The increase in $\mathrm{C}$ assimilation in plants grown under elevated $\mathrm{CO}_{2}$ is likely to lead to a considerable response in root growth, including changes in root architecture and morphology that will affect $\mathrm{P}$ acquisition from soil profiles. Second, the composition and quantity of root exudates are likely to alter under elevated $\mathrm{CO}_{2}$ and hence these will change rhizosphere properties such as $\mathrm{pH}$, Eh and the capacity for chelation and ligand exchange, which in turn will affect $\mathrm{P}$ availability. Third, these root exudates may also modify the association between microorganisms and $\mathrm{P}$ transformations. 


\subsection{Rhizosphere activities in response to elevated $\mathrm{CO}_{2}$ and phosphorous availability}

The effect of elevated $\mathrm{CO}_{2}$ on rhizosphere properties is likely to impact on the ability of plants to acquire $\mathrm{P}$ from the soil. Elevated $\mathrm{CO}_{2}$ is likely to increase $\mathrm{C}$ flow from plant to soil by increasing the release of root exudates (Lin et al., 2000; Song et al., 2014). These exudates contain functional molecules that facilitate an increase in rhizosphere $\mathrm{P}$ solubility, and hence improve $\mathrm{P}$ nutrition to plants (Richardson et al., 2009; Abou Seeda et al., 2020). Furthermore, root exudates are responsible for changes of rhizosphere $\mathrm{pH}$ and increases in microbial activity (Shen et al., 2011). These effects of elevated $\mathrm{CO}_{2}$ can change $\mathrm{P}$ availability in the rhizosphere and consequently influence plant $\mathrm{P}$ acquisition (Norby et al., 2001; de Graaff et al., 2006).

\subsection{Root exudates}

Exudates released from roots into the rhizosphere can affect the availability of soil P to plants (Randall et al., 2001; Betencourt et al., 2012). Low-molecular-weight carboxylates present in root exudates have been considered to be Pi-mobilizing agents (The effectiveness of these carboxylates to mobilize $\mathrm{P}$ depends largely on carboxyl $(-\mathrm{COOH})$ and hydroxyl $(-\mathrm{OH})$ functional groups in these molecules. Citrate (tricarboxylic acid, TCA) exhibits the greatest ability to desorb P, followed by oxalate (dicarboxylic acid), while malate, malonate and tartarated are moderately effective (Abou Seeda et al., 2020; Bolan et al., 1994; Jones, 1998; Jones et al., 2009; Richardson et al., 2009). Citrate is particularly effective at mobilizing P from Fe-phosphates and Al-phosphates in acid soils Bolan et al., (1994) and Ca-phosphates in calcareous soils, or from rock phosphate fertilizer (Dinkelaker et al., 1989). The mechanism by which the carboxylates in root exudates affect soil $\mathrm{P}$ mobilization under elevated $\mathrm{CO}_{2}$ is not known. Shen et al., (2011) suggested that desorbing and chelating P from Al-P and Fe-P complexes and from other non-labile pools mobilizes P. However, the extent that elevated $\mathrm{CO}_{2}$ increases $\mathrm{P}$ desorption depends on whether elevated $\mathrm{CO}_{2}$ stimulates the release of those carboxylates that are effective in mobilizing Pi. Significant volumes of root exudates have been measured following elevated $\mathrm{CO}_{2}$ exposure (van Ginkel et al., 2000; Allard et al., 2006). For example, after 34 weeks of growth under elevated $\mathrm{CO}_{2}$, the exudation of soluble $\mathrm{C}$ compounds from roots of short-leaf pine increased by $50 \%$ (Norby et al., 1987). Similarly, the release of low molecular-weight organic compounds increased by $120-160 \%$ and amino acids increased by $250 \%$ when Pinus sylvestris was grown for 5 weeks in a nutrient solution under elevated $\mathrm{CO} 2\left(700 \mathrm{ml} \mathrm{L}^{-1}\right)$ in comparison with ambient $\mathrm{CO}_{2}\left(350 \mathrm{ml} \mathrm{L}^{-1}\right)$ Johansson et al., (2009). Haase et al., (2007) also found that the release of malate, which is the major organic acid in the exudates from Phaseolus vulgaris, increased by $177 \%$ after the plants were exposed to elevated $\mathrm{CO}_{2}\left(800 \mathrm{ml} \mathrm{L}^{-1}\right)$ for $18 \mathrm{~d}$. The increase of these organic compounds is likely to mobilize $\mathrm{P}$ in the rhizosphere but to date the mobilization.

\subsection{Acidity of soil rhizosphere}

Soil pH can greatly influence the solubility of $\mathrm{P}$ in soils (Shen et al., 2011). In acid soils where the concentrations of trivalent $\mathrm{Fe}$ and $\mathrm{Al}$ are high, labile $\mathrm{Pi}$ in soil solution is easily precipitated as $\mathrm{Fe}-$ and Al-phosphates or sorbed onto Fe- and Al-(hydr) oxides (Abou Seeda et al., 2020). In contrast, in alkaline soils where $\mathrm{Ca}$ is the major cation, $\mathrm{Pi}$ is predominantly precipitated as Ca-phosphates (Richardson et al., 2009). Thus, soil pH from 60 to 70 provides optimal conditions for P solubility (Hinsinger, 2001). Given this relationship between soil $\mathrm{pH}$ and $\mathrm{P}$ availability, any process that alters soil $\mathrm{pH}$ will influence $\mathrm{P}$ availability in the soil solution. There are several ways that elevated $\mathrm{CO}_{2}$ is able to change $\mathrm{P}$ availability by modifying the rhizosphere $\mathrm{pH}$. The first is that elevated $\mathrm{CO}_{2}$ may change the quantity of organic acid anions and associated protons released in exudates from plant roots, leading to $\mathrm{pH}$ changes in the rhizosphere (Guo et al., 2012). Organic acid anions have often been associated with the release of protons as a source of rhizosphere acidification (Hoffland et al., 1989; Hinsinger et al., 2003). For example, the release of citrate from cluster roots of white lupin was associated with strong rhizosphere acidification Neumann and Ro"mheld, 1999), which suggests that Hp ions released to accompany the efflux of citrate were a major component of the observed acidification of the rhizosphere. As elevated $\mathrm{CO}_{2}$ is likely to increase the exudation of organic acid anions, the $\mathrm{Hp}$ extrusion accompanying this exudation would lower $\mathrm{pH}$ and thereby enhance $\mathrm{P}$ mobilization in alkaline soils rather than acidic soils (Bayuelo-Jime'nez and Ochoa-Cadavid, 2014). The second way that elevated $\mathrm{CO}_{2}$ might affect rhizosphere $\mathrm{pH}$ results from the large amount of $\mathrm{CO}_{2}$ derived from the respiration of the root and the microbes in the rhizosphere under elevated $\mathrm{CO}_{2}$. The increased activities of rhizosphere 
microorganisms Jin et al., (2014) under elevated $\mathrm{CO}_{2}$ are likely to increase $\mathrm{CO}_{2}$ concentration in soil Matamala and Schlesinger, (2000); Carrillo et al., (2014) and this $\mathrm{CO}_{2}$ will dissolve in soil $\mathrm{H}_{2} \mathrm{O}$ to form $\mathrm{H}_{2} \mathrm{CO}_{3}$. As a result, the $\mathrm{pH}$ in the rhizosphere is likely to decrease. However, this scenario in terms of rhizospheric $\mathrm{pH}$ may be marginal, because gaseous $\mathrm{CO}_{2}$ diffuses much faster than $\mathrm{H}_{2} \mathrm{CO}_{3}$ in solution Anoua et al., (1997); Hinsinger et al., (2003), and only neutral to alkaline soils can respond to the change in soil $\mathrm{CO}_{2}$ concentrations because $\mathrm{H}_{2} \mathrm{CO}_{3}$ with its first $\mathrm{pK}$ of 636 remains undissociated at low pH Lindsay, (1979).

\section{Root Network Mechanisms, and Their Importance}

Phosphorous is an immobile nutrient in soil, increases in root length and root branching under elevated $\mathrm{CO}_{2}$ may increase the plant's capacity to acquire $\mathrm{P}$ from the soil. The effect of a larger root system is shown by the work of Hammond et al., (2009) Fig. (13). They stated that P uptake in Oryza sativa and Brassica oleracea genotypes under low P supply was correlated with lateral root growth rate, lateral root length, the number of lateral roots and root surface area.

Ajmera et al., (2019) reported that Phosphate starvation responses (PSRs) act at different temporal and spatio-physical scales, i.e., field, rhizosphere, plant, organ, tissue, cell and sub-cell, Fig. (14). Plants integrate intrinsic and extrinsic factors, eliciting such responses to counter phosphate stress. This relies on both local and systemic sensing/signaling mechanisms that monitor external and internal phosphate status. External Pi is sensed by a local system around the root-tip Svistoonoff, et al., (2007), particularly, in the root cap (Bonnot, et al., 2016). This independently attenuates primary-root growth and promotes root-hair development in Arabidopsis (Chiou, et al., 2011). Along with genetic regulation, modulation in the dynamics of different hormones plays an important role in such local responses, leading to altered RSA,

In addition, the root hairs also contributed to $\mathrm{P}$ acquisition with direct evidence coming from studies with mutant plants with no root hairs (Bates and Lynch, 2000), and from the comparison of species and genotypes that have contrasting length and density of root hairs (Richardson et al., 2011). Some changes in root morphology that develop in response to $\mathrm{P}$ deficiency are important for $\mathrm{P}$ acquisition efficiency by plants (Lambers et al., 2006; Pang et al., 2010). Root morphology will probably change in response to elevated $\mathrm{CO}_{2}$ and this will alter the P-acquisition efficiency. The increase in photosynthetic $\mathrm{C}$ allocation to roots under elevated $\mathrm{CO}_{2}$ results in stimulation of root growth more than the growth of other plant organs (Norby et al., 1992; Benlloch-Gonzalez et al., 2014). The elevated $\mathrm{CO}_{2}$-mediated increase in root growth will bring about increases in root length, number, diameter and branching. Yang et al., (2007) showed that compared with ambient $\mathrm{CO}_{2}\left(350 \mu 1 \mathrm{~L}^{-1}\right), 550$ $\mu 1 \mathrm{~L}^{-1}$ increased root biomass by $45 \%$, root volume by $44 \%$, number of adventitious roots by $31 \%$ and overall root length by $37 \%$ when rice plants were grown in a Stagnic Anthrosol soil. A greater number of root clusters and a higher percentage of lateral roots were also observed in white lupin (Lupinus albus) grown under elevated $\mathrm{CO}_{2}$ (Watt and Evans, 1999; Campbell and Sage, 2002).Fig. (14). 


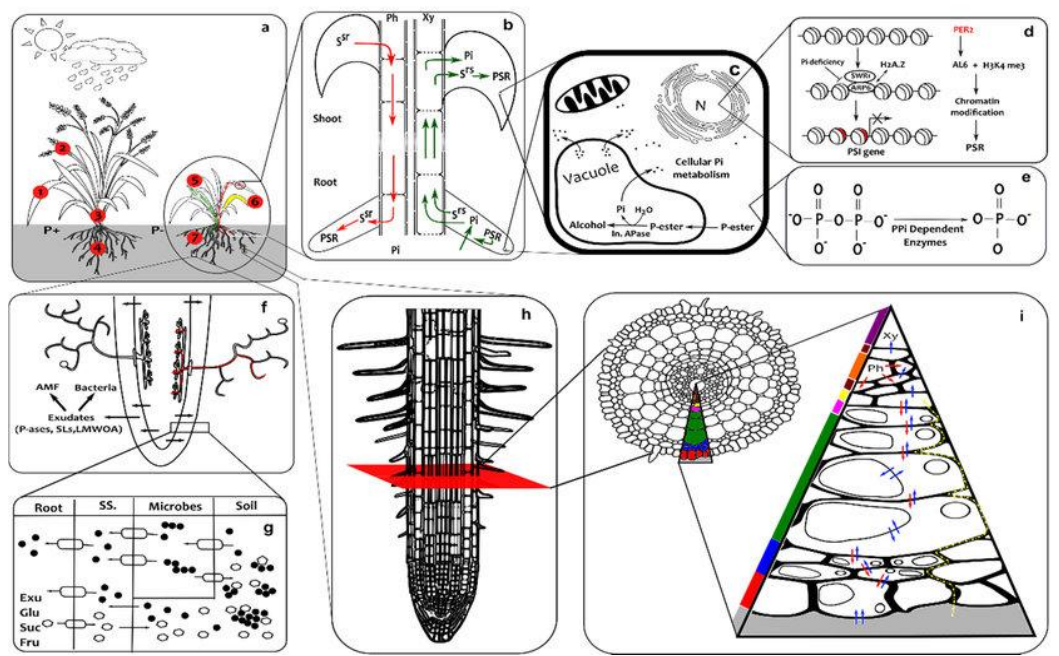

Fig. 13: Illustrates the integrated overview of phosphate starvation responses. The responses and signalling mechanisms operate at a range of scales and different locations which are depicted in nine connected panels: (a) denotes the whole plant and field scale; the numbers in red circles represent normal and low inorganic phosphate conditions (1) phosphorus playing a major role in various plant growth and developmental process including photosynthesis; (2) the highest level of Pi being found in the vegetative parts of the young plant, which upon maturation, moves into (3) fruit and seeds; (4) root development correlating with Pi levels; (5) Pi helping to increase water use efficiency and disease resistance; (6) abnormal leaf dis colouration under low Pi conditions; and (7) shallow root system with more root hairs and lateral roots. (b) denotes the whole plant scale with systemic signals systemic shoot to root (SSR) from shoot through the phloem to the root and systemic root to shoot (SRS) from the root to the shoot through the xylem; Pi, and water and other nutrients also go up to the shoot by this route. (c) Denotes cells from any part of the plant which responds to phosphate deprivation altering the lipid content, releasing phosphate stores from the vacuole where Pi is liberated from esters by Acid Phosphatases (APase). (d) denotes the epigenetic effects (principally chromatin modification) that influence transcription of Phosphate Starvation Response genes. (e) Denotes the pyrophosphate-dependent glycolytic bypass enzymes and metabolic Pi recycling system. (f) denotes rhizosphere activities, specifically the exudation of acid phosphatases (P-ases), Strigalactones (SLs) and Low Molecular Weight Organic Acids (LMWOA) which stimulate bacterial activity and attract Arbuscular Mycorrhizal Fungi (AMF) that form arbuscular structures within the root - mycorrhizal delivery of Pi is depicted in red. (g) denotes a close-up view of the rhizosphere boundaries between the root, soil sheath (SS), microbes and soil where exudates and sugars (Glu),glucose, (Suc),sucrose and (Fru),fructose, are secreted through efflux transporters respectively to solubilize Pi compounds and stimulate bacteria to do the same, 1 and $\mathrm{Pi}$ is imported through transporters of varying affinity; the exudates/sugars, transporters and $\mathrm{Pi}$ are respectively depicted by hollow ellipses, lozenges with directional arrows and black circles. (h) denotes the alteration in meristem and elongation zone length and the formation of root hairs. (i) denotes a cross section through a root and the paths taken during Pi uptake: the positions of different tissues within a root, namely, epidermis, exodermis, schlerenchyma plus cortex, endodermis, pericycle, phloem, cambium and xylem are marked respectively by red, blue, green, pink, yellow, orange, pale brown and purple; and transport of shoot-to-root signal molecules, symplastic/inter-organellar Pi and apoplastic Pi are depicted respectively by red, blue and dashed yellow arrows. 


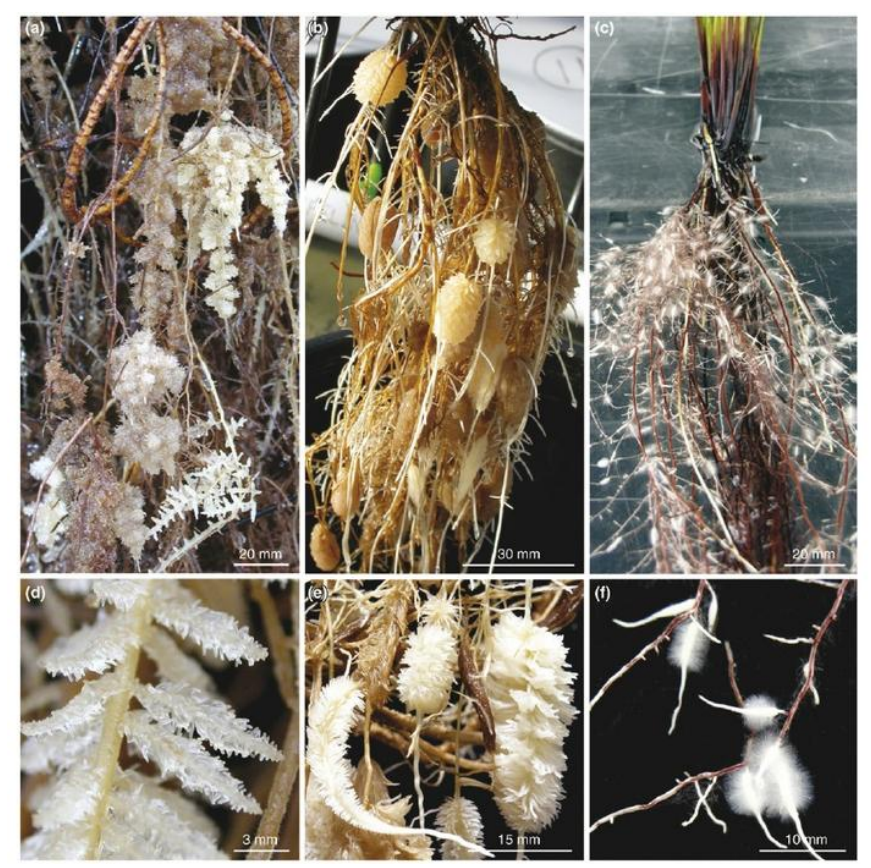

Fig. 14: Represents root morphology of Australian Proteaceae and South African Cyperaceae species grown hydroponically at extremely low P supply ( $1 \mathrm{~m} \mathrm{M}$ ). (a) Dryandra sessilis (Proteaceae) root system with 'compound' 'proteoid' root clusters. (b) Hakea prostrata (Proteaceae) root system with 'simple' 'proteoid' root clusters. (c) Tetraria species (Cyperaceae) root system with 'dauciform' root clusters. (d) Compound proteoid root cluster of Banksia grandis (Proteaceae, Western Australia) terminate with third-order branch rootlets. (e) Simple proteoid root cluster of Hakea sericea (Proteaceae, eastern Australia) terminate with second-order branch rootlets. (f) Root hairs at very high density on individual dauciform root clusters (higher magnification of Tetraria species in photograph (c) above). Photographic plate courtesy Michael W. Shane (School of Plant Biology, the University of Western Australia).

Similar trends where be found in chickpea, soybean, field pea, wheat, sorghum and cotton (Del Castillo et al., 1989; Rogers et al., 1992, 1994; Jin et al., 2013, 2015). These changes in root morphology result in an increase in the spread of roots through the root zone, which should lead to increases in nutrients uptake (Baker et al., 1990; Idso and Kimball, 1991, 1992; Rogers et al., 1992) Abou Seeda et al., (2020).

Jin et al., (2012), who reported a significant positive relationship between root length and $\mathrm{P}$ uptake under both ambient $\mathrm{CO}_{2}$ and elevated $\mathrm{CO}_{2}$, found a similar result. The longer roots under elevated $\mathrm{CO}_{2}$ in that study resulted in greater $\mathrm{P}$ acquisition. Thus, it appears that root growth positively responds to elevated $\mathrm{CO}_{2}$, enabling the roots to explore a larger volume of soil, and this will increase the plant's ability to take up nutrients (Nie et al., 2013), especially, immobile phosphate ions. The response of root morphology to elevated $\mathrm{CO}_{2}$ and the impact on $\mathrm{P}$ acquisition are fundamentally regulated at the genetic level. Ainsworth et al., (2006) reported that there were 327 independent genes that were $\mathrm{CO}_{2}$-responsive when soybean plants were exposed to elevated $\mathrm{CO}_{2}$, while Raghothama (1999) reported that there were more than 100 genes involved in plant response to P deficiency. Auxin genes including auxin-responsive promoters Chandler, (2009) and auxin transport genes (Santelia et al., 2005) are thought to be the most responsive genes to elevated $\mathrm{CO}_{2}$ and external $\mathrm{P}$ status. Auxins are hormonal compounds that regulate plant growth processes, such as the initiation and elongation of root hairs (Pitts et al., (1998); Schiefelbein, (2000). Niu et al., (2011), found that elevated $\mathrm{CO}_{2}$ resulted in the expression of auxin-specific genes, which were likely to enhance the growth of root hairs in Arabidopsis, Fig. (15). 


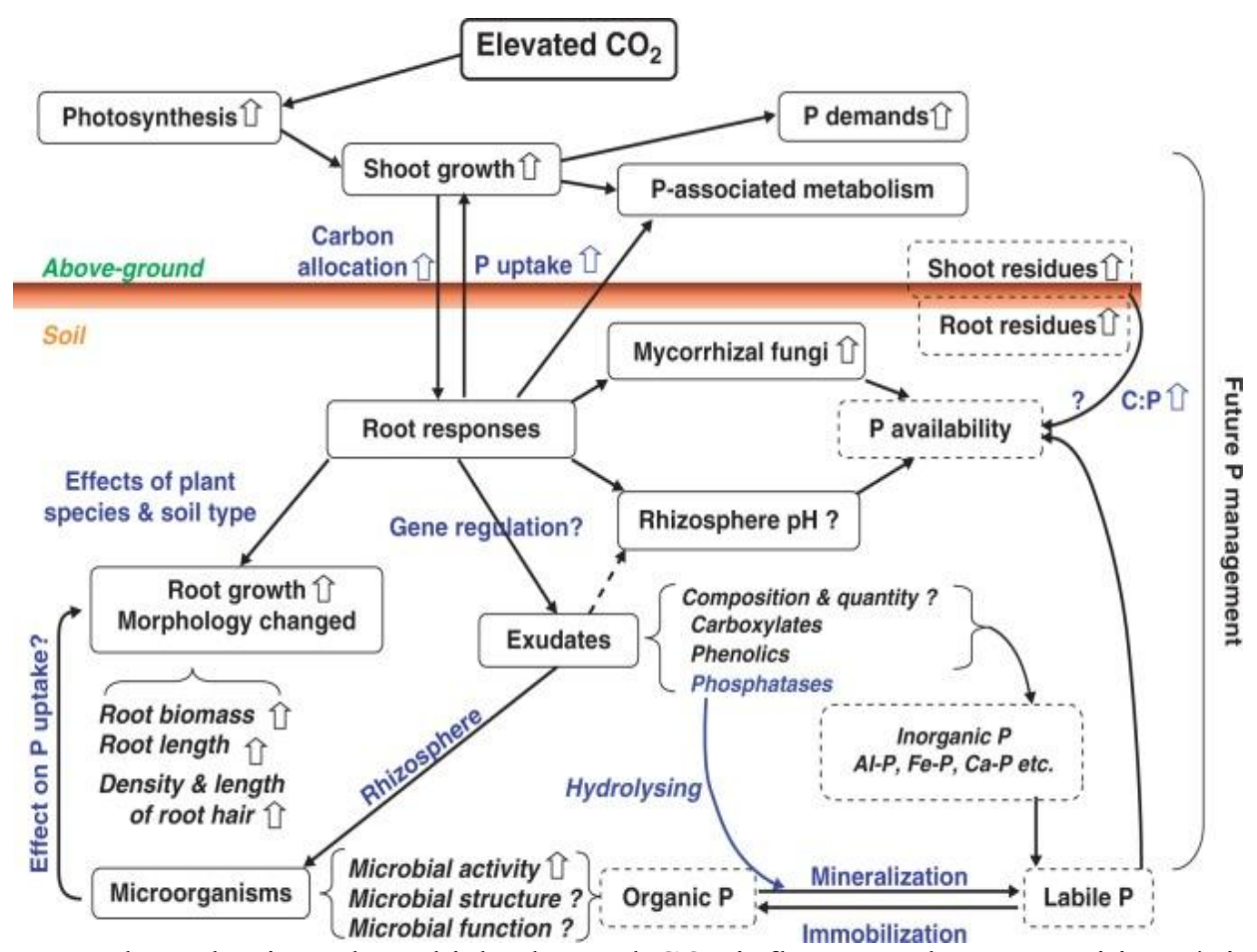

Fig. 15: Proposed mechanisms by which elevated $\mathrm{CO}_{2}$ influences plant $\mathrm{P}$ nutrition. * indicates an increase and "?" indicates an unknown effect. After Jin et al., (2015)

On the other hand, auxin genes that are responsive to $\mathrm{P}$ availability are involved in the regulation of the P starvation response in roots (Nacry et al., 2005; Jain et al., 2007). The expression of auxinresponsive genes responds to $\mathrm{P}$ deficiency by stimulating pericycle cells to produce lateral roots (Lo' pez-Bucio et al., 2005). Pe'rez-Torres et al., (2008) further showed that P deficiency increased the expression of the auxin receptor TRANSPORT INHIBITOR RESPONSE 1 (TIR1), which enhanced the sensitivity of auxins to increase the emergence of lateral roots. Therefore, the expression of these plant genes within a given environment triggers molecular, physiological and cellular processes that modify root architecture Gilroy and Jones, (2000); Niu et al., (2013b) Fig. (16).

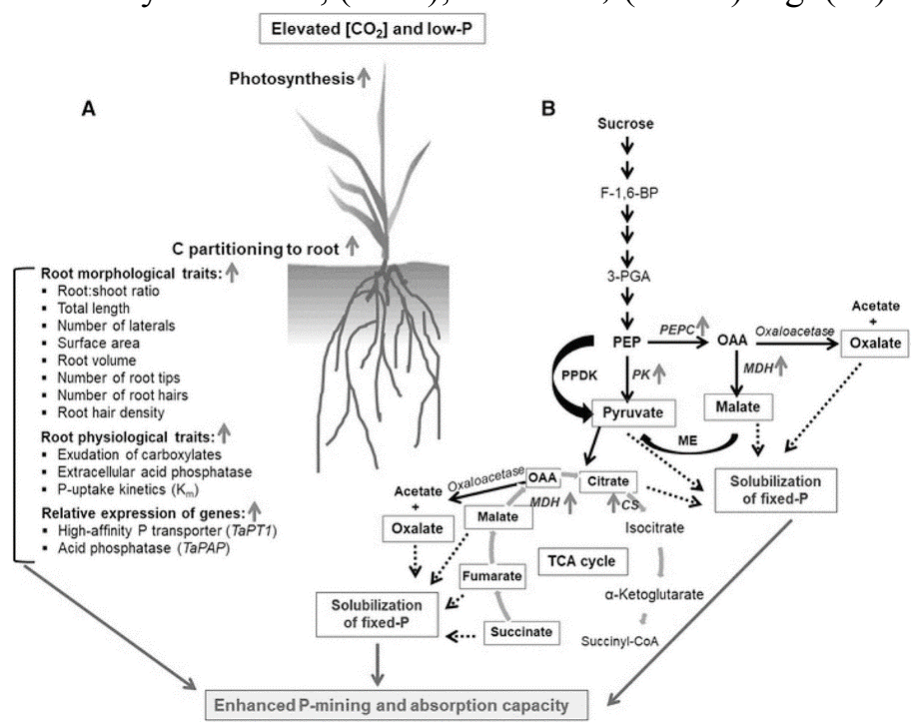

Fig. 16: Proposed P-model under elevated $\mathrm{CO}_{2}$. After Pandey et al. (2018) 
Further investigation of these genetic factors that mediate root development will be required to reveal the molecular mechanisms by which the plant adapts to $\mathrm{P}$ deficiency as well as elevated $\mathrm{CO}_{2}$ environments Fig. (17).

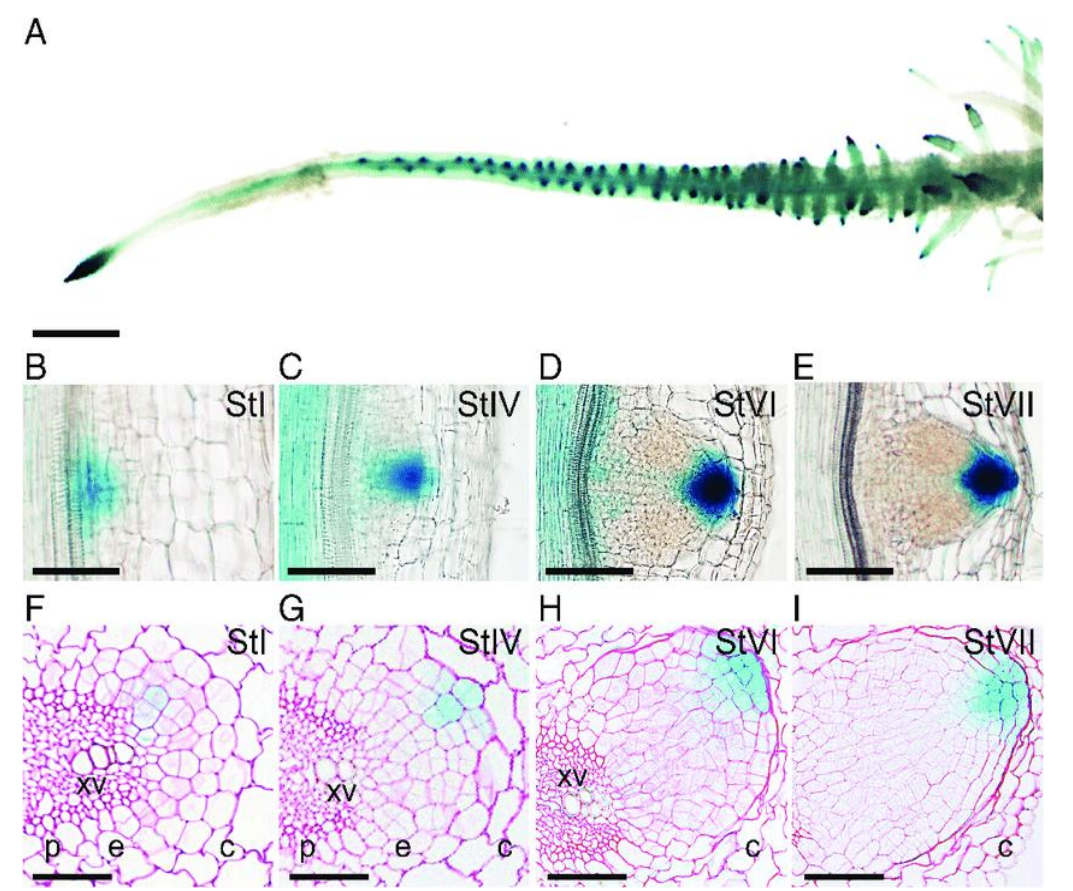

Fig. 17: Establishment of an auxin gradient during $\mathrm{CR}$ and rootlet development. (A-I) DR5: GUS pattern of expression in lupin 'hairy root' seedlings grown on low-phosphate medium. (A) Fully mature whole CR. (B-E) DR5: GUS expression was observed on thick longitudinal sections $(80 \mu \mathrm{m})$ at stage I (B), stage IV (C), stage VI (D) and stage VII (E). (F-I) DR5: GUS expression was also observed on thin cross sections $(6 \mu \mathrm{m})$ in the juvenile region of the CR counterstained with ruthenium red at corresponding stages: stage I (F), stage IV $(\mathrm{G})$, stage VI $(\mathrm{H})$ and stage VII (I). P, pericycle; e, endodermis; c, cortex; xv, xylem vessels. Scale bars are $100 \mu \mathrm{m}$. After Gallardo et al., (2019)

Gallardo et al., (2019) reported that during rootlet morphogenesis. Auxin play a major role for development describing in detail by Lavenus et al., (2013), notably with the help of the synthetic auxin reporter R5 (Ulmasov et al.,1997). We generated white lupin composite transgenic 'hairy root' plants expressing the DR5 reporter fused to the $B$-glucuronidase gene. Our first goal was to determine whether the 'hairy root' system is suitable to observe auxin-related developmental mechanisms and subsequently to determine whether an auxin gradient is established during rootlet organogenesis. In white lupin, the DR5 marker, an artificial promoter made of seven tandem repeats of an auxin responsive element isolated from soybean (Glycine max), showed that a strong conserved pattern as compared to other species. DR5 expression was seen in the CR tip and vasculature Fig. (17). In rootlet primordium, GUS activity was observed at stage I of development Fig. (17), in one of the first dividing cells, close to the protoxylem pole. At stage IV, when divisions give rise to a dome-shaped primordium, GUS activity was observed in a few cells at its tip Fig. (17). From this stage onwards, a strong DR5 response builds up in the primordium apex Fig. (17). After emergence, strong GUS activity was detected in the root cap whereas the zone above the rootlet tip was displaying a weak GUS activity Fig. (17). Expression in the vasculature was observed in mature rootlets Fig. (17). Our observations of the DR5: GUS reporter suggest that an auxin gradient is established during rootlet initiation up to their emergence and maintained during their later development.

Specifically, the quantitative relationship between auxins and pericycle cell division leading to the development of new roots, and the elevated $\mathrm{CO}_{2} / \mathrm{P}$ supply responsive molecular pathways that regulate the expression of auxin-responsive genes warrant future. The low availability of $\mathrm{Pi}$ is attributed its uneven distribution and immobility in soil Phosphate (Pi) availability has a strong effect on root system architecture (RSA), which shows distinct difference with those caused by the deficiency of other 
nutrient ions, such as nitrate Zhang et al., (1999) and iron Moog et al., (1995). Under P deficiency, plants are commonly characterized by the change of root morphology and better proliferation of roots relative shoots (Holford (1997), Hinsinger (2001) Lynch and Brown (2008).

Root architecture, and its adaptation is actually important for nutrients absorption particularly for phosphorous which is less mobile element Lynch (2007); Zhu et al., (2005). Architectural adaptations are related to the change in root branching, root length, and formation of root hairs López-Bucio et al., (2002); Richardson and Simpson (2011); Trachsel et al., (2011) Fig. (18).

\section{A}
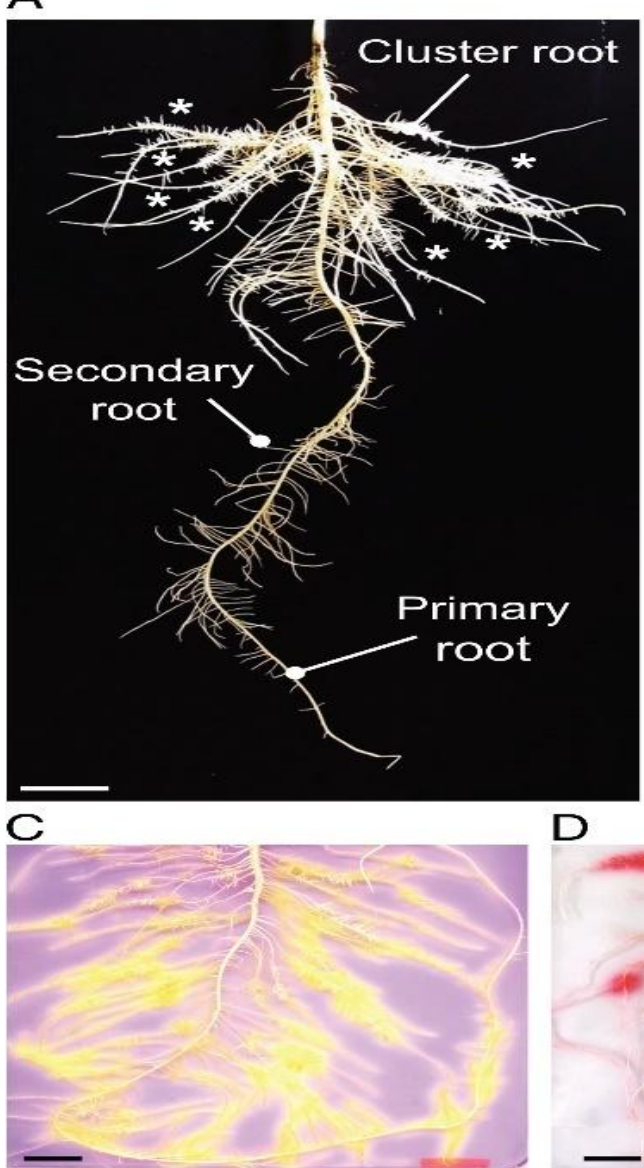

$\mathrm{B}$

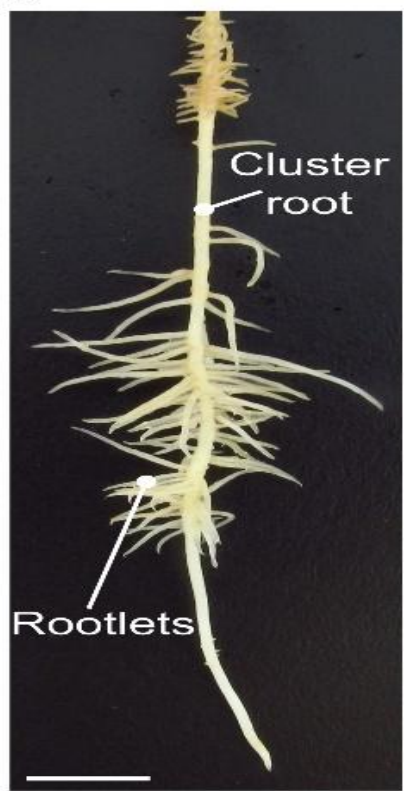

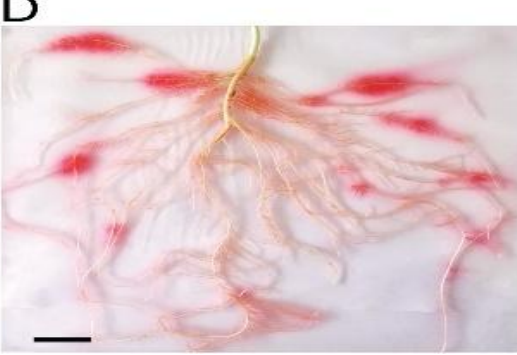

Fig. 18: White lupin architecture and physiology in low phosphate conditions. (A and B) Root architecture of a 21-day-old white lupin (Lupinus albus) comprising many CRs in the upper part of the root system (asterisks). CRs are secondary roots producing hundreds of short roots with determinate development, known as rootlets (B). (C and D) Physiological assays of 19day-old lupin root systems placed on agar plates containing bromocresol purple (BCP) (C) or bathophenanthroline disulfonic acid disodium salt (BPDS) in the presence of Na-Fe EDTA (D). (C) $\mathrm{BCP}$ is a purple $\mathrm{pH}$ indicator that turns yellow when the roots are acidifying the medium with proton excretion (pH), After Gallardo et al., (2019)

Gallardo et al., (2019) Abou Seeda et al., (2020), reported that lateral roots (LRs) producing bottlebrush-like clusters of short rootlets as presented in Fig. (18), these organs represent an evolutionary adaptation to phosphorus-impoverished soils. As a result, CRs exhibit four main characteristics regarding their development and physiology Skene (2000): (1) a massive induction of rootlets (up to $20-100$ per $\mathrm{cm}$ ); (2) a determinate development leading to a limited growth and subsequent entry into senescence; (3) an exudative burst resulting in massive secretion of protons, organic acids, phenolics and phosphate remobilizing enzymes and (4) a high phosphate uptake capacity. The secretion of protons can be imaged with a $\mathrm{pH}$ indicator such as bromocresol purple (Fig. 18C). A high level of ferric reductase activity is also associated with CR physiology and can be revealed biochemically (Fig. 18D). White lupin (Lupinus albus) is an annual legume traditionally cultivated around the Mediterranean and is the only cultivated crop that can form CRs. It is a model of interest because of its quick life cycle compared to other species, mainly bushes and trees, sharing the ability to 
form these structures. Moreover, white lupin has the capacity to form nitrogen-fixing nodules because of the symbiotic interaction with Bradyrhizobium $s p$. but has lost the ability to form mycorrhizal associations (Lambers and Teste, 2013). Interestingly, many CR forming species share this lack of ability for mycorrhization. The capacity to form CRs in lupin allows a reduction of phosphate fertilizer use in the field and results in a beneficial interaction in mixed cultures $\mathrm{Cu}$ et al., (2005); this represents an interesting example to lower our dependency on this source of agricultural input.

Plants differ in the mechanisms for absorption of P from deficient environments. Efficient plant genotypes may have adaptations to explore more soil by increasing surface area, transforming plantunavailable forms of nutrients in available forms, and take up nutrients across the plasma membrane (Khurshid et al., 2017). Plant roots perform a range of functions in plants like anchorage and absorption of nutrients and water (Bertin et al., 2003; Lambers et al., 2006, 2010; López-Bucio et al., 2003). Thus, the changes in the root architecture could affect nutrient and water absorption by plants. Root architecture is affected by three major processes, viz., (1) cell division at the primary root meristem, which determines growth by adding new cells to the root, (2) lateral root formation that improves exploration of soil by the roots, and (3) development of root hairs, thereby increasing the root surface area (López-Bucio et al., 2003). The rooting pattern of plants is mainly determined by the plant species, soil structure, and their interaction (Kim, et al., 2018). The larger root system provides more surface area for nutrient absorption by increasing the contact with soil which plays an important role for $\mathrm{P}$ absorption (Ou et al., 2018; Gahoonia and Nielsen 1998; Lynch,2007 ; Römer and Schenk, 1998). Distribution of nutrients in soils is heterogeneous or patchy. In order to enhance nutrient uptake, plant roots have to exploit these nutrient patches. Asymmetrical development and exceptional flexibility in architectural patterns of roots enable plants to exploit soils and allow root proliferation in nutrient-rich zones (Lynch, 1995). Depending upon the plant species and environmental conditions, the root systems vary widely in terms of root architecture, including number and size of root hairs (Lambers and Shane 2007 ; Lynch and Brown 2001 ; Shane et al., 2006). Various root characteristics including root architecture, root diameter, root hairs, cluster roots Bates and Lynch (2000); Hill et al., (2006) ; Singh Gahoonia and Nielsen (2004), symbiotic relationship with mycorrhiza, kinetics of P uptake, and rhizospheric processes Aziz et al., (2011a), Hinsinger (2001) ; Pang et al., (2010) ; Ryan et al., (2009 ) cause variations in P uptake among the plant species/cultivars (Lynch and Brown 2001; Singh Gahoonia and Nielsen, 2004). Response to P deficiency by plant roots involves changes in root architecture and the shift of biomass allocation from basal to adventitious roots in such a way to explore more topsoil or P-rich Lambers and Shane (2007) sites for P acquisition Liao et al., (2001), (2004); Lynch and Brown (2001). These adaptations include horizontal basal root growth, increased adventitious root formation, enhanced lateral root formation, and increased root hair density and length (Bonser et al., 1996; Liao et al., 2001; Lynch, 2007). Topsoil foraging is strongly associated with P acquisition in low-P soils Rubio et al., (2003); Zhu et al., (2005) due to low mobility of P in soil. Low $\mathrm{P}$ in the rooting zone favors the formation of lateral roots (López Bucio et al., (2002); Lynch (2007). A large root surface area is achieved by a combination of reduced mean root diameter and elongation of relatively thinner roots (Fitter et al., 2002). Root diameter is very important in exploration of soil volume by roots as it determines the volume of soil that can be explored by the roots (Fitter, 1991; Gahoonia et al., 2006). Plants with a smaller root diameter can explore more soil per unit of root surface area Fitter et al., (1991) and can efficiently uptake P from limiting environments (Singh Gahoonia and Nielsen, 2004). Root hair enhances the ability of roots to explore the rhizosphere for $P$ due to increased surface area for absorption (Hill et al., 2010; Ma et al., 2001b; Zhu et al., 2010). Root hairs constitute up to $77 \%$ of the total root surface area and thus are the major point of contact between plants and the rhizosphere (Föhse et al., 1991; Gahoonia and Nielsen, 1998). Under P deficiency, increased root hair density and length is well documented in legumes Yan et al., (2004) and barley Gahoonia and Nielsen (1998). Ma et al., (2001a) reported that root hair density in Arabidopsis thaliana was high under P deficiency. Oilseed rape was reported to contain large amount of $\mathrm{P}$ as compared to maize despite having less root and shoot biomass Morel and Hinsinger (1999), and this could be due to long root hairs of oilseed rape compared to maize (Gahoonia and Nielsen, 2004). Large differences in root morphology and distribution are present between genotypes of many plants (Bates and Lynch, 2001; Krasilnikoff et al., 2003; Römer and Schenk 1998; Vance 2001). Root characteristics such as total root length, root hair length and density, and specific root length have been shown to vary considerably between genotypes of several species (Løes and Gahoonia, 2004 ; Nielsen et al., 1997; Römer and Schenk, 1998;; 
Singh Gahoonia et al., 1997 ; Yan et al., 1995). Significant differences in P uptake in cereal cultivars grown on low-P soil were reported due to differences in length of root hairs of these cultivars Singh Gahoonia et al., (1997). Similarly, genetic differences in P uptake in cowpea and in maize due to variation in root length and root hairs have been reported (Krasilnikoff et al., 2003). Maize genotypes modified their root architecture in response to low $\mathrm{P}$ in the rooting medium (Zhu et al., 2005). Genotypes, which performed better under P-deficient conditions, develop shallow root systems to tap $\mathrm{P}$ accumulated in topsoil and have greater specific $\mathrm{P}$ absorption rate, tissue $\mathrm{P}$ contents, relative growth rate, and biomass accumulation than others (Zhu et al., 2005). Phosphorus availability regulates different aspects of root architecture like axial extension, root branching, basal root gravitropic, the relative distribution of basal root length, and adventitious roots (Liao et al.,2004 ; Miller et al., 2003 ; Ochoa et al., 2006). These differences raise the possibility of selection and breeding of crop genotypes having extensive root systems to cope with P deficiency in soils. Earlier studies showed that root growth (root size, root weight, etc.) positively correlated with biomass production in different crops (Barraclough, 1984; Gill and Ahmad 2003; Kosar et al., 2002; Olaleye et al., 2011).

\subsection{Influence of root plasticity and plant nutrient acquisition in phosphorus}

Phosphorus $(\mathrm{P})$ is one of the most growth-limiting macronutrients, and root systems display diverse morphological and physiological strategies to enhance its uptake at low and heterogeneous $\mathrm{P}$ availability in soil (Lambers et al., 2006, 2013). For example, under P limitation, primary root growth is suppressed and the root architecture changes to a shallower root system featuring roots that are more lateral and increased root hair density. This enables the roots to explore a larger soil volume (Pe'ret $e t$ al., 2011). Root physiological strategies include exudation of various organic anions and release of extracellular phosphatases to mobilize the otherwise unavailable P in the rhizosphere (Lambers et al., 2011; Richardson et al., 2011).

An important root morphological trait, root hairs (single-cell extension of epidermal cells), contribute up to $80 \%$ to plant $\mathrm{P}$ uptake by increasing the root surface area and, hence, the contact space between root and soil for absorption (Jungk, 2001; Jakobsen et al., 2005; Li et al., 2014). Increased surface area with root hairs, in turn, contributes to the release of root-derived organics and phosphatases, which subsequently increase $\mathrm{P}$ acquisition. For example, barley roots possessing hairs radially extended the rhizosphere by three times as compared to the mutant lacking root hairs (Holz et al., 2018). Another important root functional trait with complementary function (increased $\mathrm{P}$ acquisition) is root colonization by arbuscular mycorrhizal fungi (AMF) (Munyanziza et al., 1997). Plants trade carbon (C) to AMF for in exchange of nutrients. The extraradical mycelia of AMF may also enter the very fine soil pores, thereby increasing the nutrient uptake (Khalvati et al., 2005). Here, we emphasize the rationale to consider root colonization with AMF as a 'trait' because approximately $18 \%$ of angiosperm species (e.g., members of Brassicaceae, Chenopodiaceae, Cyperaceae, Zygophyllaeae families) lack any symbiotic associations with fungi and about $30 \%$ of angiosperm species establish other (than AMF) types of mycorrhizal associations (Brundrett, 2002; Brundrett and Tedersoo, 2019). Given that a fungus is considered as mycorrhizal only after its successful interaction with roots to form a specific type of symbiotic association, the consideration of root colonization by mycorrhizal fungi as a trait is highly feasible. Mycorrhizal symbiosis may trigger various adaptive strategies into plant such as changes in the root-to-shoot ratio Veresoglou et al., (2012), root architecture and longevity Hooker and Atkinson, (1996), root length Camenzind et al., (2016), and root diameter (Comas et al., 2014). Such allometric changes are plant-species-specific and depend on the duration of the experiments as well as on the identity of the plant and its fungal partner identities (Veresoglou et al., 2012). Much of this information is derived from plant phylogeny by determining changes in root morphological and architectural traits using phylogenetically independent contrasts (Comas et al., 2014). Accordingly, an in-depth understanding requires empirical evidence. The notion that plants colonized with AMF increase their root diameter has been forwarded Brundrett and Tedersoo, (2019), but explicit observations are missing. Moreover, most studies on plant-mycorrhizal interactions have focused on one plant growth stage, almost ignoring the dynamics of nutrient acquisition related to plant phenology. Such temporal changes in plant microbial interactions are defined as a 'missing factor' and highlight the necessity of incorporating those in future ecological studies (Schofield et al.,2018). Interactions between roots and microorganisms are established at early plant growth stages. At later stages, such interactions gain importance due to plant-growth-associated changes in root morphology, soil properties Philippot et 
al.,(2013); Wen et al., (2017), and variation in rhizo-deposits quality and quantity Chaparro et al., (2014). Intense competition between plants and soil microorganisms for limited nutrients also play a role (Kuzyakov and $\mathrm{Xu}, 2013$ ). For example, root exudation changes with plant growth stage Chaparro et al., (2014) and results in altered enzyme activities in rooted soil (Kumar et al., 2018). Throughout the growth period, plants adapt their strategies to maximize nutrient uptake, but no explicit relationship between specific root traits and nutrient acquisition has been determined (Chen et al., 2016). Such strategies are plant-species-specific and the causes of variations are not conclusive. For example, increased root hair length and density in Brach podium cultivars were insufficient to increase plant $P$ uptake and must be combined with other root traits to enhance $\mathrm{P}$ acquisition (Zhang et al., 2018). The present study focuses on the root trait plasticity for plant $\mathrm{P}$ acquisition in P-limited soil and on the response of these traits to increased $\mathrm{P}$ availability via $\mathrm{P}$ fertilization. To this end, maize with (wild type, WT) and without root hairs (roothairless 3 mutant, rth3) were grown for 64 days in a climate chamber under controlled environmental conditions. Subsets of both genotypes were fertilized with KH2PO4. We hypothesized that $(\boldsymbol{a})$ in P-limited soils and in absence of root hairs (key trait for plant nutrient acquisition), plant growth is maintained by shifting the root traits to attract colonization by AMF for $\mathrm{P}$ acquisition, whereas (b) with $\mathrm{P}$ fertilization, plants become less dependent on specific root traits for $\mathrm{P}$ uptake. This study provides the opportunity to understand the plants' $\mathrm{P}$ uptake strategies through plasticity in root traits at three plant growth stages (tillering, stem extension, maize heading).

Kumar et al., (2019) reported that, many plants have developed complex nutrient acquisition strategies including altering root morphology, root hair formation or colonization by arbuscular mycorrhizal fungi (AMF) particularly under soil nutrient limitation. The interactions of these strategies and their plasticity are, however, affected by soil nutrient status throughout plant growth. Such plasticity is decisive for plant phosphorus (P) acquisition in P-limited soils. We investigated the $\mathrm{P}$ acquisition strategies and their plasticity of two maize genotypes characterized by the presence or absence of root hairs. We hypothesized that in the absence of root hairs plant growth is facilitated by traits with complementary functions, e.g., by higher root mycorrhizal colonization. This dependence on complementary traits will decrease in P fertilized soils. At early growth stages, root hairs are of little benefit for nutrient uptake. Regardless of the presence or absence of root hairs, plants produced average root biomass of $0.14 \mathrm{~g}$ per plant and exhibited $23 \%$ root mycorrhizal colonization. At later growth stages of maize, contrasting mechanisms with functional complementarity explained similar plant biomass production under P limitation: the presence of root hairs versus higher root mycorrhizal colonization (67\%) favored by increased fine root diameter in absence of root hairs. P fertilization decreased the dependence of plant on specific root traits for nutrient acquisition. Through root trait plasticity, plants can minimize trade-offs for developing and maintaining functional traits, while increasing the benefit in terms of nutrient acquisition and plant growth. The present study highlights the plasticity of functional root traits for efficient nutrient acquisition strategies in agricultural systems with low nutrient availability

They also concluded that function of root traits and their plasticity are crucial for plant $\mathrm{P}$ uptake in P-limited soils. The absence of root hairs induced an increase in the average fine root diameter thereby promoting root mycorrhizal colonization by AMF, Fig. (19). In turn, the presence of root hairs decreased the dependency of plants on root mycorrhizal colonization for plant $\mathrm{P}$ acquisition. Reduced colonization after P fertilization highlighted the maize plant's resource allocation by lowering tradeoffs for $\mathrm{P}$ acquisition. Overall, maize alters its root morphology and biological traits as a nutrient acquisition strategy to maximize benefits and therefore, growth. 


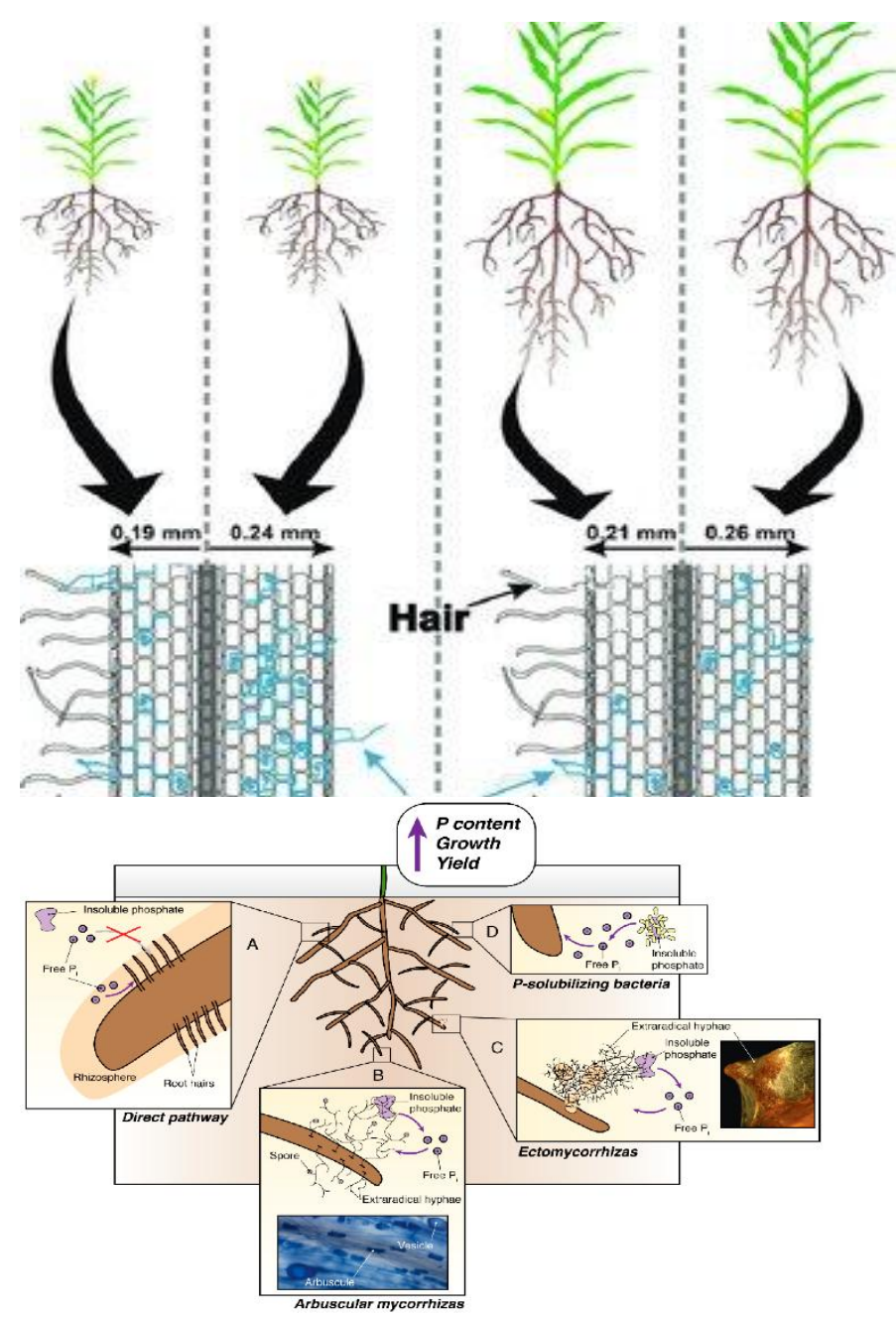

Fig. 19: Illustrates root traits in the presence (WT) and absence (rth3) of root hairs. When root hairs are absent, maize plants increased the average fine root diameter to facilitate root colonization by arbuscular mycorrhizal fungi to maintain P acquisition and growth. After Kumar et al., (2019), Kafle et al., (2019)

\section{Water Use Efficiency Under Elevated $\mathrm{CO}_{2}$}

Water shortage present one of the primary world issues, and according to climate change projections, it will be more critical in the future. Since water availability and accessibility are the most significant constraining factors for crop production, addressing this issue is indispensable for areas affected by water scarcity. Because of increasing water scarcity and drought, resulting from climate change, considerable water use for irrigation is expected to occur in the context of tough competition between agribusiness and other sectors of the economy. In addition, the estimated increment of the global population growth rate points out the inevitable increase of food demand in the future, with an immediate impact on farming water use. Since a noteworthy relationship exists between the water possessions of a country and the capacity for food production, assessing the irrigation needs is indispensable for water resource planning in order to meet food needs and avoid excessive water consumption.

Hussain et al., (2019), stated that water deficits pose a serious threat to crop productivity and food security in many parts of the world due to poor or erratic rainfall and depletion of groundwater reserves. Improving crop productivity under shortage water availability conditions is vital to meet global food demand (Balyan et al., 2017). Agricultural production gradually required substantial amounts of water. Rahaman et al., (2016) reported that to produce $1 \mathrm{~kg}$ of rice, consumed about 2497 liters. Therefore, improving rice genotypes with increased water use efficiency is essential without compromising yields (Shahane et al., 2019). Climate change is predicted to increase the frequencies of droughts and floods, both of which will be problematic for food production (Mar et al., 2018; Yao et 
al., 2017). Recent strategies such as growth enhancements or increases in photosynthetic efficiency have the potential to increase intrinsic yields (Ambavaram et al., (2014). Plant breeding is a good solution to accelerate the production of improved crop cultivars that are more tolerant to drought and other stresses.

High crop yield under optimal as well as environmental stress conditions is a valuable cropstability trait that is targeted for improvement using classical breeding as well as genetic engineering (Century et al., (2008). Many approaches have been proposed to boost intrinsic yield, such as enhancement of growth or increase in photosynthetic rate and capacity (Gibson et al., 2011). Photosynthesis, the basis of life on earth that converts light energy to chemical energy in integrated photosynthetic carbon metabolism (PCM) processes, is complex and requires a systems-wide approach to coordinately improve plant productivity and yield Zhu et al., (2010) that is stable under environmental stresses. Transcription factors (TFs) have shown promise in coordinately improving specific traits in rice, such as photosynthetic assimilation and plant biomass Karaba et al., (2007) or grain yield (GY) components under drought Jeong, et al., 2010), and have the potential to coordinately regulate photosynthesis and PCM for crop yield. Although photosynthesis is accepted as the basis of absolute yield, yield improvement via direct improvement of photosynthetic efficiency has not yet been successful (Taranto et al., 2018). Nonetheless, evidence that elevated $\mathrm{CO}_{2}$ can increase leaf photosynthesis in crops by as much as $22.6 \%$ over the growing season suggests that increasing photosynthesis can increase productivity and yield (Abdelrahman, et al., 2018). One of the primary strategies has been on engineering RuBis CO to improve photosynthetic efficiency Spreitzer and Salvucci (2002), although many more metabolic reactions in PCM and associated processes in sucrose synthesis and photorespiration have been shown to play an equivalent role. Metabolic analysis using a dynamic model of PCM Zhu, et al., (2007), suggests that the partitioning of resources among enzymes of $\mathrm{PCM}$ in $\mathrm{C}_{3}$ crop leaves is not optimal for maximizing the light-saturated rate of photosynthesis and under elevated $\mathrm{CO}_{2}$ predicted for the future, this problem is amplified. The selection of changes to the photosynthetic process intended to improve biomass production and crop yield must take into account a complex matrix of interacting genes and mechanisms. It is recognized that combining systems modelling with modern breeding and transgenic technologies holds promise to design new pathways, such as improved $\mathrm{CO}_{2}$ fixation and photo respiratory pathways Kebeish, et al., (2007), or new geneticregulatory networks Barrett et al., (2006) to improve photosynthetic efficiency. GY in cereals such as rice is limited by environmental stresses such as drought and high temperature, which are also increasing due to climate-change effects. Photosynthesis and related carbon metabolism is primarily affected by stress, thereby reducing GY (Chaves et al., 2009). Understanding of this complex interaction in a systems biology approach will provide the genetic tools to maintain yield under stress. Amongst cereals, rice as a paddy field crop is particularly susceptible to water stress and it is estimated that $50 \%$ of the world rice production is affected by drought. Major research efforts are directed at understanding the mechanism of plant responses to drought stress to identify gene products that confer adaptation to water deficit. Molecular mechanisms of water stress response have been investigated primarily in the model plant species Arabidopsis. Upon exposure to drought-stress conditions, many stress-related genes are induced, and their products are thought to function as cellular protectors from stress-induced damage Oh et al., (2009). The expression of stress-related genes is largely regulated by TFs. The rice and Arabidopsis genomes code for $41,500 \mathrm{TFs}$ and about $45 \%$ of them are reported from plant-specific families. Various drought-stress studies have identified TF families with putative functions in drought including MYB, bZIP, Zinc finger, NAM and APETALA2 (AP2) (Oh, et al., 2009). The AP2 family is one of the plant-specific TFs whose members share a highly conserved DNA-binding domain known as AP2, and members of this family have been associated with various developmental processes and stress tolerance (Haake, et al., 2002). The AP2 TF CBF4, also known as DREB1, was shown by overexpression analysis to lead to drought adaptation in Arabidopsis (Haake, et al., 2002). The Arabidopsis AP2 TF called HARDY was reported to provide enhanced drought tolerance and wateruse efficiency (WUE) in Arabidopsis and rice (Karaba et al., 2007). Ectopic expression of these genes confer drought tolerance and/or adaptation by modifying cellular structures of leaves and roots, $\mathrm{CO}_{2}$ exchange and parameters such as WUE, which correlate with the transformed plants' ability to withstand drought. Taken together, these and other findings indicate that AP (Gibson et al., 2011). TFs offer the potential to engineer plants in a way that makes them more productive under stress conditions. Although drought stress can alter the growth and development of a plant at any time during its life cycle, 
water limitations during reproductive growth stages can be especially conducive to yield losses in crops such as rice and maize (Zea mays) (Zinselmeier et al., 1995). Accordingly, the reproductive phases in these plants should be an important stage to study for identifying stress-responsive genes that might have a protective, or yield-altering, function in drought. Advances in plant genomics, including the availability of the complete genome sequence of rice, have provided an opportunity to identify stressrelated TFs that control yield under drought. To this end, a genome-wide analysis of drought-stress responses was conducted and led to the identification of a candidate drought induced AP2/ERF TF in reproductive tissues. To determine whether the TF could play a role in enhancing the tolerance of rice and possibly other crops to drought stress, transgenic plants were generated that contain the candidate gene driven by the CaMV 35S promoter. The HYR (HIGHER YIELD RICE) gene-expressing transgenic plants here are referred to as HYR lines, as they showed higher GY under well watered and drought-stress conditions. In addition, the HYR lines expressed multiple component traits involved in photosynthesis, sugar levels, root and shoot biomass and WUE under well-watered and drought-stress conditions. The enhanced productivity and the drought-resistant phenotype of the transgenic plants compared with the wild type (WT) are discussed. These studies provide an insight into improvement of plant productivity through enhancement of photosynthesis and multiple downstream biological processes (BPs) in combination with stress tolerance in plants.

Several reports in this issue Kunert and Vorster, (2020), Melandri et al., (2020a); Nutan et al., (2020b); Sulpice, (2020); Zhu et al., (2018), highlight the physiological, molecular, and biochemical responses of plants to drought stress. A metabolite profiling analysis of the flag leaves of 292 indica rice accessions has led to the identification of new molecular markers for drought tolerance and sensitivity in terms of grain yield (Melandri et al., 2020a; Sulpice, 2020). Melandri et al., (2020a), highlights the central role of the ascorbate-glutathione cycle and of lipid peroxidation in mitigating drought-induced yield losses. Dehydroascorbate reductase activity and malondialdehyde levels were shown to be accurate biomarkers for drought tolerance. These markers have potential use in breeding for improved rice grain yield stability under drought condition. Melandri et al., (2020b) report an association mapping and genetic dissection study of drought-induced canopy temperature differences in rice in another paper. Intriguingly, these authors report that low canopy temperature is a useful indicator of access to moisture during drought (Kaler et al., 2018). Kamburova et al., (2017) stated that an important strategy for soybean yield improvement. These authors have identified quantitative trait loci (QTLs) regulated by slow canopy wilting $(\mathrm{SW})$ in late maturing soybean genotypes Abdelrahman et al., (2018). The SW trait, which is associated with drought tolerance, involves at least two distinct mechanisms: water use efficiency and conservation. Since drought already causes $\sim 40 \%$, reduction in soybean yields Specht et al., (1999), the findings reported by Abdelrahman et al., (2018) represent an important new direction of research Kunert and Vorster, (2020), have identified genetic resources for improving drought tolerance in early maturity group soybeans.

\subsection{Irrigation water in agricultural lands under climatic changes.}

Qadir et al., (2003) stated that the import-export of virtual water could help to alleviate the future increase of water demand for food, due to climate change impacts and population growth. Increasing water scarcity and drought condition, however, point to the necessity for a more sustainable approach to water resource management in agriculture at the global, regional and local level. However, in some countries such as the Mediterranean region, irrigation is mainly applied during the summer, which coincides with the main tourism period and results in a competition between these two sectors. This aspect highlights the necessity of water resource planning to allocate water supply among different economic sectors. First step in the agricultural sector is to compute how much water crops with regard to climate conditions need. Some techniques, such as soil monitoring, lysimeters, eddy covariance, the Bowen ratio and surface renewal, are used to monitor and measure irrigation needs. While the monitoring approach may require delicate and expensive sensors or the assistance of experts, the application of models (e.g., soil water balance models) could provide a low-cost method for on-farm and regional systems for computing the crop water requirement and estimating the depth of water storage required to satisfy the agricultural demand. Once the crop water requirement is known, improving the efficiency of the irrigation application is a key strategy for water savings in agriculture. The term "efficiency" is commonly used to indicate "the level of performance" of a system. In the 
agricultural sector, the concept of "water use efficiency" is often used to highlight the relationship between crop growth development and the amount of water used.

Sinclair et al., (1983) described plant water use efficiency as the ratio of biomass accumulation (expressed as carbon dioxide assimilation), total crop biomass or crop grain yield to transpiration by the crop.

Nowadays, many strategies are implemented to improve water productivity, starting with the optimal choice of irrigation system, followed by the application of the proper irrigation scheduling in terms of both timing and quantity of water applied and concluding with the choice of the best crop management concerning the soil and climate conditions. The selection of the proper irrigation system depends on several factors, such as water availability, crop selection, soil characteristics such as deep percolation, runoff, evaporation rate and topography and the associated installation and maintenance costs. The main systems are separated into gravity systems, where water moves naturally over the soil surface due to the force of gravity, and pressurized systems. Burt et al., (1997) describe several measures of irrigation efficiency. An important measure to evaluate the performance of irrigation systems is the application efficiency (AE), which is defined as the ratio of the average depth of irrigation water contributing to the target divided by the average depth of irrigation water applied. The target depth is generally based on the soil water depletion before irrigation or a smaller amount to adjust for rainfall contributions. The target can also include excess water for reclamation or for salinity control. Many studies have been conducted to determine the AE for different systems, and the overall conclusion is that pressurized systems are generally more efficient for transporting water to crops than traditional gravity systems (Chimonides, 1995).

In recent years, several irrigation systems have significantly improved the application efficiency at the farm level, enhancing irrigation water management. Although the traditional gravity approach is still widely used Abou Seeda et al., (2020), particularly, in the southern part of Europe, it is gradually being replaced (European Environment Agency (EEA) (2009). Abou Seeda et al., (2020) nevertheless, the application efficiency of a system depends on the amount and timing of water applied, as well as on the considered crop, soil and climate conditions. To maximize crop yield and meet the crop water requirement, irrigation to refill soil water depletion is typically applied at each irrigation. This approach is valid for most field crops and many orchard crops. Holzapfel et al., (2009), however, indicated that providing deficit irrigation to some tree and vine crops can lead to more profits due to a small reduction in yield, but better quality and reduced water application. Improving the crop technical efficiency may be another solution to overcome the water for food issue. The choice of the best cultivar, such as more drought-tolerant cultivars, or crop management concerning the soil and climate conditions can provide a method to improve water productivity.

\subsection{Climate change affects soil salinity in agriculture soils}

Climate change is defined by: high atmospheric $\mathrm{CO}_{2}$ (i.e. $>400 \mathrm{ppm}$ ); increasing air temperatures; abrupt and significant changes in daily, seasonal and between-year temperature; changes in wet and dry cycles; intensive rainfall events; extended drought periods; extreme frost; and hot, dry spells that elevate fire hazard levels. Changes in climatic patterns are expected to significantly influence terrestrial systems, soil properties, surface waters and stream flows (Patterson, et al., 2013). High levels of uncertainty exist in climate model projections, particularly at regional and local scales, but climate change models do agree on some basic global trends. The models indicate that climate change is expected to affect primarily precipitation, potential evapotranspiration (ET) and temperature. Changes will occur in irradiance, ultraviolet irradiance and evaporative demand, as well as on the secondary factor ozone (Yeo, 1999).

Climate change models suggest (a) an increase in the average global temperature, (b) altered weather patterns with shifts in rainfall patterns, and (c) an increase in climatic extremes within localized areas (Yeo, 1999). Increased global temperatures will raise ocean levels as polar ice caps melt and will bring more extreme weather conditions. Droughts and flooding are expected to increase in frequency and intensity. Hot dry areas are expected to become hotter and drier, some wet areas wetter, and isolated cold areas will be colder. There is an expectation that climate change will bring increased frequency of extreme weather events around the globe, with unusually high rainfall events leading to floods and low precipitation, higher temperatures, and higher potential ET resulting in longer, harder and more frequent droughts. 
The National Center for Atmospheric Research released a collection of drought severity maps projecting drought levels using the Palmer Drought Severity Index for the period 2000-2099. The drought maps show that much of the Western Hemisphere and large parts of Eurasia, Africa and Australia will experience extreme drought, whereas higher-latitude regions from Alaska to Scandinavia are likely to become wetter and experience flooding. Evidence of the impact of the change on climate patterns is found worldwide. For instance, the USA experienced an increase in moderate to severe levels of drought, particularly in the southwest, but other areas are not exempt (e.g., the Midwest and southeast). Arguably, the most notable from a public- awareness perspective, due to its impact on agricultural productivity, was the California drought of 2011-2015. This caused drastic reductions in irrigation water allocations to farmers in the agriculturally productive San Joaquin Valley (SJV) and heightened water conservation measures in urban areas.

Other recent worldwide droughts include a 1 in a 1000-year drought in Australia (e.g., lower portion of the Murray-Darling River Basin), which began in 1995 and continued until 2009; Spain's drought in Catalonia; northern India's drought in the first decade of the new millennium; and droughts in northern China, Syria and southeastern Brazil. Recent floods include Queensland, Australia; Tennessee, Arkansas, Texas and Wisconsin in the USA; Pakistan; and India. Even though there is no short-term extreme weather event that can be conclusively attributed to climate change, there is a statistical record of these events showing that they clearly occur with increased frequency and/or intensity (Dai, 2011). Ironically, some of the most crop-productive areas of the world occur in waterscarce regions, such as the arid southwestern USA e.g., California's San Joaquin and ImperialCoachella Valleys and other arid regions of the world, including the Middle East, the Hai He, Huang He and Yangtze basins in China, and along the Nile River in Egypt and Sudan.

In most cases, these areas owe their successful crop productivity to mild year-round climates and available sources of surface water and/or groundwater for irrigated agriculture. Climate change will influence global rainfall patterns, affecting both the amount and distribution of rainfall. Global climate change model predictions indicate decreased precipitation for drier regions of the world, with annual average precipitation decreases likely to occur in most of the Mediterranean, north and south Africa, northern Sahara, Central America, the American southwest and the southern Andes, as well as southwestern Australia (Collins et al., 2013). Arid regions are the most prone to desertification and salinization (Geist, 2005; Szabolcs, 1990). Agriculture is directly linked to climate change. Crop yield, water use, biodiversity and soil health are directly affected by changes in the climate. Changes in the frequency and intensity of rainfall, temperature and other extreme weather events will influence agricultural productivity, with the net effect of climate change on world agriculture most likely to be negative. Even though some regions and crops may benefit from increased $\mathrm{CO}_{2}$, many will not.

Increasing of $\mathrm{CO}_{2}$ atmospheric are likely to increase organic matter in soil and stimulate growth and improve water-use efficiency in some crops, but heat waves, droughts and flooding may dampen these potential yield increases. Recent research has indicated that increasing atmospheric $\mathrm{CO}_{2}$ may not have as large influences on plant and crop productivity as once thought (Jarvis, et al., 2010; Körner, 2006; Long, et al., 2005; Poorter and Navas, 2003; Zaehle, et al., 2010; Zavaleta et al., 2003. Ostensibly, increasing ozone levels may counteract the $\mathrm{CO}_{2}$ effect (Long et al., 2005). The negative effects of increased temperature on plant growth may also counteract the $\mathrm{CO}_{2}$ effect (Jarvis et al., 2010). Furthermore, indirect climatic impacts, such as greater competition by insects, weeds and pathogens, will decrease yield.

Higher atmospheric $\mathrm{CO}_{2}$ concentrations, higher temperatures, more intensive rainfalls and extended droughts and heat waves will accelerate weathering of rocks and minerals in soils either chemical or physical; both are effective on weathering processes. In a 44-year field study by Gislason et al., (2009), weathering rates were found to be already increasing because of global warming. There are both positive and negative effects of climate change induced accelerated weathering. Accelerating weathering can increase the inorganic carbon pool in soils due to carbonate mineral formation, which will help decrease atmospheric $\mathrm{CO}_{2}$ levels. In addition, the dissolution of elements that serve as nutrients for microbes and plants will stimulate microbial and plant growth and biotic $\mathrm{C}$ sequestration, which will help decrease atmospheric $\mathrm{CO}_{2}$ levels (Qafoku, 2014). In contrast, accelerated weathering may perturb the balance of the biotic and in arid and semi-arid regions, soil salinity and irrigation management go hand in hand because salinity control is generally a consequence of leaching. Soil 
salinity refers to the concentration of salts in the soil solution, consisting of four major cations such as $\mathrm{Na}^{+}, \mathrm{K}^{+}, \mathrm{Mg}^{+2}$ and $\mathrm{Ca}^{+2}$ ) and five major anions as $\mathrm{HCO}_{3}{ }^{-}, \mathrm{Cl}^{-}, \mathrm{NO}_{3}{ }^{-}, \mathrm{SO}_{4}{ }^{-2}$ and $\mathrm{CO}_{3}{ }^{-2}$ ).

Soil salinity is characterized in terms of the concentration and composition of the soluble salts and is most commonly measured in the laboratory as the electrical conductance of the saturation extract in $\mathrm{dS} \mathrm{m}^{-1}$ (Corwin and Yemoto, 2017). The accumulation of soil salinity could reduce plant growth, yield production, and in severe cases, crop failure. Salinity limits water uptake by plants by reducing the osmotic potential, making it more difficult for the plant to extract water. Salinity may also cause specific ion toxicity effects e.g., $\mathrm{Na}^{+}$ion toxicity depending on the soil $\mathrm{pH}$ and upset the nutritional balance of plants. The salt composition of the soil water influences the composition of cations on the exchange complex of soil particles, which influences soil permeability and tilth. Sodic soils have soil structure degradation and permeability reduction.

Furthermore, soil salinization is driver for desertification phenomena and creating land degradation processes such as arable land abandonment and soil erosion (Qin et al., 2013). Because of the potential detrimental impacts of soil salinity accumulation and its ubiquitous association with irrigated agriculture, salinity is a soil chemical property that is crucial to soil health. The impact of climate change on soil salinity levels in the root zone has been far less studied than other soil properties, such as organic matter, $\mathrm{N}$ and $\mathrm{P}$. This may be because salinity is among the most spatially complex and temporally dynamic soil properties, with a coefficient of variation generally over $60 \%$ (Corwin et al., 2003). Another reason may be the lack of quantitative spatial data over large spatial extents to make comparisons of changes over time. Salt-affected soils are estimated to comprise $23 \%$ of the cultivated land, approximately $3.5 \times 108$ ha (Massoud, 1981).

However, no directly measured global inventories of soil salinity, all known global inventories of soil salinity and, with only one exception, all known regional-scale inventories are gross approximations based on qualitative and not quantitative data (Lobell, 2010; Lobell et al.,2010). Until the recent development of proximal and remote sensors with associated protocols and guidelines for measuring soil salinity from field to regional scales, the ability to map and monitor soil salinity across multiple scales has been too formidable due to the high spatial and temporal variability of soil salinity (Corwin and Scudiero, 2016). Alternatively, because, unlike many other soil properties, soil salinity can be easily managed by the addition of water to leach salts. As long as the water source is plentiful and sufficiently good in quality, then salinity is generally not regarded as a problem of concern. However, if droughts become more frequent as climatologists predict, then salinity is likely to become a growing issue of concern. Global food security focuses on four major crops that account for $85 \%$ of the world's cereal exports: wheat, rice, maize and soybean (Teh and Koh, 2016). Past climate change, trends in crop production are evident in several regions across the globe Lu, et al., (2013). Lobell et al., (2011) provided evidence that climate change had already affected wheat and maize yields both regionally and globally. The expectation is that climate change will fundamentally alter the patterns of global food production, with negative impacts on crop productivity of wheat, rice and maize in low latitude and tropical regions (FAO, 2016). Temperate zones will also be impacted, such as for maize in the USA and wheat in the European Union, due to increased water scarcity, more frequent and intense heat events, and accelerated phenology (FAO, 2016).

Even though most climate change impacts on crop productivity are expected to be negative, there are studies that predict positive impacts in areas where increases in precipitation are expected to occur. For instance, the combined use of climate and crop models for the grain-producing zone of Central Eurasia indicates an increase in yield because of higher atmospheric $\mathrm{CO}_{2}$, warmer temperatures and longer growing seasons with less frost

According to climate models, the Mediterranean Basin will increase in winter temperatures combined with altered rainfall patterns and changes in rainfall amount (Qafoku, 2014). The Gaza Strip, like most arid and semi-arid agricultural areas within the Mediterranean Basin, has serious water-deficit problems regarding both quantity and quality (Massoud, 1981; Zheng, etal. 2009). Over 70\% of the total groundwater extracted in the Gaza Strip is used for agriculture (Corwin and Yemoto, 2017). Simulations of seawater intrusion by Loáiciga et al., (2012) showed that groundwater extraction is a significant factor in seawater intrusion. 
The relationship between $\mathrm{Na}^{+}, \mathrm{Cl}^{-}$and the spatial variation of ionic ratios of $\mathrm{rCa}^{2+}=\left(\mathrm{rHCO}_{3}^{-}+\right.$ $\mathrm{rSO}_{4}{ }^{2-}$ ) in coastal areas of the Gaza Strip show that the aquifer currently used as an irrigation water source exhibited seawater intrusion (Benbi and Kaur, 2009; Corwin and Yemoto, 2017). It is expected that seawater intrusion in the Gaza Strip and throughout the Mediterranean Basin will be exacerbated by several climate change projections: (a) air temperature will increase from 2 . to $5.1^{\circ} \mathrm{C},(\boldsymbol{b})$ precipitation will decrease from 4 to $27 \%$, (c) drought periods will increase, with a higher frequency of days exceeding $30^{\circ} \mathrm{C}$, and (d) sea level will increase by around $0.35 \mathrm{~m}$, with a concomitant increase in seawater intrusion (Loáiciga et al., 2012). These projected changes in climate for the Mediterranean Basin will have an impact on salinity accumulation due to seawater intrusion, which will influence crop productivity and directly affect crop yield (Corwin and Yemoto, 2017). found that in the Gaza Strip the impact of an increase in salinity on irrigation requirements is considerably higher than the impact of climate change.

\section{Impact of Climate Change on Soil Health}

Several manuscripts in this issue focus on different aspects of climatic change impacts on soil physical properties hear however, chemical parameters were completely discussing during the subtopics in our review. Several manuscripts in this issue focus on different aspects of climatic change impacts on soil physical properties hear however, chemical parameters were completely discussing during the subtopics in our review. The potential impact on soil health resulting due to the climate change is through organic matter supply, temperature regimes, hydrology and salinity. Following are the major consequences of global climate change on soil health. Some soil physical properties such as (Soil texture and structure, creating type of soil porosity influences on water infiltration and water available for plant, bulk density, rooting depth, type of vegetation, Soil temperature) . Higher temperature, high and low extremes of rainfall, increase in $\mathrm{CO}_{2}$ concentration and their interactions due to climate change are expected to influence on several soil physical process which will subject the soils to significant risk of salinization, decreased water availability and changes in $\mathrm{C}$ and $\mathrm{N}$ dynamics, nutrient storage in soil and reduction in soil biodiversity (Benbi and Kaur, 2009). The physical properties and processes of soil affect soil health by altering water movement through soil, root penetration in soil and water congestion, some of climate change are as follow.

\subsection{Soil texture}

Soil texture is the relative proportion of soil competence such as sand, silt and clay fraction that has direct impact of climate change. The four potential climate scenarios (Arid, Semi-arid, Sub-humid and Humid) have great impact on important soil processes as the texture differentiation in the soil profile (Brinkman and Brammer, 1990; Scharpenseel et al., 1990).

\subsection{Soil structure and aggregate stability}

Soil structure defined by arrangement and organization of primary and secondary particles in a soil mass, therefore controlling water and air present in soil pores.

Soil aggregates are groups of soil particles that bind to each other more strongly than to adjacent particles. The space between the aggregates provides pore space for retention and exchange of air and water. Aggregation affects erosion, movement of water, and plant root growth. Desirable aggregates are stable against rainfall and water movement. Aggregates that break down in water or fall apart when struck by raindrops release individual soil particles that can seal the soil surface and clog pores. This breakdown creates crusts that close pores and other pathways for water and air entry into a soil and restrict emergence of seedlings from a soil. Optimum conditions have a large range in pore size distribution. This includes large pores between the aggregates and smaller pores within the aggregates. The pore space between aggregates is essential for water and air entry and exchange. This pore space provides zones of weakness through which plant roots can grow. If the soil mass has a low bulk density or large pore spaces, aggregation is less important. For example, sandy soils have low aggregation, but roots and water can move readily (Dalal and Moloney, 2000; Moebius et al., 2007).

The nature and quality of the structure is strongly influenced by the amount and quality of organic matter present, inorganic constituents of the soil matrix, cultivation methods and natural physical processes such as shrink-swell and freeze thaw behaviour. Deceasing of soil organic matter levels 
decreasing in soil aggregate stability, infiltration rates and increase in susceptibility to compaction, runoff furthermore, susceptibility to erosion (Bot and Benites, 2005; Karmakar et al., 2016).

\subsection{Soil porosity}

A measure of the void spaces in a material as fraction (volume of voids to that of total volume) and pore size distribution provide the ability of soil to store root zone water and air necessary for plant growth (Reynolds et al., 2002). Pore characteristics are strongly linked to soil physical quality, bulk density, micro porosity and functions of pore volume. While soil porosity and water release characteristics directly influence a range of soil indices including soil aeration capacity, plant available water capacity and relative field capacity. Since root, development and soil enzyme activities are closely related soil porosity and pore size distribution. Moreover, because of future climate change scenarios elevated $\mathrm{CO}_{2}$ and temperature, variable and extreme rain fall events) may alter root development and soil biological activities. Soil porosity and pore size distribution consequently, soil functions are affected in unexpected directions. This aspects needs alteration in future studies on the relationship of soil health and climate change. Decreased microbial activity, reduced root growth and exudates, reduce aggregate stability, gradually increased rain fall intensities where rain droplets impact causes surface erosion and sealing on sodic soils. It will leads to poor crop emergence, growth and increases chances of surface runoff.

\subsection{Infiltration and plant available water}

The water availability for plant growth and important soil processes are governed by a range of soil properties including porosity, field capacity, lower limit of plant available water (thus, excluding osmotic potential), micro pore flow and texture (Jarvis, 2007; Reynolds et al., 2002). Plant available water capacity has been used as part of integrative soil health tests to assess management impacts. Further, more the soil available water and distribution may respond rapidly to climate change, especially, to variable and high intensity rainfall or drought events and thus, management strategies, could be planting of cover crops, conservation tillage and incorporation of organic matter, that maintain or even enhance water infiltration and available water in soil may help in mitigating the impact of severe rainfall and drought events or severe erosion events (Lal, 1995; Salvador Sandris et al., 2008).

\subsection{Bulk density}

Bulk density is routinely assessed to characterize the state of soil compactness in response to land use and management (Hakansson and Lipiec, 2000). Bulk density in general negatively correlated with soil organic matter (SOM) or soil organic carbon (SOC) content (Weil and Magdoff, 2004). The loss of organic carbon from increased decomposition due to elevated temperature Davidson and Janssens, (2006), may lead to increase in bulk density and hence, making soil more prone to compaction viz. land management activities and climate change stresses from variable and high intensity rain falls and drought events (Birkas et al., 2009).

\subsection{Rooting depth}

Changes in rooting depth is likely to affect plant available water capacity, subsoil salinity, SOC content or other properties to indicate major constraints in the soil profile Birkas et al., (2009); Dalal and Moloney, (2000). Under prolonged drought, the impact of sub soil constraints such as salinity and high chloride concentrations (Dang et al., 2008; Box and Bruce, 1996) are likely to be greater on plant available water and hence plant productivity.

\subsection{Soil surface cover (vegetation)}

Soil surface cover provides range of important ecological functions including protection of soil surface water and nutrient retention, C- fixation and in some instances $\mathrm{N}$ fixation and support native seed germination (Box and Bruce, 1996). Soil structural conditions such as soil crust and soil seal formation, primarily related to sodicity are used to characterize soil health under climate change. The formation of soil crusts and seals can affect a range of soil processes, including water infiltration, oxygen diffusion, runoff, surface water evaporation and soil erosion. 


\subsection{Soil temperature}

Soil temperature regime is governed by gains and losses of sun radiation at the surface, the process of evaporation, heat conduction through the soil profile and convective transfer via the movement of gas and water (Karmakar et al., 2016). As with soil moisture, soil temperature is a prime mover in most soil processes. Warmer soil temperature will accelerate soil processes, rapid decomposition of organic matter, increased microbiological activity, quicker nutrients release, increase nitrification rate and generally accentuate chemical weathering of minerals. However, soil temperatures will also be affected by the type of vegetation occurring at its surface, which may change itself because of climate change or adaptation management.

\section{Conclusions}

Climate change represents one of the greatest research challenges currently faced by plant biologists, agronomists and conservation biologists. Greenhouse gas emissions set to continue to rise for the near future. Climate change has both direct and indirect impacts on agricultural production systems. Direct impacts include effects caused by a modification of physical characteristics such as temperature levels and rainfall distribution on specific agricultural production systems. Indirect impacts are those that affect production through changes on other species such as pollinators, pests, disease vectors and invasive species. These indirect effects can play a major role. They are much more difficult to assess and project given the high number of interacting parameters and links, many of which are still unknown

Climatic change can promote the accumulation of soluble sugar including glucose and fructose, and the accumulation of antioxidants including ascorbic acid, total phenols, and total flavonoids, but reduce the levels of protein, nitrate, $\mathrm{Mg}, \mathrm{Fe}$, and $\mathrm{Zn}$ in products. Nutrient deficiencies are one of the major causes of quality and production losses around the world, understanding the interaction of these stresses with $\mathrm{eCO}_{2}$ is of paramount importance. Due to extreme weather, events the frequency of global warming is expected to increase that ultimately disturb the ecosystem globally. Living organisms e.g. plants, animals, fishes, and humans affected by the extreme environmental conditions. Food security and agricultural yield are considerably affected by the adverse weather. With elevation in temperature, the production of major crops has been reduced evidently around the world. The increased frequency of drought and heavy rainfall, temperature fluctuations, salinity, and insect pest attacks are anticipated to decrease crop productivity leading to higher threats of starvation. Crop adaptability has suffered not only because of temperature variations, but also because of rainfall

Climate change, it can also improve crop performance by increasing rates of photosynthesis and water-use efficiency, particularly, in $\mathrm{C}_{3}$ plants. However, longer treatments with $\mathrm{eCO}_{2}$ might lead to photosynthetic acclimation, due to increased soluble sugars leading to an imbalanced $\mathrm{C}$ : $\mathrm{N}$ ratio accelerated leaf senescence and/or limited growth, water deficit and temperature extremes owing to climate change; gradually influence the reproductive phase of plant growth. It was described that the flower initiation and inflorescence is badly affected by the water stress particularly, in cereals crops. Genetic mechanisms and of the physiological and molecular processes, determining mineral nutrients absorption are essential and will help to improve the nutritional performance of grains subject to climate change.

\section{References}

Abadía, J., A.F. López-Millán, A. Rombolá, and A. Abadía, 2002. Organic acids and Fe deficiency: a review. Plant Soil, 241.

Abbas, S., P. Sharmila, D. Uprety, and P. Saradhi, 2009. Effects of elevated $\mathrm{CO}_{2}$ on soil physicochemical characteristics under Free Air $\mathrm{CO}_{2}$ Enrichment (FACE) technology. IOP Conference Series: Earth and Environmental Science, 6: 292045

Abdel gawad, H., E.R. Farfan-Vignolo, D. Vos, and H. Asard, 2015. Elevated $\mathrm{CO}_{2}$ mitigates drought and temperature-induced oxidative stress differently in grasses and legumes. Plant Sci., 231:110.

Abdelrahman, M., D.J. Burritt, A. Gupta, H. Tsujimoto, and L.S.P. Tran, 2020. Heat stress effects on source-sink relationships and metabolome dynamics in wheat. Journal of Experimental Botany, 71: 543-554. 
Abdelrahman, M., S. Jogaiah, D.J. Burritt, and L.S.P. Tran, 2018. Legume genetic resources and transcriptome dynamics under abiotic stress conditions. Plant Cell Environ. 2018, 41: 19721983.

Abdelrahman, M., A.M. Al-Sadi, A. Pour-Aboughadareh, D.J. Burritt, and L.-S.P. Tran, 2018. Genome editing using CRISPR/Cas9-targeted mutagenesis: An opportunity for yield improvements of crop plants grown under environmental stresses. Plant Physiol. Biochem., 131: 31-36.

Abel, S., C.A. Ticconi, and C.A. Delatorre, 2002. Phosphate sensing in higher plants. Physiologia sPlantarum, 115: 1-8.

Abou Seeda, M.A, E.A.A Abou El-Nour, and A.A Yassen, 2020. Role of Essential Plant Nutrients and their Risk Assessment ISBN: 978-1-63278-907-5 Published: September 2020 Print September 2020 Published by Innovation info eBooks, Heathrow Stockley Park, Heathrow UB11BD, UK

Abou Seeda M.A, E.A.A Abou El-Nour, A.A Yassen, and S.A Hammad, 2020. Approaching Methods of Irrigation and Technologies for Improving and Maximizing Water Use Efficiency, ISBN: 978-1-63278-982-2, Published: December 2020, Print: December 2020 Published by Innovation info eBooks, Heathrow Stockley Park, Heathrow UB11BD, UK.

Achat, D.L., C. Morel, M.R. Bakker, et al., 2010. Assessing turnover of microbial biomass phosphorus: Combination of an isotopic dilution method with a mass balance model. Soil Biology and Biochemistry, 42: 2231-2240.

Ackerly, D.D., S. Dudley, S.E. Sultan, et al., 2000. "The evolution of plant ecophysiological traits: recent advances and future directions," BioScience, 50(11): 979-995,

Aerts, R., 1996. Nutrient resorption from senescing leaves of perennials: are there general patterns? Journal of Ecology, 84: 597-608.

Ahmed, M., C.O. Stöckle, R. Nelson, and S. Higgins, 2017. Assessment of Climate Change and Atmospheric $\mathrm{CO}_{2}$ Impact on Winter Wheat in the Pacific Northwest Using a Multimodel Ensemble. Front Ecol. Environ. 5.

Ahuja, I., R.C. De Vos, A.M. Bones, and R.D. Hall, 2010. Plant molecular stress responses face climate change. Trends Plant Sci., 15: 664-674.

Ai, F., N. Eisenhauer, Y. Xie, J. Zhu, A. Jousset, W. Du, Y. Yin, X. Zhang, R. Ji, and H. Guo, 2018. Elevated $\mathrm{CO}_{2}$ accelerates polycyclic aromatic hydrocarbon accumulation in a paddy soil grown with rice. PLoS One, 13: e0196439.

Ainsworth, E.A., and S.P. Long, 2005. What have we learned from 15 years of free-air $\mathrm{CO}_{2}$ enrichment (FACE)? A meta-analytic review of the responses of photosynthesis, canopy properties and plant production to rising $\mathrm{CO}_{2}$. New Phytol., 165:351- 372.

Ainsworth, E.A., A. Rogers, H. Blum, J. No"sberger, and S.P. Long, 2003. Variation in acclimation of

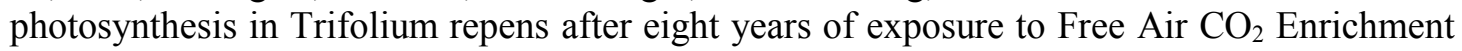
(FACE). Journal of Experimental Botany 393: 2769-2774.

Ainsworth, E.A., A. Rogers, R. Nelson, and S.P. Long, 2004. Testing the "source-sink" hypothesis of down-regulation of photosynthesis in elevated [CO2] in the field with single gene substitutions in Glycine max. Agric For Meteorol., 122:85-94.

Ainsworth, E.A., A. Rogers, L.O. Vodkin, A. Walter, and U. Schurr, 2006. The effects of elevated $\mathrm{CO}_{2}$ concentration on soybean gene expression. An analysis of growing and mature leaves. Plant Physiology, 142: 135-147.

Allard, V., C. Robin, P.C.D. Newton, M. Lieffering, and J.F. Soussana, 2006. Short and long-term effects of elevated $\mathrm{CO}_{2}$ on Lolium perenne rhizodeposition and its consequences on soil organic matter turnover and plant N yield. Soil Biology and Biochemistry, 38: 1178-1187.

Allen, M., W. Swenson, J. Querejeta, L. Egerton-Warburton, and K. Treseder, 2003. Ecology of mycorrhizae: a conceptual framework for complex interactions among plants and fungi. Annual Review of Phytopathology, 41: 271-303.

Altieri, M.A., and C.I. Nicholls, 2017. The adaptation and mitigation potential of traditional agriculture in a changing climate. Clim. Chang., 140: 33-45.

Ambavaram, M.M., S. Basu, A. Krishnan, V. Ramegowda, U. Batlang, L. Rahman, N. Baisakh, and A. Pereira, 2014. Coordinated regulation of photosynthesis in rice increase yield and tolerance to environmental stress. Nature Communications, 5: 5302. 
Andrews, T., M. Doutriaux-Boucher, O. Boucher, and P.M. Forster, 2011. A regional and global analysis of carbon dioxide physiological forcing and its impact on climate, Clim. Dyn., 36: 783-792.

Anoua, M., B. Jaillard, T. Ruiz, and J.C. Be 'net, 1997. Couplages entre transferts de matie're et re'actions chimiques dans un sol. II. Application au transfert de matie're dans la rhizosphe`re. Entropie, 207: 13-24.

Araus, J., G. Slafer, M. Reynolds, and C. Royo, 2002. Plant breeding and drought in C3 cereals: What should we breed for? Ann. Bot., 89, 925-940.

Arenque, B.C., A. Grandis, O. Pocius, A.P. de Souza, and M.S. Buckeridge, 2014. Responses of Senna reticulata, a legume tree from the Amazonian floodplains, to elevated atmospheric $\mathrm{CO}_{2}$ concentration and waterlogging. Trees, 28:1021-1034.

Arnone, J.A., J.G. Zaller, E.M. Spehn, P.A. Niklaus, C.E. Wells, and C. Ko"rner, 2000. Dynamics of root systems in native grasslands: effects of elevated atmospheric $\mathrm{CO}_{2}$. New Phytologist, 147: $73-85$.

Arntz, M.A and L.F. Delph, 2001. Pattern and process: evidence for the evolution of photosynthetic traits in natural populations. Oecologia, 127(4): 455-467.

Arora, V.K., et al., 2013. Carbon-concentration and carbon-climate feedbacks in CMIP5 earth system models, J. Clim., 26: 5289-5314,

Arunanondchai, P., C. Fei, A. Fisher, B.A. McCarl, W. Wang, and Y. Yang, 2018. How does climate change affect agriculture. In the Routledge Handbook of Agricultural Economics; Routledge: Abingdon-on-Thames, UK.

Ashraf, M.A., 2012. Waterlogging stress in plants: A review. Afr. J. Agric. Res., 7(13).

Ashraf, M.A., A. Akbar, S.H. Askari, M. Iqbal, R. Rasheed, and I. Hussain, 2018. Recent Advances in Abiotic Stress Tolerance of Plants through Chemical Priming: An Overview. In Advances in Seed Priming; Springer: Berlin/Heidelberg, Germany): 51-79.

Asif, M., C.E. Tunc, +L. Ozturk, 2018. Changes in yield attributes and $\mathrm{K}$ allocation in wheat as affected by $\mathrm{K}$ deficiency and elevated $\mathrm{CO}_{2}$. Plant Soil, 426:153-162.

Asif, M., C.E. Tunc, M.A. Yazici, Y. Tutus, R. Rehman, A. Rehman, and L. Ozturk, 2019. Effect of predicted climate change on growth and yield performance of wheat under varied nitrogen and zinc supply. Plant Soil, 434:231-244

Asif, M., O. Yilmaz, and L. Ozturk, 2017a. Elevated carbon dioxide ameliorates the effect of Zn deficiency and terminal drought on wheat grain yield but compromises nutritional quality. Plant Soil, 411:57-67.

Asif, M., O. Yilmaz, and L. Ozturk, 2017b. Potassium deficiency impedes elevated carbon dioxideinduced biomass enhancement in well-watered or drought-stressed bread wheat. J. Plant Nutr. Soil Sc., 180:474-481.

Asseng, S., F. Ewert, P. Martre, R.P. Rötter, D. Lobell, D. Cammarano, B. Kimball, M. Ottman, G. Wall, and J.W. White, 2015. Rising temperatures reduce global wheat production. Nat. Clim. Change., 5, 143.

Bailey-Serres, J., J.E. Parker, E.A. Ainsworth, G.E.D. Oldroyd, and J.I. Schroeder, 2019. Genetic strategies for improving crop yields. Nature, 575: 109-118.

Baker, J.T., L.H. Allen, and K.J. Boote, 1990. Growth and yield responses of rice to carbon-dioxide concentration. Journal of Agricultural Science, 115: 313-320.

Balaguer L., E. Mart'inez-Ferri, F. Valladares et al., 2001. "Population divergence in the plasticity of the response of Quercus coccifera to the light environment," Functional Ecology, 15(1): 124135.

Balyan, S., M. Kumar, R.D. Mutum, U. Raghuvanshi, P. Agarwal, S. Mathur, and S. Raghuvanshi, 2017. Identification of miRNA-mediated drought responsive multi-tiered regulatory network in drought tolerant rice, Nagina 22. Scientific Reports 7, 15446.

Barão, L., A. Alaoui, C. Ferreira, G. Basch, G. Schwilch, V. Geissen, W. Sukkel, J. Lemesle, F. GarciaOrenes, and A. Morugán-Coronado, 2019. Assessment of promising agricultural management practices. Sci. Total Environ., 649:610-619.

Barnabás, B., K. Jäger, and A. Fehér, 2008. The effect of drought and heat stress on reproductive processes in cereals. Plant Cell Environ., 31, 11-38. 
Baroowa, B., and N. Gogoi, 2014. Biochemical changes in black gram and green gram genotypes after imposition of drought stress. J. Food Legum., 27, 350-353.

Barrett, D.J., A.E. Richardson, and R.M. Gifford, 1998. Elevated atmospheric $\mathrm{CO}_{2}$ concentrations increase wheat root phosphatase activity when growth is limited by phosphorus. Funct Plant Biol., 25:87-94.

Barrett, D.L., and R.M. Gifford, 1995. Acclimation of photosynthesis and growth by cotton to elevated $\mathrm{CO}_{2}$ : interactions with severe phosphate deficiency and restricted rooting volume. Australian Journal of Plant Physiology, 22: 955-963.

Barrett, C.L., T.Y. Kim, H.U. Kim, B.O. Palsson, and S.Y. Lee, 2006. Systems biology as a foundation for genome-scale synthetic biology. Curr. Opin. Biotechnol. 17, 488-492

Bassiri Rad, H., V.P. Gutschick, and J. Lussenhop, 2001. Root system adjustments: regulation of plant nutrient uptake and growth responses to elevated $\mathrm{CO}_{2}$. Oecologia, 126: 305-320.

Bassiri Rad, H., J.F. Reynolds, R.A. Virginia, and M.H. Brunelle, 1997. Growth and root NO3- and PO4 3- uptake capacity of three desert species in response to atmospheric $\mathrm{CO}_{2}$ enrichment. Australian Journal of Plant Physiology, 24: 353-358.

Bassu, S., N. Brisson, J.L. Durand, K. Boote, J. Lizaso, J.W. Jones, C. Rosenzweig, A.C. Ruane, M. Adam, and C. Baron, 2014. How do various maize crop models vary in their responses to climate change factors? Glob Chang Biol., 20:2301-2320.

Bates, T.R., and J.P. Lynch, 2000. The efficiency of Arabidopsis thaliana (Brassicaceae) root hairs in phosphorus acquisition. American Journal of Botany, 87: 964-970.

Bavorova, M., N. Imamverdiyev, and E. Ponkina, 2018. Farm-level economics of innovative tillage technologies: the case of no-till in the Altai Krai in Russian Siberia. Environ Sci Pollut. R., 25:1016-1032.

Bayuelo-Jime'nez, J., and I. Ochoa-Cadavid, 2014. Phosphorus acquisition and internal utilization efficiency among maize landraces from the central Mexican highlands. Field Crops Research, 156: $123-134$.

Beard, J.L., 2008. Why iron deficiency is important in infant development. J. Nutr., 138:2534-2536.

Bebber, D.P., M.A.T. Ramotowski, and S.J. Gurr, 2013. Crop pests and pathogens move polewards in a warming world. Nature Climate Change, 3: 985-988.

Beer, C., et al., 2010. Terrestrial gross carbon dioxide uptake: Global distribution and covariation with climate, Science, 329(5993): 834-8.

Bellaloui, N., Y. Hu, A. Mengistu, H.K. Abbas, M.A. Kassem, and M. Tigabu, 2016. Elevated atmospheric carbon dioxide and temperature affect seed composition, mineral nutrition, and $15 \mathrm{~N}$ and $13 \mathrm{C}$ dynamics in soybean genotypes under controlled environments. Atlas J Plant Biol., 56-65.

Benbi, D.K., and R. Kaur, 2009. Modeling soil processes in relation to climate change. J Ind. Soc. Soil Sci., $57: 433-444$.

Benbi, D.K., and N. Senapati, 2009. Soil aggregation and carbon and nitrogen stabilization in relation to residue and manure application in rice-wheat systems in northwest India. Nutrient Cycling in Agroecosystems.,87: 233-247.

Bencke-Malato, M., A.P. De Souza, M. Ribeiro-Alves, J.F. Schmitz, M.S. Buckeridge, and M. AlvesFerreira, 2019. Short-term responses of soybean roots to individual and combinatorial effects of elevated $\left[\mathrm{CO}_{2}\right]$ and water deficit. Plant Sci., 280: 283-296.

Benevenuto, R.F., S.Z. Agapito-Tenfen, V. Vilperte, O.-G. Wikmark, P.J. Van Rensburg, and R.O. Nodari, 2017. Molecular responses of genetically modified maize to abiotic stresses as determined through proteomic and metabolomic analyses. PLoS ONE, 12: e0173069.

Benlloch-Gonzalez, M., R. Bochicchio, J. Berger, H. Bramley, and J.A. Palta, 2014. High temperature reduces the positive effect of elevated $\mathrm{CO}_{2}$ on wheat root system growth. Field Crops Research, 165: 71-79.

Betencourt, E., M. Duputel, B. Colomb, D. Desclaux, and P. Hinsinger, 2012. Intercropping promotes the ability of durum wheat and chickpea to increase rhizosphere phosphorus availability in a low P soil. Soil Biology and Biochemistry, 46: 181-190.

Birkas, M., A. Dexter, and A. Szemok, 2009. Tillage induced soil compaction as a climate threat increasing stressor. Cereal Res. Commun., 37:379-382 
Blagodatskaya, E., S. Blagodatsky, M. Dorodnikov, and Y. Kuzyakov, 2010. Elevated atmospheric $\mathrm{CO}_{2}$ increases microbial growth rates in soil: results of three $\mathrm{CO}_{2}$ enrichment experiments. Global Change Biology, 16: 836-848.

Bloom, A.J., D.R. Smart, D.T. Nguyen, and P.S. Searles, 2002. Nitrogen assimilation and growth of wheat under elevated carbon dioxide. P. Natl. Acad. Sc., 99:1730-1735.

Bolan, N.S., R. Naidu, S. Mahimairaja, and S. Baskaran, 1994. Influence of low molecular- weight organic acids on the solubilization of phosphorus. Biology and Fertility of Soils, 18: 311-319.

Bonan, G.B.,+ S.C. Doney, 2018. Climate, ecosystems, and planetary futures: The challenge to predict life in Earth system models. Science, 359, eaam8328

Bonito A., L. Varone, and L. Gratani, 2011. "Relationship between acorn size and seedling morphological and physiological traits of Quercus ilex L. from different climates," Photosynthetica, 49(1): 75-86.

Bonnot, C., B. Pinson, M. Clément, S. Bernillon, S. Chiarenza, S. Kanno, N. Kobayashi, E. Delannoy, T.M. Nakanishi, L. Nussaume, et al., 2016. A chemical genetic strategy identify the PHOSTIN, a synthetic molecule that triggers phosphate starvation responses in Arabidopsis thaliana. New Phytol. 209: 161-176.

Bot, A., and J. Benites, 2005. The importance of soil organic matter: Key to drought-resistant soil and sustained food and production. FAO Soils Bull. No. 80. Food and Agriculture Organization of the United Nations, Rome, Italy., 78

Boucher, O., A. Jones, and R.A. Betts, 2009. Climate response to the physiological impact of carbon dioxide on plants in the Met Office Unified Model HadCM3, Clim. Dyn., 32: 237-249.

Bouis, H.E., and A. Saltzman, 2017. Improving nutrition through biofortification: A review of evidence from Harvest Plus, 2003 through 2016. Glob Food Sec., 12:49-58.

Bowes, G., 1993. Facing the inevitable: plants and increasing atmospheric $\mathrm{CO}_{2}$. Annu. Rev Plant Physiol., 44:309-332.

Box, J.E., and R.R. Bruce, 1996. The effect of surface cover on infiltration and soil erosion. In: Agassi M. (ed), Soil erosion, conservation and rehabilitation. Marcel Dekker, Inc. New York., 107118.

Boyer, J.S., 1982. Plant productivity and environment. Science, 218, 443-448.

Bradshaw A.D., 1965. "Evolutionary significance of phenotypic plasticity in plants," Advances in Genetics, 13): 115-155,

Briat, J.-F., C. Dubos, and F. Gaymard, 2015. Iron nutrition, biomass production, and plant product quality. Trends Plant Sci., 20: 33-40.

Brinkman, R., and H. Brammer, 1990. The influence of a changing climate on soil properties. Proceedings of the Transactions 14th International Congress of Soil Science, August 1990, Kyoto, Japan., 283-288

Broadley, M., P. Brown, I. Cakmak, Z. Rengel, and F. Zhao, 2012. Function of nutrients: micronutrients. In: Marschner's mineral nutrition of higher plants. Elsevier Ltd, London, 191248

Broberg, M., P. Högy, and H. Pleijel, 2017. $\mathrm{CO}_{2}$-induced changes in wheat grain composition: metaanalysis and response functions. Agron. 7:32.

Brouder, S.M., and J.J. Volenec 2008. Impact of climate change on crop nutrient and water use Efficiencies. Physiologia Plantarum., 133(4):705-724.

Brown, L.K., T.S. George, G.E. Barrett, S.F. Hubbard, and P.J. White, 2013. Interactions between root hair length and arbuscular mycorrhizal colonization in phosphorus deficient barley (Hordeum vulgare). Plant and Soil, 372: 195-205.

Brumbarova, T., A. Matros, H.-P. Mock, and P. Bauer, 2008. A proteomic study showing differential regulation of stress, redox regulation and peroxidase proteins by iron supply and the transcription factor FER. Plant J 54:321-334.

Brundrett, M.C., 2002. Biogeography of Mycorrhizal Symbiosis. Springer, Cham, Switzerland

Brundrett, M., and L. Tedersoo, 2019. Misdiagnosis of mycorrhizas and inappropriate recycling of data can lead to false conclusions. New Phytol., 221: 18-24

Bu"hler, S., A. Oberson, S. Sinaj, D.K. Friesen, and E. Frossard, 2003. Isotope methods for assessing plant available phosophorus in acid tropical soils. European Journal of Soil Science, 54: 605616. 
Bünemann, E.K., F. Steinebrunner, P.C. Smithson, E. Frossard, and A. Oberson, 2004. Phosphorus dynamics in a highly weathered soil as revealed by isotopic labeling techniques. Soil Science Society of America Journal, 68: 1645- 1655.

Buddrick, O., OA.H. Jones, H.J. Cornell, and D.M. Small, 2014. The influence of fermentation processes and cereal grains in wholegrain bread on reducing phytate content. Journal of Cereal Science, 59: 3-8.

Buendı'a, C., S. Aren, T. Hickler, S.I. Higgins, P. Porada, and A. Kleidon, 2014. On the potential vegetation feedbacks that enhance phosphorus availability-insights from a process-based model linking geological and ecological timescales. Biogeosciences, 11:3661-3683.

Bunce, J.A., 2008. Contrasting responses of seed yield to elevated carbon dioxide under field conditions within Phaseolus vulgaris. Agric Ecosyst Environ., 128:219-224.

Bunce, J.A., 2015. Elevated Carbon Dioxide Effects on Reproductive Phenology and Seed Yield among Soybean Cultivars. Crop Sci., 55:339-343.

Burgess, P., and B. Huang, 2014. Root protein metabolism in association with improved root growth and drought tolerance by elevated carbon dioxide in creeping bentgrass. Field Crop Res., 165:80-91.

Burrell, L.D., F. Zehetner, N. Rampazzo, B. Wimmer, and G. Soja, 2016. Longterm effects of biochar on soil physical properties. Geoderma, 282: 96-102.

Burritt, D.J., 2019. Crop Plant Adaption to Climate Change and Extreme Environments. In: Melton L, Shahidi F, Varelis P (eds) Encyclopedia of Food Chemistry. Academic Press, Oxford, 196-201

Burt, C.M., A.J. Clemmens, T.S. Strelkot, K.H. Solomon, R.D. Bliesner, L.A. Hardy, T.A. Howell, and D.E. Eisenhauer, 1997. Irrigation performance measures: Efficiency and uniformity. J. Irrig. Drain. Eng., 123: 423-422.

Butterly, C.R., R. Armstrong, D.L. Chen, and C. Tang, 2015. Carbon and nitrogen partitioning of wheat and field pea grown with two nitrogen levels under elevated $\mathrm{CO}_{2}$. Plant and Soil, 391: 367-382.

Cakmak I, 2005. The role of potassium in alleviating detrimental effects of abiotic stresses in plants. J. Plant Nutr. Soil Sc., 168: 521-530.

Cakmak, I., M. Kalayci, Y. Kaya, A. Torun, N. Aydin, Y. Wang, Z. Arisoy, H. Erdem, A. Yazici, and O. Gokmen, 2010. Biofortification and localization of zinc in wheat grain. J. Agric. Food Chem., 58: 9092-9102.

Cakmak, I., and U.B. Kutman, 2018. Agronomic biofortification of cereals with zinc: a review. Eur. J. Soil Sci., 69:172-180.

Camenzind, T., J. Homeier, K. Dietrich, S. Hempel, D. Hertel, A. Krohn, C. Leuschner, Y. Oelmann, P.A. Olsson, J.P. Suarez, and M. Rillig, 2016. Opposing effects of nitrogen versus phosphorus additions on mycorrhizal fungal abundance along an elevational gradient in tropical montane forests. Soil Biol. Biochem. 94, 37-47

Campbell, C.D., and R.F. Sage, 2002. Interactions between atmospheric $\mathrm{CO}_{2}$ concentration and phosphorus nutrition on the formation of proteoid roots in white lupin (Lupinusalbus L.). Plant, Cell and Environment 25: 1051-1059.

Campbell, B.M., S.J. Vermeulen, P.K. Aggarwal, C. Corner-Dolloff, E. Girvetz, A.M. Loboguerrero, J. Ramirez-Villegas, T. Rosenstock, L. Sebastian, and P.K. Thornton, 2016. Reducing risks to food security from climate change. Glob. Food Sec., 11, 34-43.

Cao, L., G. Bala, K. Caldeira, R. Nemani, and G. Ban-Weiss, 2010. Importance of carbon dioxide physiological forcing to future climate change, Proc. Natl. Acad. Sci., 107, 9513-9518

Carrillo, Y., F.A. Dijkstra, E. Pendall, D. LeCain, and C. Tucker, 2014. Plant rhizosphere influence on microbial $\mathrm{C}$ metabolism the role of elevated $\mathrm{CO} 2, \mathrm{~N}$ availability and root stoichiometry. Biogeochemistry, 117: 229-240.

Carvalho, S.M.P., and M.W. Vasconcelos, 2013. Producing more with less: Strategies and novel technologies for plant-based food biofortification. Food Res. Int., 54:961-971.

Century, K., T.L. Reuber, and O.J. Ratcliffe, 2008. Regulating the regulators: The future prospects for transcription-factor-based agricultural biotechnology products. Plant Physiol., 147: 20-29

Cernusak, L.A., K. Winter, C. Martinez, E. Correa, J. Aranda, M. Garcia, C. Jaramillo, and B.L. Turner, 2011. Responses of legume versus nonlegume tropical tree seedlings to elevated $\mathrm{CO} 2$ concentration. Plant Physiology, 157:372-385. 
César T.-M., 2017. The Effects of Nitrogen Availability on the Response of Terrestrial Ecosystems to Elevated Carbon Dioxide, $\mathrm{PhD}$, thesis

Chandler, J.W., 2009. Local auxin production: a small contribution to a big field. Bio. Essays, 31: 6070.

Chaparro, J.M., D.V. Badri, J.M. Vivanco, 2014. Rhizosphere microbiome assemblage is affected by plant development. ISME, J. 8, 790-803.

Chapin F.S., K. Autumn, and F. Pugnaire, 1993. Evolution of suites of traits in response to environmental stress. American Naturalist, 142: S78-S92.

Chaturvedi, A.K., R.N. Bahuguna, M. Pal, D. Shah, S. Maurya, and K.S. Jagadish, 2017. Elevated CO2 and heat stress interactions affect grain yield, quality and mineral nutrient composition in rice under field conditions. Field Crop Res., 206:149- 157.

Chaves, M.M., J. Flexas, and C. Pinheiro, 2009. Photosynthesis under drought and salt stress: regulation mechanisms from whole plant to cell. Ann. Bot. 103, 551-560.

Chen, Z., B. Wang, J. Wang, G. Pan, and Z. Xiong, 2016. Contrasting effects of elevated CO 2 and warming on temperature sensitivity of soil organic matter decomposition in a Chinese paddy field. Environ Monit Assess., 188:545.

Chen, W., R.T. Koide, T.S. Adams, J.L. DeForest, L. Cheng, and D.M. Eissenstat, 2016. Root morphology and mycorrhizal symbioses together shape nutrient foraging strategies of temperate trees. Proc. Natl. Acad. Sci. USA. 113: 8741-8746

Cheng, L., F.L. Booker, C. Tu, K.O. Burkey, L. Zhou, H.D. Shew, T.W. Rufty, and S. Hu, 2012. Arbuscular Mycorrhizal Fungi Increase Organic Carbon Decomposition Under Elevated CO2. Science, 337:1084-1087.

Cheng, L., F.L. Booker, C. Tu, K.O. Burkey, L. Zhou, H.D. Shew, T.W. Rufty, and S. Hu, 2012. Arbuscular Mycorrhizal Fungi Increase Organic Carbon Decomposition Under Elevated CO2. Science, 337:1084-1087.

Cheng, W.X., and D.W. Johnson, 1998. Elevated CO2, rhizosphere processes, and soil organic matter decomposition. Plant and Soil, 202: 167-174

Chimonides, S.J., 1995. Irrigation management under water shortage conditions. In Water Resources Management under Drought or Water Shortage Conditions; Tsiourtis, N.X., Ed., Balkema: Rotterdam, The Netherlands, 73-78.

Chiou, T.J., and S.I. Lin, 2011. Signaling network in sensing phosphate availability in plants. Annu. Rev. Plant Biol., 62:185-206

Chneider, M.K., A. Lu“scher, M. Richter, et al., 2004. Ten years of free-air CO2 enrichment altered the mobilization of $\mathrm{N}$ from soil in Lolium perenne L. swards. Global Change Biology, 10: 13771388.

Chrysargyris, A., E. Papakyriakou, S.A. Petropoulos, and N. Tzortzakis, 2019. The combined and single effect of salinity and copper stress on growth and quality of Mentha spicata plants. J. Hazard Mater, 368:584-593.

Collins, M., R. Knutti, J. Arblaster, J.-L. Dufresne, T. Fichefet, P. Friedlingstein, X. Gao, W.J. Gutowski, T. Johns, G. Krinner, M. Shongwe, C. Tebaldi, A.J. Weaver, and M. Wehner, 2013. Long-term climate change: Projections, commitments and irreversibility, In: T. F. Stocker,

Comas, L.H., H.S. Callahan, and P.E. Midford, 2014. Patterns in root traits of woody species hosting arbuscular and ectomycorrhizas: implications for the evolution of belowground strategies. Ecol. E4, 2979-2990

Conroy, J.P., P.J. Milham, and E.W.R. Barlow, 1992. Effect of nitrogen and phosphorus availability on the growth-response of Eucalyptus grandis to high CO2. Plant, Cell and Environment, 15: 843847.

Conroy, J.P., P.J. Milham, M.L. Reed, and E.W. Barlow, 1990. Increases in phosphorus requirements for CO2-enriched pine species. Plant Physiology, 92: 977-982.

Cook, S.A. and M.P. Johnson, 1968. Adaptation to heterogeneous environments. I. Variation in heterophylly in Ranunculus flammula. Evolution, 22: 496-516.

Corwin, D.L., and E. Scudiero, 2016. Field-scale apparent soil electrical conductivity. In S. Logsdon (Ed.), Methods of soil analysis (online) (1) (1-29). Madison, WI: SSSA. 
Corwin, D.L., and K. Yemoto, 2017. Salinity: Electrical conductivity and total dissolved solids. In S. Logsdon (Ed.), Methods of soil analysis (2, (1-16). Madison, WI: Soil Science Society of America.

Corwin, D.L., S.R. Kaffka, J.W. Hopmans, Y. Mori, S.M. Lesch, and J.D. Oster, 2003. Assessment and field-scale mapping of soil quality properties of a saline-sodic soil. Geoderma, 114: 231-259.

Cotrufo MF, PD Angelis, and A. Polle, 2005. Leaf litter production and decomposition in a poplar shortrotation coppice exposed to free air CO2 enrichment (POPFACE). Global Change Biology, 11: 971-982.

Cox, P.M., R.A. Betts, C.D. Jones, S.A. Spall, and I.J. Totterdell, 2000. Acceleration of global warming due to carbon-cycle feedbacks in a coupled climate model, Nature, 408(6809) : 184-187.

Cramer, M.D., M.W. Shane, and H. Lambers, 2005. Physiological changes in white lupin associated with variation in root-zone $\mathrm{CO} 2$ concentration and cluster root P mobilization. Plant, Cell and Environment, 28: 1203-1217.

Crick, J.C. and J.P. Grime, 1987. Morphological plasticity and mineral nutrient capture in two herbaceous species of contrasted ecology. New Phytologist, 107(2): 403-414.

Cross, A.F., and W.H. Schlesinger, 1995. A literature review and evaluation of the Hedley fractionation: applications to the biogeochemical cycle of soil phosphorus in natural ecosystem. Geoderma, 64: 197-214.

$\mathrm{Cu}$, S.T.T., J. Hutson, and K.A. Schuller, 2005. Mixed culture of wheat (Triticum aestivum L.) with white lupin (Lupinus albus L.) improves the growth and phosphorus nutrition of the wheat. Plant and Soil, 272: 143-151

Cure, J.D., T.W. Rufty, and D.W. Israel, 1988. Phosphorus stress effects on growth and seed yield responses of nonnodulated soybean to elevated carbon-dioxide. Agronomy Journal, 80: 897902.

Qin, D., G.-K.P., M. Tignor, S.K. Allen, J. Boschung, ... P.M. Midgley (Eds.), Climate Change 2013 The Physical Science Basis: Contribution of Working Group I to the Fifth Assessment Report of the Intergovernmental Panel on Climate Change (1029- 1136), Cambridge, UK; New York, NY: Cambridge University Press.

Dai, A., 2011. Drought under global warming: A review. Wiley Interdisciplinary Review: Climate Change, 2(1) : 45-65.

Dalal, R.C., and D. Moloney, 2000. Sustainability indicators of soil health and biodiversity. In: Hale P, Petrie A, Moloney D, Sattler P. (eds.), Management for sustainable ecosystems. Centre for Conservation Biology, Brisbane, 101- 108

Dang, Y.P., R.C. Dalal, D. Mayer, M. McDonald, R. Routley, G.D. Schwenke, et al., 2008. High subsoil chloride concentrations reduce soil water extraction and crop yield on Vertisol in Northeastern Australia. Aust. J. Agric. Res., 59:321- 330

Daroub, S.H., F.J. Pierce, and B.G. Ellis, 2000. Phosphorus fractions and fate of phosphorus- 33 in soils under plowing and no-tillage. Soil Society of America Journal 64: 170-176.

Daryanto S, L Wang, and PA Jacinthe, 2017. Meta-analysis of phosphorus loss from no-till soils. J. Environ. Qual., 46:1028-1037.

Das, S., P. Bhattacharyya, and T. Adhya, 2011. Impact of elevated CO 2, flooding, and temperature interaction on heterotrophic nitrogen fixation in tropical rice soils. Biol Fertil Soils, 47:25-30.

Davidson, E.A., and I.A. Janssens, 2006. Temperature sensitivity of soil carbon decomposition and feedbacks to climate change. Nature., 440:165-173.

De Graaff, M.A., K.J. van Groenigen, J. Six, B. Hungate, and C. van Kessel, 2006. Interactions between plant growth and soil nutrient cycling under elevated $\mathrm{CO} 2$ : a meta-analysis. Global Change Biology, 12: 2077-2091

De Oliveira, E.D., H. Bramley, K.H. Siddique, S. Henty, J. Berger, and J.A. Palta, 2013. Can elevated $\mathrm{CO} 2$ combined with high temperature ameliorate the effect of terminal drought in wheat? Funct. Plant Biol., 40:160-171.

Del Castillo, D., B. Acock, V.R. Reddy, and M.C. Acock, 1989. Elongation and branching of roots on soybean plants in a carbon dioxide-enriched aerial environment. Agronomy Journal, 81: 692695. 
DeLucia, E., R. Callaway, E. Thomas, and W. Schlesinger, 1997. Mechanisms of phosphorus acquisition for ponderosa pine seedlings under high $\mathrm{CO} 2$ and temperature. Annals of Botany, 79: 111-120.

Dey, S.K., B. Chakrabarti, R. Prasanna, D. Pratap, S.D. Singh, T.J. Purakayastha, and H. Pathak, 2017. Elevated carbon dioxide level along with phosphorus application and cyanobacterial inoculation enhances nitrogen fixation and uptake in cowpea crop. Arch Agron. Soil Sci., 63:1927-1937

Dhankher, O.P., and C.H. Foyer, 2018. Climate resilient crops for improving global food security and safety. Plant, Cell and Environment, 41: 877-884.

Dhankher, O.P., Y. Li, B.P. Rosen, J. Shi, D. Salt, J.F. Senecoff, N.A. Sashti, and R.B. Meagher, 2002. Engineering tolerance and hyperaccumulation of arsenic in plants by combining arsenate reductase and gamma-glutamyl cysteine synthetase expression. Nature Biotechnology, 20: $1140-1145$.

Dhankher, O.P., and C.H. Foyer, 2018. Climate resilient crops for improving global food security and safety. Plant Cell Environ., 41: 877-884.

Dietterich, L.H., A. Zanobetti, I. Kloog, P. Huybers, A.D.B. Leakey, A.J. Bloom, E. Carlisle, N. Fernando, G. Fitzgerald, T. Hasegawa, N.M. Holbrook, R.L. Nelson, R. Norton, M.J. Ottman, V. Raboy, H. Sakai, K.A. Sartor, J. Schwartz, S. Seneweera, Y. Usui, S. Yoshinaga, and S.S. Myers, 2015. Impacts of elevated atmospheric CO2 on nutrient content of important food crops. Scientific Data, 2:150036.

Dinkelaker, B., V. Ro"mheld, and H. Marschner, 1989. Citric acid exudation and precipitation of calcium citrate in the rhizosphere of white lupin (Lupinus albus L.). Plant, Cell and Environment, 12: 265-292.

D’Odorico, P., A. Bhattachan, K.F. Davis, S. Ravi, and C.W. Runyan, 2013. Global desertification: Drivers and feedbacks. Advances in Water Resources, 51: 326-344.

Döll, P., 2002. Impact of climate change and variability on irrigation requirements: A global perspective. Clim. Chang., 54: 269-293.

Dong, J., N. Gruda, S.K. Lam, X. Li, and Z. Duan, 2018b. Effects of Elevated CO2 on Nutritional Quality of Vegetables: A Review. Front Plant Sci 9.

Dong, J., S. Grylls, J. Hunt, R. Armstrong, E. Delhaize, and C. Tang, 2018c. Elevated CO2 (free-air $\mathrm{CO} 2$ enrichment) increases grain yield of aluminum-resistant but not aluminium sensitive wheat (Triticum aestivum) grown in an acid soil. Ann. Bot.-London 123:461-468.

Dong, J.-1., X. Li, G. Nazim, and D. Z -q, 2018a. Interactive effects of elevated carbon dioxide and nitrogen availability on fruit quality of cucumber (Cucumis sativus L.). J Integr Agric., 17:2438-2446.

Donohue, R.J., M.L. Roderick, T.R. McVicar, and G.D. Farquhar, 2013. Impact of CO2 fertilization on maximum foliage cover across the globe's warm, arid environments, Geophys. Res. Lett., 40, 3031-3035

Dorn L.A., E.H. Pyle, and J. Schmitt, 2000. Plasticity to light cues and resources in Arabidopsis thaliana: testing for adaptive value and costs. Evolution, 54(6): 1982-1994.

Doughty P., 1995. Testing the ecological correlates of phenotypically plastic traits within a phylogenetic framework. Acta Oecologica, 16(4): 519-524.

Drake, B.G., M.A. Gonzlez-Meler, and S.P. Long, 1997. More efficient plants: a consequence of rising atmospheric CO2? Annual Review of Plant Physiology and Plant Molecular Biology, 48: 609639.

Drigo, B., G.A. Kowalchuk, A.V. Johannes, 2008.Climate change goes underground: effects of elevated atmospheric $\mathrm{CO}_{2}$ on microbial community structure and activities in the rhizosphere. Biology and Fertility Soils., 44(5):667-679.

Drigo, B., G.A. Kowalchuk, B.A. Knapp, A. Pijl, H.T.S. Boschker, and J.A. van Veen, 2013. Impacts of 3 years of elevated atmospheric $\mathrm{CO} 2$ on rhizosphere carbon flow and microbial community dynamics. Global Change Biology, 19: 621-636.

Drigo, B., A.S. Pijl, H. Duyts, et al., 2010. Shifting carbon flow from roots into associated microbial communities in response to elevated atmospheric CO2. Proceedings of the National Academy of Sciences of the United States of America, 107: 10938-10942. 
Drigo, B., J.A. van Veen, and G.A. Kowalchuk, 2009. Specific rhizosphere bacterial and fungal groups respond differently to elevated atmospheric CO2. ISME Journal 3: 1204-1217.

Drissner, D., H. Blum, D. Tscherko, and E. Kandeler, 2007. Nine years of enriched CO2 changes the function and structural diversity of soil microorganisms in a grassland. European Journal of Soil Science, 58: 260-269.

Duval, B.D., J.C. Blankinship, P. Dijkstra, and B.A. Hungate, 2012. Retracted article: CO2 effects on plant nutrient concentration depend on plantfunctional group and available nitrogen: a metaanalysis. Plant Ecol., 213:505-521. 8

Dwivedi, S.L., K.H. Siddique, M. Farooq, P.K. Thornton, and R. Ortiz, 2018. Using BiotechnologyLed Approaches to Uplift Cereal and Food Legume Yields in Dryland Environments. Front Plant Sci., 9:1249.

Earth and Planetary Science Letters, 277: 213-222.

Eastburn, D.M., M.M. Degennaro, E.H. Delucia, O. Dermody, and A.J. McElrone, 2010. Elevated atmospheric carbon dioxide and ozone alter soybean diseases at SoyFACE. Glob. Chang. Biol., 16: $320-330$.

Easterling, W.E., P.K. Aggarwal, P. Batima, K.M. Brander, L. Erda, S.M. Howden, A. Kirilenko, J. Morton, J.-F. Soussana, and J. Schmidhuber, 2007. Food, fiber and forest products. Clim. Chang., 273- 313.

Edwards, E.J., S. McCaffery, and J.R. Evans, 2005. Phosphorus status determines biomass response to elevated CO2 in a legume: C4 grass community. Global Change Biology, 11: 1968-1981.

Egamberdiyeva, D., and G. Hoflich, 2003. Influence of growth-promoting bacteria on the growth of wheat in different soils and temperatures. Soil Biology and Biochemistry, 35: 973-978.

Elia, A., and G. Conversa, 2015. A decision support system ( $\mathrm{Ges} C \mathrm{CN})$ for managing fertigation in open field vegetable crops. Part I-methodological approach and description of the software. Front Plant Sci., 6:319.

Elias, D., L. Wang, and P.-A. Jacinthe, 2018. A meta-analysis of pesticide loss in runoff under conventional tillage and no-till management. Environ. Monit. Assess., 190:79.

Elmer, W., and J.C. White, 2018. The Future of Nanotechnology in Plant Pathology. Annual Review of Phytopathology, 56: 111-133.

Elser, J.J., W.F. Fagan, A.J. Kerkhoff, N.G. Senson, and B.J. Enquist, 2010. Biological stiochiometry of plant production: metabolism, scaling and ecological response to global change. New Phytologist, 186: 593-608.

Ershova, A., N. Popova, and O. Berdnikova, 2011. Production of reactive oxygen species and antioxidant enzymes of pea and soybean plants under hypoxia and high $\mathrm{CO} 2$ concentration in medium. Russ J. Plant Physl., 58:982.

European Environment Agency (EEA)., 2009. Water Resources across Europe Confronting Water Scarcity and Drought; Report No. 2/2009; EEA: Copenhagen, Danmark.

Facelli, E., S.E. Smith, J.M. Gacelli, H.M. Chrisophersen, and F.A. Smith, 2010. Understanding friends or enemies: model plant help to unravel direct and indirect effects of arbuscular mycorrhizal fungi on plant competition. New Phytologist, 185: 1050-1061.

Fangmeier, A., L. De Temmerman, L. Mortensen, K. Kemp, J. Burke, R. Mitchell, M. van Oijen, and 1.H.J. Weige, 1999. Effects on nutrients and on grain quality in spring wheat crops grown under elevated $\mathrm{CO} 2$ concentrations and stress conditions in the European, multiple-site experiment 'ESPACE-wheat'. European Journal of Agronomy, 10: 215-229.

Fanzo, J., C. Davis, R. McLaren, and J. Choufani, 2018. The effect of climate change across food systems: Implications for nutrition outcomes. Glob. Food Secur., 18:12-19.

FAO, 2017. The future of food and agriculture - Trends and challenges. Roeme. Feng G-Q, Li Y, Cheng Z-M, 2014. Plant Molecular and Genomic Responses to Stresses in Projected Future CO2 Environment. Crit Rev Plant Sci., 33:238-249.

FAO., 2016. Climate change and food security: Risks and responses. Rome, Italy: Food and Agriculture Organization of the United Nations.

FAO; UNICEF; WFP; WHO. The State of Food Security and Nutrition in the World, 2018. Building Resilience for Peace and Food Security; Food and Agriculture Organization of the United Nations (FAO): Rome, Italy,

FAOSTAT., 2017. Available online: http://www.fao.org/faostat/en/\#data (accessed on 2 August 2017). 
FAOSTAT., 2019. Data. http://www.fao.org/faostat/en/\#data. Accessed 24 February, 2019.

Fauchereau, N., M. Trzaska, M. Rouault, et al., 2003. Rainfall variability and changes in Southern Africa during the 20th century in the global warming context. Natural Hazards., 29(2):139-154.

Feng, G.Q., Y. Li, and Z.M. Cheng, 2014. Plant molecular and genomic responses to stresses in projected future CO2 environment. Critical Reviews in Plant Sciences, 33: 238-249.

Fernando, N., J. Panozzo, M. Tausz, R. Norton, G. Fitzgerald, and S. Seneweera, 2012a. Rising atmospheric $\mathrm{CO} 2$ concentration affects mineral nutrient and protein concentration of wheat grain. Food Chem., 133:1307-1311.

Fernando, N., J. Panozzo, M. Tausz, R.M. Norton, G.J. Fitzgerald, S. Myers, C. Walker, J. Stangoulis, and S. Seneweera, 2012b. Wheat grain quality under increasing atmospheric CO2 concentrations in a semi-arid cropping system. J. Cereal Sci., 56: 684-690.

Fernando, N., J. Panozzo, M. Tausz, R.M. Norton, G.J. Fitzgerald, S. Myers, M.E. Nicolas, and S. Seneweera, 2014. Intra-specific variation of wheat grain quality in response to elevated [CO2] at two sowing times under rain-fed and irrigation treatments. J. Cereal Sci., 59:137-144.

Fernando, N., J. Panozzo, M. Tausz, R.M. Norton, G.J. Fitzgerald, S. Myers, C. Walker, J. Stangoulis, and S. Seneweera, 2012b. Wheat grain quality under increasing atmospheric CO2 concentrations in a semi-arid cropping system. J. Cereal Sci., 56: 684-690.

Fischer, S., T. Hilger, H.-P. Piepho, I. Jordan, and G. Cadisch, 2019. Do we need more drought for better nutrition? The effect of precipitation on nutrient concentration in East African food crops. Sci. Total Environ., 658:405-415.

Florez-Sarasa, I., A.R. Fernie, and K.J. Gupta, 2020. Does the alternative respiratory pathway offer protection against the adverse effects resulting from climate change? Journal of Experimental Botany, 71: 465-469.

Flowers, T.J., and T.D. Colmer, 2008. Salinity tolerance in halophytes. New Phytologist, 179: 945-963.

Fo"hse, D., N. Claassen, and A. Jungk, 1988. Phosphorus efficiency of plants. I. external and internal P requirement and P uptake efficiency of different plant species. Plant and Soil, 110: 101-109.

Foyer, C.H., A. Baker, M. Wright, I.A. Sparkes, A. Mhamdi, J.H.M. Schippers, and F.V. Breusegem, 2020. On the move: redox-dependent protein relocation in plants. Journal of Experimental Botany, 71: 620-631.

Franco-Zorrilla, J.M., A.C. Martı'n, A. Leyva, and J. Paz-Ares, 2005. Interaction between phosphate starvation, sugar, and cytokinin signaling in Arabidopsis and the roles of cytokinin receptors CRE1/AHK4 and AHK3. Plant Physiol., 138:847-857

Friedlingstein, P., et al., 2006. Climate-carbon cycle feedback analysis: Results from the C4MIP model intercomparison, J. Climate, 19: 3337-3353,

Fu, L., Z. Wang, O.P. Dhankher, and B. Xing, 2020. Nanotechnology as a new sustainable approach for controlling crop diseases and increasing agricultural production. Journal of Experimental Botany, 71: 507-519.

Gallardo, C., H. Barbara, C. Célia, A. Carine, G. Fanny, D. Fanchon, M. Laurence, D. Patrick and P. Benjamin, 2019. Anatomical and hormonal description of rootlet primordium development along white lupin cluster root. Physiologia Plantarum 165: 4-16, Scandinavian Plant Physiology Society, ISSN 0031-9317

Gamper, H., M. Peter, J. Jansa, A. Luscher, U.A. Hartwig, and A. Leuchtmann, 2004. Arbuscular mycorrhizal fungi benefit from 7 years of free air $\mathrm{CO} 2$ enrichment in well-fertilized grass and legume monocultures. Global Change Biology, 10: 189-199.

Garcna-Quirs, E., J.D. Alché, B. Karpinska, and C.H. Foyer, 2020. Glutathione redox state plays a key role in flower development and pollen vigour. Journal of Experimental Botany, 71: 730741.

Garrity, D., and J. O'Toole, 1994. Screening rice for drought resistance at the reproductive phase. Field Crops Res., 39: 99-110.

Geist, H., 2005. The causes and progression of desertification. Aldershot, Hants, UK: Ashgate Publishing Limited.

Gentile, R., M. Dodd, M. Lieffering, S.C. Brock, P.W. Theobald, and P.C.D. Newton, 2012. Effects of long-term exposure to enriched $\mathrm{CO} 2$ on the nutrient supplying capacity of a grassland soil. Biology and Fertility of Soils, 48: 375-362. 
Ghalambor C.K. and T.E. Martin, 2002. "Comparative manipulation of predation risk in incubating birds reveals variability in the plasticity of responses," Behavioral Ecology, 13(1): 101- 108.

Gibson, K. et al., 2011. Exploiting leaf starch synthesis as a transient sink to elevate photosynthesis, plant productivity and yields. Plant Sci., 181: 275-281.

Gifford, R.M., D.J. Barrett, and J.L. Lutze, 2000. The effects of elevated [CO2] on the C: N and C:Pmass ratios of plant tissues. Plant and Soil, 224: 1-14.

Gifford, R.M., J. Lutze, and D. Barrett, 1996. Global atmospheric change effects on terrestrial carbon sequestration: exploration with a global C- and N-cyclemodel (CQUESTN). Plant and Soil, 187: 369-387.

Gifford, R.M., 1992. Interaction of carbon dioxide with growth- limiting environmental factors in vegetation productivity: Implications for the global carbon cycle. Advances in Bioclimatology, $1: 25-58$.

Gilroy, S., and D.L. Jones, 2000. Through form to function: root hair development and nutrient uptake. Trends in Plant Science, 5: 56-60.

Gislason, S.R., E.H. Oelkers, E.S. Eiriksdottir, M.I. Kardjilov, G. Gisladottir, B. Sigfusson, and N. Oskarsson, 2009. Direct evidence of the feedback between climate and weathering.

Godfray, H.C.J., J.R. Beddington, I.R. Crute, L. Haddad, D. Lawrence, J.F. Muir, J. Pretty, S. Robinson, S.M. Thomas, and C. Toulmin, 2010. Food Security: The Challenge of Feeding 9 Billion People. Science, 327:812-818.

Gomiero, T., 2016. Soil degradation, land scarcity and food security: Reviewing a complex challenge. Sustainability, 8:281

Gong, M., S.-N. Chen, Y.-Q. Song, and Z.-G. Li, 1997. Effect of calcium and calmodulin on intrinsic heat tolerance in relation to antioxidant systems in maize seedlings. Funct. Plant Biol., 24: 371379.

Gotthard, K. and S. Nylin, 1995. Adaptive plasticity and plasticity as an adaptation: a selective review of plasticity in animal morphology and life history. Oikos, 74(1): 3-17.

Goudriaan, J., and H.E. Deruiter, 1983. Plant-growth response to CO2 enrichment at two levels of nitrogen and phosphorus supply. 1. Dry-matter, leaf-area and development. Netherlands Journal of Agricultural Science, 31: 157-169.

Goufo, P., J. Pereira, J. Moutinho-Pereira, et al., 2014. Rice (Oryza sativa L.) phenolic compounds under elevated carbon dioxide (CO2) concentration. Environmental and Experimental Botany, 99: 28-37.

Gratani, L., 1996. Leaf and shoot growth dynamics of Quercus ilex L. Acta Oecologica, 17(1): 17-27.

Gratani, L., F. Covone, and W. Larcher, 2006. Leaf plasticity in response to light of three evergreen species of the Mediterranean maquis," Trees - Structure and Function, 20(5): 549-558.

Gratani, L., M. Meneghini, P. Pesoli, and M.F. Crescente, 2003. Structural and functional plasticity of Quercus ilex seedlings of different provenances in Italy. Trees-Structure and Function, 17(6): 515-521.

Gratani, L., P. Pesoli, M.F. Crescente, K. Aichner, and W. Larcher, 2000. Photosynthesis as a temperature indicator in Quercus ilex L. Global and Planetary Change, 24(2): 153-163.

Gratani L. and M.F. Crescente, 1997. Phenology and leaf adaptive strategies of Mediterranean maquis plants," Ecologia Mediterranea, 23: 11-19.

Gray, S.B., and S.M. Brady, 2016. Plant developmental responses to climate change. Dev. Biol., 419:64-77.

Griffin, J.J., T.G. Ranney, and D.M. Pharr, 2004. Heat and drought influence photosynthesis, water relations, and soluble carbohydrates of two ecotypes of redbud (Cercis canadensis). J. Am. Soc. Hortic. Sci., 129: 497-502.

Grover, M., M. Maheswari, S. Desai, K.A. Gopinath, and B. Venkateswarlu, 2015. Elevated CO2: Plant associated microorganisms and carbon sequestration. Appl. Soil Ecol., 95:73-85.

Grusak, M.A., 2001. Plant Macro- and Micronutrient Minerals. eLS In: Encyclopedia of Life Sciences. Nature Publishing Group, London. Guo J, Zhang M-q, Wang X-w, W-j Z, 2015. A possible mechanism of mineral responses to elevated atmospheric $\mathrm{CO} 2$ in rice grains. J. Integr. Agric., 14:50-57.

Guo, J., M.-Q. Zhang, X.-W. Wang, and Z. W-j, 2015. A possible mechanism of mineral responses to elevated atmospheric CO2 in rice grains. J. Integr. Agric., 14:50-57. 
Guo, J., W.J. Zhang, M.Q. Zhang, L. Zhang, and X.M. Bian, 2012. Will elevated CO2 enhance mineral bioavailability in wetland ecosystems? Evidence from a rice ecosystem. Plant and Soil, 355: 251-263

Ha, K.V., P. Marshener, and E.K. Bnemann, 2008. Dynamics of C, N, P and microbial community composition in particulate soil organic matter during residue decomposition. Plant and Soil, 303: 253-264.

Haake, V. et al., 2002. Transcription factor CBF4 is a regulator of drought adaptation in Arabidopsis. Plant Physiol. 130, 639-648

Haase, S., G. Neumann, A. Kania, Y. Kuzyakov, V. Römheld, and E. Kandeler, 2007. Elevation of atmospheric $\mathrm{CO} 2$ and Nnutritional status modify nodulation, nodule-carbon supply, and root exudation of Phaseolus vulgaris L. Soil Biol. Biochem., 39:2208-2221.

Haase, S., A. Rothe, A. Kania, et al., 2008. Responses to iron limitation in Hordeum vulgare L. as affected by the atmospheric CO2 concentration. Journal of Environmental Quality, 37: 1541262.

Hajiboland, R., 2012. Effect of Micronutrient Deficiencies on Plants Stress Responses. In: Ahmad P, Prasad MNV (eds) Abiotic Stress Responses in Plants: Metabolism, Productivity and Sustainability. Springer New York, New York,

Hakansson, I., and J. Lipiec, 2000. A review of the usefulness of relative bulk density values in studies of soil structure and compaction. Soil Till. Res., 53:71-85

Haling, R.E., L.K. Brown, A.G. Bengough, et al., 2013. Root hairs improve root penetration, root-soil contact, and phosphorus acquisition in soils of different strength. Journal of Experimental Botany, 64: 3711-3721.

Hammond, J.P., M.R. Broadley, P.J. White, et al., 2009. Shoot yield drives phosphorus use efficiency in Brassica oleraceaand correlates with root architecture traits. Journal of Experimental Botany, 60: 1953-1968.

Haque, E., H. Taniguchi, M.M. Hassan, P. Bhowmik, M.R. Karim, M. Śmiech, K. Zhao, M. Rahman, and T. Islam, 2018. Application of CRISPR/Cas9 Genome Editing Technology for the Improvement of Crops Cultivated in Tropical Climates: Recent Progress, Prospects, and Challenges. Front Plant Sci., 9:617.

Hartley, S., C.G. Jones, G.C. Couper, and T.H. Jones, 2000. Biosynthesis of plant phenolic compounds in elevated atmospheric CO2. Global Change Biology, 6: 497-506.

Hartley, T.N., A.S. Thomas, and F.J. Maathuis, 2020. A role for the OsHKT 2;1 sodium transporter in potassium use efficiency in rice. Journal of Experimental Botany, 71: 699-706.

Hashiguchi, A., N. Ahsan, S. Komatsu, 2010. Proteomics application of crops in the context of climatic changes. Food Res. Int., 43:1803 - 1813.

Hatfield, J.L., and C.L. Walthall, 2014. Climate Change: Cropping System Changes and Adaptations. In: Van Alfen NK (ed) Encyclopedia of Agriculture and Food Systems. Academic Press, Oxford He J, Wang J, He D, Dong J, Wang Y, 2011. The design and implementation of an integrated optimal fertilization decision support system. Math Comput Model, 54:1167-1174.

Haugen, T.O. and L.A. Vollestad, 2000. "Population differences in early life-history traits in grayling," Journal of Evolutionary Biology, 13(6): 897-905.

Hawkes, C., E. Achadi, A. Ahuja, M. Ag Bendech, K. Bhatia, Z. Bhutta, M. Blossner, E. Borghi, and K. Eriksen, 2015. Global Nutrition Report 2015: Actions and accountability to advance nutrition and sustainable development. Intl Food Policy Res Inst.

Heger, M., G. Zens, M. Bangalor, 2018. Does the environment matter for poverty reduction? The role of soil fertility and vegetation vigor in poverty reduction. Washington, DC: The World Bank.

Hellin, J., M.R. Bellon, and S.J. Hearne, 2014. Maize landraces and adaptation to climate change in Mexico. J. Crop Improv., 28: 484-501.

Hinsinger, P., C. Plassard, C. Tang, and B. Jaillard, 2003. Origins of root-mediated pH changes in the rhizosphere and their responses to environmental constraints: a review. Plant and Soil, 248: 4359.

Hinsinger, P., 2001. Bioavailability of soil inorganic P in the rhizosphere as affected by root-induced chemical changes: a review. Plant and Soil, 237:173-195.

Hodge, A., and P. Millard, 1998. Effect of elevated CO2 on carbon partitioning and exudate release from Plant ago lanceolata seedlings. Physiologia Plantarum, 103: 280-286. 
Hodge, A., 2004. The plastic plant: root responses to heterogeneous supplies of nutrients. New Phytologist, 162: 9-24.

Hoffland, E., C.R Findenegg, and J.A. Nelemans, 1989. Solubilization of rock phosphate by rape. 2. Local root exudation of organic-acids as a response to Pstarvation. Plant and Soil, 113: 161165.

Hoffland, E., R. Van Den Boogaard, J. Nelemans, and G. Findenegg, 1992. Biosynthesis and root exudation of citric and malic acids in phosphate starved rape plants. New Phytologist, 122: $675-680$.

Han, N.H, H.X. Hao, S.K. Lam, H. Wang, Y. Li, T.J. Wheeler and H.E. Lin, 2015. Yield and nitrogen accumulation and partitioning in winter wheat under elevated $\mathrm{CO} 2$ : A 3-year free-air $\mathrm{CO} 2$ enrichment experiment. Agric. Ecosyst. Environ., 209:132- 137

Högy, P., M. Brunnbauer, P. Koehler, K. Schwadorf, J. Breuer, J. Franzaring, D. Zhunusbayeva, and A. Fangmeier, 2013. Grain quality characteristics of spring wheat (Triticum aestivum) as affected by free-air $\mathrm{CO} 2$ enrichment. Environ. Exp. Bot., 88: 11-18.

Högy, P., and A. Fangmeier, 2008. Effects of elevated atmospheric CO2 on grain quality of wheat. J. Cereal Sci., 48:580-591.

Högy, P., H. Wieser, P. Köhler, K. Schwadorf, J. Breuer, J. Franzaring, R. Muntifering, and A. Fangmeier, 2009. Effects of elevated $\mathrm{CO} 2$ on grain yield and quality of wheat: results from a 3-year free air CO2 enrichment experiment. Plant Biol., 11:60-69.

Holford, I.C.R., 1997. Soil phosphorus: its measurement and its uptake by plants. Aust J Soil Res., 35:227-239.

Holz, M., M. Zarebanadkouki, Y. Kuzyakov, J. Pausch, and A. Carminati, 2018. Root hairs increase rhizosphere extension and carbon input to soil. Ann. Bot., 121: 61-69

Holzapfel, E.A., A. Pannunzio, I. Lorite, A.S. Silva de Oliveira, and I. Farkas, 2009. Design and management of irrigation systems. Review. Chil. J. Agric. Res., 69: 17-25.

Hooker, J.E., and D. Atkinson, 1996. Arbuscular mycorrhizal fungiinduced alteration to tree-root architecture and longevity. Z. Pflanz. Bodenkunde, 159: 229-234

Hu, H., C. Tang, and Z. Rengel, 2005a. Role of phenolics and organic acids in phosphorus mobilization in calcareous and acidic soils. Journal of Plant Nutrition 28: 1427-1439.

Hu, S., F.S. Chapin, M.K. Firestone, et al., 2001. Nitrogen limitation of microbial decomposition in a grassland under elevated CO2. Nature., 409:188- 191.

Hu, Y., Z. Burucs, S. von Tucher, and U. Schmidhalter, 2007. Short-term effects of drought and salinity on mineral nutrient distribution along growing leaves of maize seedlings. Environ. Exp. Bot., 60:268-275.

Hu, X. et al., 2010. Genome-wide analysis of cyclins in maize (Zea mays). Genet. Mol. Res. 9, 14901503.

Hu, H., C. Tang, and Z. Rengel, 2005b. Influence of phenolic acids on phosphorus mobilization in acidic and calcareous soils. Plant and Soil, 268: 173-180.

Hulme, P.E., 2008. Phenotypic plasticity and plant invasions: is it all Jack. Functional Ecology, 22(1): $3-7$.

Hummel, M., B.F. Hallahan, G. Brychkova, J. Ramirez-Villegas, V. Guwela, B. Chataika, E. Curley, P.C. McKeown, L. Morrison, E.F. Talsma, S. Beebe, A. Jarvis, R. Chirwa, and C. Spillane, 2018. Reduction in nutritional quality and growing area suitability of common bean under climate change induced drought stress in Africa. Sci. Rep., 8:16187.

Hungate, B.A., J.S. Dukes, M.R. Shaw, Y.Q. Luo, and C.B. Field, 2003. Nitrogen and climate change. Science, 302: 1512-1513.

Hussain, H.A., S. Men, S. Hussain, et al., 2019. Interactive effects of drought and heat stresses on morpho-physiological attributes, yield, nutrient uptake and oxidative status in maize hybrids. Scientific Reports, 9: 3890.

Idso, S.B., and B.A. Kimball, 1991. Effects of two and half years of atmospheric $\mathrm{CO}_{2}$ enrichment on the root density distribution of 3-year-old sour orange trees. Agricultural and Forest Meteorology, 55: 345-349.

Idso, S.B., and B.A. Kimball, 1992. Seasonal fine-root biomass development of sour orange trees grown in atmospheres of ambient and elevated CO2 concentration. Plant Cell and Environment, 15: $337-341$. 
Impa, S.M., V.S.J. Sunoj, I. Krassovskaya, R. Bheemanahalli, T. Obata, and S.V.K. Jagadish, 2019. Carbon balance and source-sink metabolic changes in winter wheat exposed to high night-time temperature. Plant, Cell and Environment, 4: 1233-1246.

Intergovernmental Panel on Climate Change (IPCC). 2007. Climate Change: Impacts, Adaptation, and Vulnerability; Contribution of Working Group II to the Fourth Assessment Report of the Intergovernmental Panel on Climate Change; Cambridge University Press: Cambridge, UK,

Intergovernmental Panel on Climate Change (IPCC). 2000. Special Report on Emissions Scenarios; A Special Report of Working Group III of the Intergovernmental Panel on Climate Change; Cambridge University Press: Cambridge, UK,

Intergovernmental Panel on Climate Change., 2018. Summary for policymakers. In: Masson-Delmotte $\mathrm{V}$, Zhai P, Prtner H-O, et al., eds. Global warming of $1.5^{\circ} \mathrm{C}$. An IPCC special report on the impacts of global warming of $1.5^{\circ} \mathrm{C}$ above pre-industrial levels and related global greenhouse gas emission pathways, in the context of strengthening the global response to the threat of climate change, sustainable development, and efforts to eradicate poverty. Geneva, Switzerland: World Meteorological Organization, 32.

IPCC, 2014. Climate Change 2014: Synthesis Report. Contribution of Working Groups I, II and III to the Fifth Assessment Report of the Intergovernmental Panel on Climate Change. IPCC, 2018. IPCC, 2018: Summary for Policymakers. In: Global warming of $1.5^{\circ} \mathrm{C}$. An IPCC Special Report on the impacts of global warming of $1.5^{\circ} \mathrm{C}$ above pre-industrial levels and related global greenhouse gas emission pathways, in the context of strengthening the global response to the threat of climate change, sustainable development, and efforts to eradicate poverty.

Israel, D.W., T.W. Rufty, and J.D. Cure, 1990. Nitrogen and phosphorus nutrition interactions in a $\mathrm{CO}_{2}$ enriched environment. Journal of Plant Nutrition, 13: 1419-1433.

Ito, R., H.L. Vasconcelos, and K.J. Feeley, 2018. Global climate change increases risk of crop yield losses and food insecurity in the tropical Andes. Glob. Chang. Biol., 24: e592-e602.

Iyamuremye, F., R.P. Dick, and J. Baham, 1996. Organic amendments and phosphorus dynamics.1. Phosphorus chemistry and sorption. Soil Science, 167: 426-435.

Jablonski, L.M., X. Wang, and P.S. Curtis, 2002. Plant reproduction under elevated $\mathrm{CO}_{2}$ conditions: a meta-analysis of reports on 79 crop and wild species. New Phytol., 156: 9-26.

Jain, A., M.D. Poling, A.S. Karthikeyan, J.J. Blakeslee, W.A. Peer, B. Tiapiwatanakun, A.S. Murphy, and K.G. Raghothama, 2007. Differential effects of sucrose and auxin on localized phosphate deficiency-induced modulation of different traits of root system architecture in Arabidopsis. Plant Physiology, 144: 232-247.

Jakobsen, I., S.E. Smith, F.A. Smith, S.J. Watts-Williams, S.S. Clausen, and M. Grønlund, 2016. Plant growth responses to elevated atmospheric $\mathrm{CO}_{2}$ are increased by phosphorus sufficiency but not by arbuscular mycorrhizas. J. Exp. Bot., 67:6173-6186.

Jakobsen, I., B.Chen, L. Munkvold, T. Lundsgaard, and Y.-G. Zhu, 2005. Contrasting phosphate acquisition of mycorrhizal fungi with that of root hairs using the root hairless barley mutant. Plant Cell Environ., 28: 928-938.

Janni, M., G. Mariolina, E. Maestri, M. Marmiroli, B. Valliyodan, T. Nguyen Henry, and N. Marmiroli, 2020. Molecular and genetic bases of heat stress response in crop plants for increased resilience and productivity. Journal of Experimental Botany, 71.

Jarvis, N.J., 2007. A review of non-equilibrium water flow and solute transport in soil macropores: principles, controlling factors and consequences for water quality. Eur. J Soil Sci., 58:523-546

Jarvis, A., J. Ramirez, B. Anderson, C. Leibing, and P. Aggarwal, 2010. Scenarios of climate change within the context of agriculture. In M. P. Reynolds (Ed.), Climate change and crop production (9-37). Chippenham, UK: CPI Antony Rowe.

Jeong, J.S. et al., 2010. Root-specific expression of OsNAC10 improves drought tolerance and grain yield in rice under field drought conditions. Plant Physiol., 153: 185-197

Jhazmat, D.G.T., F.G. Sui, N. Sa, N.B. Sun, X. Ha, and C.L. Tong, 2010. Differential responses of yield and selected nutritional compositions to drought stress in summer maize grains, J. Plant Nutr., 33:1811-1818.

Jiang, Z., F. Lian, Z. Wang, and B. Xing, 2020. The role of biochars in sustainable crop production and soil resiliency. Journal of Experimental Botany, 71: 520-542. 
Jin, C.W., S.T. Du, W.W. Chen, G.X. Li, Y.S. Zhang, and S.J. Zheng, 2009. Elevated Carbon Dioxide Improves Plant Iron Nutrition through Enhancing the Iron-Deficiency-Induced Responses under Iron-Limited Conditions in Tomato. Plant Physiol, 150: 272-280.

Jin, J., R. Armstrong, and C. Tang, 2019. Impact of elevated $\mathrm{CO}_{2}$ on grain nutrient concentration varies with crops and soils - A long-term FACE study. Sci Total Environ., 651:2641-2647.

Jin, J., D. Lauricella, R. Armstrong, P. Sale, and C. Tang, 2014. Phosphorus application and elevated $\mathrm{CO}_{2}$ enhance drought tolerance in field pea grown in a phosphorus-deficient vertisol. Ann BotLondon, 116:975-985

Jin, J., C. Tang, R. Armstrong, C. Butterly, and P. Sale, 2013. Elevated $\mathrm{CO}_{2}$ temporally enhances phosphorus immobilization in the rhizosphere of wheat and chickpea. Plant and Soil, 368:315328.

Jin, J., C. Tang, R. Armstrong, and P. Sale, 2012. Phosphorus supply enhances the response of legumes to elevated $\mathrm{CO}_{2}$ (FACE) in a phosphorus-deficient Vertisol. Plant and Soil, 358: 91-104.

Jin, J., C. Tang, A. Robertson, A.E. Franks, R. Armstrong, and P. Sale, 2014. Increased microbial activity contributes to phosphorus immobilization in the rhizosphere of wheat under elevated $\mathrm{CO}_{2}$. Soil Biology and Biochemistry, 75: 292-299.

Jin, J., C. Tang, and P. Sale, 2015. The impact of elevated carbon dioxide on the phosphorus nutrition of plants: a review. Ann BotLondon, 116:987-999.

Joel, G., F.S. Chapin, N.R. Chiariello, S.S. Thayer, and C.B. Field, 2001. Species-specific responses of plant communities to altered carbon and nutrient availability. Global Change Biology, 7: 435450.

Johansson, E.M., P.M.A. Fransson, R.D. Finlay, and P.A.W. van Hees, 2009. Quantitative analysis of soluble exudates produced by ectomycorrhizal roots as a response to ambient and elevated $\mathrm{CO}_{2}$. Soil Biology and Biochemistry, 41: 1111-1116.

Johnson, D.W., P.H. Henderson, J.T. Ball, and R.F. Walker, 1996. Effects of $\mathrm{CO}_{2}$ and $\mathrm{N}$ on growth and $\mathrm{N}$ dynamics in ponderosa pine: Results from the first two growing seasons. In: GW Koch, HA Mooney, eds. Carbon dioxide and terrestrial ecosystems. San Diego, CA: Academic Press, 2340.

Jones, D.L., C. Nguyen, and R.D. Finlay, 2009. Carbon flow in the rhizosphere: carbon trading at the soil-root interface. Plant and Soil, 321: 5-33.

Jones, D.L., 1998. Organic acids in the rhizosphere-a critical review. Plant and Soil 205: 25-44.

Joshi, R., K.K. Sahoo, A.K. Singh, K. Anwar, R.K. Gautam, S.K. Sopory, A. Pareek, and S.L. SinglaPareek, 2020. Engineering trehalose biosynthesis pathway improves yield potential in rice under drought, saline and sodic conditions. Journal of Experimental Botany, 71: 653-668.

Jung, M., et al., 2011. Global patterns of land-atmosphere fluxes of carbon dioxide, latent heat, and sensible heat derived from eddy covariance, satellite, and meteorological observations, J. Geophys. Res., 116.

Jungk, A., 2001. Root hairs and the acquisition of plant nutrients from soil. J. Plant Nutr. Soil Sci. 164: 121-129

Juroszek, P., and A. von Tiedemann, 2011. Potential strategies and future requirements for plant disease management under a changing climate. Plant Pathology, 60: 100-112.

Kafle, A., R.C. Kevin, R. Rachel, K.Y. Jaya, S. Senthil, B. Heike and G. Kevin, 2019. Harnessing Soil Microbes to Improve Plant Phosphate Efficiency in Cropping Systems, Journal of Agronomy, 9: 127.

Kaler, A.S., J.D. Ray, W.T. Schapaugh, A.R. Asebedo, C.A. King, E.E. Gbur, and L.C. Purcell, 2018. Association mapping identifies loci for canopy temperature under drought in diverse soybean genotypes. Euphytica, 214: 135.

Kanani H, B Dutta, and M.I. Klapa, 2010. Individual vs. combinatorial effect of elevated, CO 2 conditions and salinity stress on Arabidopsis thaliana liquid cultures: comparing the early molecuelar response using time-series transcriptomic and metabolomic analyses. BMC Syst. Biol., 4:177

Kanda, H., Y. Kasukabe, H. Fujita, T. Washino, and S. Tchibana, 1994. Effect of low root temperature on ribonucleic-acid concentrations in fig leaf gourd and cucumber roots differing in tolerance to chilling temperature. Journal of the Japanese Society for Horticultural Science, 63: 611-618. 
Kang, Y., S.Khan, and X. Ma, 2009. Climate change impacts on crop yield, crop water productivity and food security-A review. Prog. Nat. Sci., 19:1665-1674.

Kanojia, A., and P.P. Dijkwel, 2018. Abiotic Stress Responses are Governed by Reactive Oxygen Species and Age. Annul. Plant Rev., 1-32.

Kaplan, F., W. Zhao, J.T. Richards, R.M. Wheeler, C.L. Guy, and L.H. Levine, 2012. Transcriptional and metabolic insights into the differential physiological responses of Arabidopsis to optimal and supraoptimal atmospheric $\mathrm{CO}_{2}$. PLoS One, 7: e43583.

Kamburova, V.S., E.V. Nikitina, S.E. Shermatov, Z.T. Buriev, S.P. Kumpatla, C. Emani, and I.Y. Abdurakhmonov, 2017. Genome editing in plants: An overview of tools and applications. Int. J. Agron., 1-15. [CrossRef]

Kim, D., B. Alptekin, and H. Budak, 2018. CRISPR/Cas9 genome editing in wheat. Funct. Integr. Genom. 18: 31-41.

Karaba, A. et al., 2007. Improvement of water use efficiency in rice by expression of HARDY, an Arabidopsis drought and salt tolerance gene. Proc. Natl Acad. Sci. USA 104, 15270-15275

Karkanis, A., G.N. Ntatsi, L. Lepse, J.A. Fernández, I.M. Vågen, B. Rewald, I. Alsiņa, A. Kronberga, A. Balliu, and M. Olle, 2018. Faba bean cultivation-Revealing novel managing practices for more sustainable and competitive European cropping systems. Front Plant Sci., 9:1115.

Karmakar, R., I. Das, D. Dutta, and A. Rakshit, 2016. Potential effects of climate change on soil properties: A review. Sci. Int., 4:51-73

Khurshid, H., S.A. Jan, Z.K. Shinwari, M. Jamal, and S.H. Shah, 2017. An Era of CRISPR/Cas9 ().Mediated Plant Genome Editing. Curr. Issues Mol. Biol., 26: 47-54.

Kashyap, P.L., P. Rai, A.K. Srivastava, and S. Kumar, 2017. Trichoderma for climate resilient agriculture. World Journal of Microbiology and Biotechnology, 33: 155.

Kazemi, S., H.R. Eshghizadeh, and M. Zahedi, 2018. Responses of Four Rice Varieties to Elevated $\mathrm{CO}_{2}$ and Different Salinity Levels. Rice Sci., 25:142-151.

Kebeish, R., et al., 2007. Chloroplastic photorespiratory bypass increases photosynthesis and biomass production in Arabidopsis thaliana. Nat. Biotechnol., 25: 593-599

Keerthisinghe, G., P.J. Hocking, P.R. Ryan, and E. Delhaize, 1998. Effect of phosphorus supply on the formation and function of proteoid roots of white lupin (Lupinus albus L.). Plant, Cell and Environment, 21: 467-478.

Khalvati, M.A., Y. Hu, A. Mozafar, and U. Schmidhalter, 2005. Quantification of water uptake by arbuscular mycorrhizal hyphae and its significance for leaf growth, water relations, and gas exchange of barley subjected to drought stress. Plant Biol., 7: 706-712

Khan, F.N., M. Lukac, G. Turner, and D.L. Godbold, 2008. Elevated atmospheric $\mathrm{CO}_{2}$ changes phosphorus fractions in soils under a short rotation poplar plantation (EuroFACE). Soil Biology and Biochemistry, 40: 1716-1723.

Khan, A., M. Ijaz, J. Muhammad, A. Goheer, G. Akbar, and M. Adnan, 2016. Climate Change Implications for Wheat Crop in Dera Ismail Khan District of Khyber Pakhtunkhwa. Pak. J. Meteorol., 13: 17-27.

Kiers, E.T., M. Duhamel, Y. Beesetty, et al., 2011. Reciprocal rewards stabilize cooperation in the mycorrhizal symbiosis. Science, 333: 880-882.

Kimball, B., K. Kobayashi, and M. Bindi, 2002. Responses of agricultural crops to free-air $\mathrm{CO}_{2}$ enrichment. Elsevier, ADV AGRON Kobayashi T, Nishizawa NK, 2012. Iron Uptake, Translocation, and Regulation in Higher Plants. Annu. Rev. Plant Biol., 63: 131-152.

Kimball, B.A., K. Kobayashi, and M. Bindi, 2002. Responses of agricultural crops to free-air $\mathrm{CO}_{2}$ enrichment. Advances in Agronomy, 77: 293-368.

Kirkby, E.A., 2008. Role of magnesium in carbon partitioning and alleviating photooxidative damage. Physiol Plant, 133:692-704.

Kitano, H., 2002. Systems biology: A brief overview. Science, 295: 1662-1664.

Kjellstrom, E., G. Nikulin, G. Strandberg, O.B. Christensen, D. Jacob, K. Keuler, G. Lenderink, E. Van Meijgaard, and C. Schar, 2018. European climate change at global mean temperature increases of 1.5 and 2 degrees above pre-industrail conditions as simulated by the EURO-CORDEX regional climate models. Earth. Syst. Dyn., 9: 459-478.

Kleunen, M.V. and M. Fischer, 2007. Progress in the detection of costs of phenotypic plasticity in plants. New Phytologist, 176(4): 727-730. 
Köhler, I.H., S.C. Huber, C.J. Bernacchi, and I.R. Baxter, 2018. Increased temperatures may safeguard the nutritional quality of crops under future elevated $\mathrm{CO}_{2}$ concentrations. Plant J., 97:872- 886 .

Körner, C., 2006. Plant $\mathrm{CO}_{2}$ responses: An issue of definition, time and resource supply. The New Phytologist, 172: 393-411.

Krey, T., N. Vassilev, C. Baum, and B.E. Lo"bermann, 2013. Effects of long-term phosphorus application and plant-growth promoting rhizobacteria on maize phosphorus nutrition under field conditions. European Journal of Soil Biology, 55: 124-130.

Krężel, A., and W. Maret, 2016. The biological inorganic chemistry of zinc ions. Arch Biochem Biophys, 611:3-19.

Kromdijk, J., and S.P. Long, 2016. One crop breeding cycle from starvation? How engineering crop photosynthesis for rising $\mathrm{CO}_{2}$ and temperature could be one important route to alleviation. $\mathrm{P}$. Roy. Soc. B-Biol. Sci., 283:20152578.

Kucharik, C.J., 2008. Contribution of planting date trends to increase maize yields in the central United States. Agron. J., 100: 328-336.

Kuiper, D. and P.J.C. Kuiper, 1988. Phenotypic plasticity in a physiological perspective," Acta Oecologica Oecologia Plantarum, 9: 43-59.

Kukal, M.S., and S. Irmak, 2018. Climate-driven crop yield and yield variability and climate change impacts on the U.S. great plains agricultural production. Scientific Reports, 8: 3450.

Kumagai, E., N. Aoki, Y. Masuya, and H. Shimono, 2015. Phenotypic Plasticity Conditions the Response of Soybean Seed Yield to Elevated Atmospheric $\mathrm{CO}_{2}$ Concentration. Plant Physiol., 169:2021-2029.

Kumar, A., A.K. Nayak, B.S. Das, N. Panigrahi, P. Dasgupta, S. Mohanty, U. Kumar, P. Panneerselvam, and H. Pathak, 2019. Effects of water deficit stress on agronomic and physiological responses of rice and greenhouse gas emission from rice soil under elevated atmospheric $\mathrm{CO}_{2}$. Sci. Total Environ., 650: 2032-2050.

Kumar, A., M. Shahbaz, E. Blagodatskaya, Y. Kuzyakov, and J. Pausch, 2018. Maize phenology alters the distribution of enzyme activities in soil: Field estimates. Appl. Soil Ecol. 125: 233-239

Kumari, S., and M. Agrawal, 2014. Growth, yield and quality attributes of a tropical potato variety (Solanum tuberosum L. cv Kufri chandramukhi) under ambient and elevated carbon dioxide and ozone and their interactions. Ecotox Environ Safe 101: 146-156. Lal R, Reicosky D, Hanson J, 2007. Evolution of the plow over 10,000 years and the rationale for no-till farming. Soil Tillage Res., 93:1-12

Kunert, K., and B.J. Vorster, 2020. Search for drought-tolerant soybean: is the slow-wilting phenotype more than just a curiosity? Journal of Experimental Botany, 71:457-460.

Kuzyakov, Y., and X. Xu, 2013. Competition between roots and microorganisms for nitrogen: Mechanisms and ecological relevance. New Phytol., 198: 656-669

Kwabiah, A.B., C.A. Palm, N.C. Stoskopf, and R.P. Voroney, 2003. Response of soil microbial biomass dynamics to quality of plant materials with emphasis on $\mathrm{P}$ availability. Soil Biology and Biochemistry, 35: 207-216.

Lal, R., 1995. Tillage systems in the tropics: management options and sustainability implications. FAO Soils Bull. No. 71. Food and Agriculture Organization of the United Nations, Rome, Italy, 180

Lambers, H., J.A Raven, G.R. Shaver, and S.E. Smith, 2008. Plant nutrient acquisition strategies change with soil age. Trends in Ecology Evolution, 23: 95-103.

Lambers, H., M.W. Shane, M.D. Cramer, S.J. Pearse, and E.J. Veneklaas, 2006. Root structure and functioning for efficient acquisition of phosphorus: matching morphological and physiological traits. Annals of Botany, 98: 693-713.

Lambers, H., and F.P. Teste, 2013. Interactions between arbuscular mycorrhizal and non-mycorrhizal plants: do non-mycorrhizal species at both extremes of nutrient availability play the same game? Plant Cell Environ., 36: 1911-1915

Lambers, H., F.S. Chapin, and T.L. Pons .( 2008a ) Plant physiological ecology, 2nd ed. Springer, New York, New York, USA

Lambers, H., J.C. Clements, and M.N. Nelson, 2013. How a phosphorus-acquisition strategy based on carboxylate exudation powers the success and agronomic potential of lupines (Lupinus, Fabaceae). Am. J. Bot., 100:263-288. 
Lambers, H., P.M. Finnegan, E. Laliberte' , S.J. Pearse, M.H. Ryan, M.W. Shane, and E.J. Veneklaas, 2011. Phosphorus nutrition of proteaceae in severely phosphorus-impoverished soils: are there lessons to be learned for future crops? Plant Physiol., 156: 1058-1066.

Lande, R., 2009. "Adaptation to an extraordinary environment by evolution of phenotypic plasticity and genetic assimilation," Journal of Evolutionary Biology, 22(7): 1435-1446.

Larbi, A., F. Morales, A. Abadía, and J. Abadía, 2010. Changes in iron and organic acid concentrations in xylem sap and apoplastic fluid of iron-deficient Beta vulgaris plants in response to iron resupply. J. Plant Physiol., 167.

Larcher, W., 2003. Physiological Plant Ecology, Springer, Berlin, Germany, 4th edition.

Lavenus, J., T. Goh, I. Roberts, S. Guyomarc'h, M. Lucas, I. De Smet, H. Fukaki, T. Beeckman, M. Bennett, and L. Laplaze, 2013. Lateral root development in Arabidopsis: fifty shades of auxin. Trends Plant Sci., 18: 1360-1385.

Lawson, J.R., K.A. Fryirs, and M.R. Leishman, 2017. Interactive effects of waterlogging and atmospheric $\mathrm{CO}_{2}$ concentration on gas exchange, growth and functional traits of Australian riparian tree seedlings. Ecohydrology, 10:e1803.

Leakey, A.D.B., E.A. Ainsworth, C.J. Bernacchi, A. Rogers, S.P. Long, and D.R. Ort, 2009. Elevated $\mathrm{CO}_{2}$ effects on plant carbon, nitrogen, and water relations:six important lessons from FACE. Journal of Experimental Botany, 60: 2859-2876.

Lee, J.S., 2011. Combined effect of elevated $\mathrm{CO}_{2}$ and temperature on the growth and phenology of two annual C3 and C4 weedy species. Agriculture, Ecosystems and Environment, 140: 484-191.

Lenssen, G.M., W.E. van Duin, P. Jak, and J. Rozema, 1995. The response of Aster tripolium and Puccinellia maritima to atmospheric carbon dioxide enrichment and their interactions with flooding and salinity. Aquat. Bot., 50:181-192.

Lesk, C., P. Rowhani, and N. Ramankutty, 2016. Influence of extreme weather disasters on global crop production. Nature, 529: 84.

Lewis, J.D., J.K. Ward, and D.T. Tissue, 2010. Phosphorus supply drives nonlinear responses of cottonwood (Populus deltoides) to increases in $\mathrm{CO}_{2}$ concentration from glacial to future concentrations. New Phytologist, 187: 438-448.

Li, J., X. Wu, S. Hao, X. Wang, and H. Ling, 2008. Proteomic response to iron deficiency in tomato root. Proteomics, 397.

Li, M., Y. Li, W. Zhang, S. Li, Y. Gao, X. Ai, D. Zhang, B. Liu, and Q. Li, 2018a. Metabolomics analysis reveals that elevated atmospheric $\mathrm{CO}_{2}$ alleviates drought stress in cucumber seedling leaves. Anal Biochem., 559:71-85.

Li, T., Z. Di, X. Han, and X. Yang, 2012. Elevated $\mathrm{CO}_{2}$ improves root growth and cadmium accumulation in the hyperaccumulators Sedum alfredii. Plant and Soil, 354: 325-334.

Li, Y., Z. Yu, J. Jin, Q. Zhang, G. Wang, C. Liu, J. Wu, C. Wang, and X. Liu, 2018b. Impact of Elevated $\mathrm{CO}_{2}$ on Seed Quality of Soybean at the Fresh Edible and Mature Stages. FRONT PLANT SCI 9.

Li, T., G. Lin, X. Zhang, Y. Chen, S. Zhang, and B. Chen, 2014. Relative importance of an arbuscular mycorrhizal fungus (Rhizophagus intraradices) and root hairs in plant drought tolerance. Mycorrhiza, 24: 595-602

Li, Y., Y. Zhenhua, J. Jian, Z. Qiuying, W. Guanghua, L. Changkai, W. Junjiang, W. Cheng and L. Xiaobing, 2018. Impact of Elevated $\mathrm{CO}_{2}$ on Seed Quality of Soybean at the Fresh Edible and Mature Stages, Plant Sci., 9:1413.

Lin, W., F. Zhang, and K. Bai, 2000. Response of plant rhizosphere to atmospheric $\mathrm{CO}_{2}$ enrichment. Chinese Science Bulletin, 45: 97-100.

Lindsay, W.L., 1979. Chemical equilibria in soils. New York: John Wiley and Sons Ajmera, Ishan T., Charlie Hodgman and L. Chungui, 2019. An Integrative Systems Perspective on Plant Phosphate Research, 10: 139.

Lo'pez-Bucio, J., E. Herna'ndez -Abreu, L. Sa'nchez - Caldero'n, A. Pe'rez -Torres, R.A. Rampey, B. Bartel, and L. Herrera-Estrella, 2005. An auxin transport independent pathway is involved in phosphate stress-induced root architectural alterations in Arabidopsis. Identification of BIG as a mediator of auxin in Pericycle cell activation. Plant Physiology, 137: 681-691. 
Lo'pez-Bucio, J., E. Hernandez-Abreu, L. Sanchez-Calderon, M.F. Nieto- Jacobo, J. Simpson, and L. Herrera-Estrella, 2002. Phosphate availability alters architecture and causes changes in hormone sensitivity in the Arabidopsis root system. Plant Physiol., 129: 244-256

Loáiciga, H.A., J.T. Pingel, and E.S. Garcia, 2012. Sea water intrusion by sea-level rise: Scenarios for the 21st century. Ground Water, 50: 37-47.

Lobell, D.B., 2010. Remote sensing of soil degradation: Introduction. Journal of Environmental Quality, 39: 1-4.

Lobell, D.B., S.M. Lesch, D.L. Corwin, M.G. Ulmer, K.A. Anderson, D.J. Potts, M.J. Baltes, 2010. Regionalscale assessment of soil salinity in the Red River Valley using multi-year MODIS EVI and NDVI. Journal of Environmental Quality, 39: 35-41

Lobell, D.B., W. Schlenker, and J. Costa-Roberts, 2011. Climate trends and global crop production since 1980. Science, 333 (6042) : 616-620.

Lobell, D.B., M. Bänziger, C. Magorokosho, and B. Vivek, 2011. Nonlinear heat effects on African maize as evidenced by historical yield trials. Nat. Clim. Chang, 1: 42.

Lobell, D.B., and C.B. Field, 2007. Global scale climate-crop yield relationships and the impacts of recent warming. Environ. Res. Lett., 2: 014002

Lobo, C.B., M.S.J. Tomás, E. Viruel, M.A. Ferrero, and M.E. Lucca, 2018. Development of low-cost formulations of plant growth promoting bacteria to be used as inoculants in beneficial agricultural technologies. Microbiol., Res., 219:12-25.

Lohani, N., M.B. Singh, and P.L. Bhalla, 2020. High temperature susceptibility of sexual reproduction in crop plants. Journal of Experimental Botany, 71: 555-568.

Loladze, I., 2002. Rising atmospheric $\mathrm{CO}_{2}$ and human nutrition: toward globally imbalanced plant stoichiometry. Trends Ecol. Evol., 17:457-461.

Loladze, I., 2014. Hidden shift of the ionome of plants exposed to elevated $\mathrm{CO}_{2}$ depletes minerals at the base of human nutrition. Elife, 3: e02245-e02245.

Loneragan, J.F., and C.J. Asher, 1967. Response of plants to phosphate concentration in solution culture. II. Rate of phosphate absorption and its relation to growth. Soil Science, 103: 311-317.

Long, S.P., E.A. Ainsworth, A. Rogers, and D.R. Ort, 2004. Rising atmospheric carbon dioxide: plants FACE the future. Annu. Rev. Plant Biol., 55:591-628.

Long, S.P., and D.R. Ort, 2010. More than taking the heat: crops and global change. Current Opinion in Plant Biology, 13: 241-248.

Long, S.P., E.A. Ainsworth, A.D.B. Leakey, and P.B. Morgan, 2005. Global food security. Treatment of major food crops with elevated carbon dioxide or ozone under large-scale fully open-air conditions suggests recent models may have overestimated future yields. Philosophical Transactions of the Royal Society of London. Series B, Biological Sciences, 360(1463):20112020.

López-Millán, A., F. Morales, Y. Gogorcena, A. Abadía, and J. Abadía, 2009. Metabolic responses in iron deficient tomato plants. J. Plant Physiol., 166.

López-Millán, A.F., F. Morales, A. Abadía, and J. Abadía, 2000. Effects of iron deficiency on the composition of the leaf apoplastic fluid and xylem sap in sugar beet. Implications for iron and carbon transport. Plant Physiol., 124.

Lovelli, S., M. Perniola, E. Scalcione, A. Troccoli, and L.H. Ziska, 2012. Future climate change in the Mediterranean area: Implications for water use and weed management. IJA, 7: 44-49.

Lu, M., D.-F. Zhang, Y.-S. Shi, Y.-C. Song, T.-Y. Wang, and Y. Li, 2013. Expression of SbSNAC1, a NAC transcription factor from sorghum, confers drought tolerance to transgenic Arabidopsis. Plant Cell Tissue Organ. Cult., 115: 443-455.

Ludewig, F., and U. Sonnewald, 2000. High $\mathrm{CO}_{2}$-mediated down-regulation of photosynthetic gene transcripts is caused by accelerated leaf senescence rather than sugar accumulation. FEBS Lett., 479:19-24.

Luo, X., L. Wang, G. Liu, X. Wang, Z. Wang, and H. Zheng, 2016. Effects of biochar on carbon mineralization of coastal wetland soils in the Yellow River Delta, China. Ecological Engineering, 94: 329-336.

Luo, Y., B. Su, W.S. Currie, et al., 2004. Progressive nitrogen limitation of ecosystem responses to rising atmospheric carbon dioxide. Bioscience, 54: 731-739. 
Lynch, J.P., and K.M. Brown, 2008. Root strategies for phosphorus acquisition. Plant Ecophysiol., $7: 83-116$

Lynch, J.P., 2011. Root phones for enhanced soil exploration and phosphorus acquisition: tools for future crops. Plant Physiology, 156: 1041-1049

Ma, Y., G. Schwenke, L. Sun, D. Li Liu, B. Wang, and B. Yang, 2018. Modeling the impact of crop rotation with legume on nitrous oxide emissions from rain-fed agricultural systems in Australia under alternative future climate scenarios. Sci. Total Environ. 630:1544-1552.

Ma, Z., J. Flynn, G. Libra, and Z. Shi, 2017. Elevated $\mathrm{CO}_{2}$ Accelerates Depletion of Phosphorus by Common Bean (Phaseolus vulgaris) in association with Altered Leaf Biochemical Properties. Pedosphere.

Madan, P., S. Jagadish, P. Craufurd, M. Fitzgerald, T. Lafarge, and T. Wheeler, 2012. Effect of elevated $\mathrm{CO}_{2}$ and high temperature on seed-set and grain quality of rice. J. Exp. Bot., 63: 3843-3852

Maleki, A., A. Naderi, R. Naseri, A. Fathi, S. Bahamin, and R. Maleki, 2013. Physiological performance of soybean cultivars under drought stress. Bull. Environ. Pharmacol. Life Sci., 2: 38-44.

Manderscheid, R., J. Bender, H.J. Ja"ger, and H.J. Weigel, 1995. Effects of season long $\mathrm{CO}_{2}$ enrichment on cereals. II. Nutrient concentrations and grain quality. Agriculture, Ecosystems and Environment, 54: 175-185.

Manners, R., and J. van Etten, 2018. Are agricultural researchers working on the right crops to enable food and nutrition security under future climates? Glob. Environ. Chang, 53:182-194.

Mar, S., H. Nomura, Y. Takahashi, K. Ogata, and M. Yabe, 2018. Impact of erratic rainfall from climate change on pulse production efficiency in lower Myanmar. Sustainability, 10: 402.

Maracchi, G., O. Sirotenko, and M. Bindi, 2005. Impacts of present and future climate variability on agriculture and forestry in the temperate regions: Europe. Clim. Chang., 70: 117-135.

Marschner, H., 2012. Marschner's Mineral Nutrition of Higher Plants. (Ed.): Marschner, P. Academic press. McGrath JM, Lobell DB, 2013. Reduction of transpiration and altered nutrient allocation contribute to nutrient decline of crops grown in elevated $\mathrm{CO}_{2}$ concentrations. Plant Cell Environ., 36:697-705.

Massonneau, A., N. Langlade, S. Leon, J. Smutny, E. Vogt, G. Neumann, and E. Martinoia, 2001. Metabolic changes associated with cluster root development in white lupin (Lupinus albus L.): relationship between organic acid excretion, sucrose metabolism and energy status. Planta, 213: 534-542.

Massoud, F.I., 1981. Salt Affected Soils at a Global Scale and Concepts for Control. Technical Paper. Rome, Italy: FAO Land and Water Development Division, Food and Agriculture Organization of the United Nations.

Matamala, R., and W.H. Schlesinger, 2000. Effects of elevated atmospheric $\mathrm{CO}_{2}$ on fine root production and activity in an intact temperate forest ecosystem. Global Change Biology, 6: 967-979.

Matesanz S., E. Gianoli, and F. Valladares, 2010. Global change and the evolution of phenotypic plasticity in plants. Annals of the New York Academy of Sciences, 1206: 35-55.

Matthews, H.D., M. Eby, T. Ewen, P. Friedlingstein, and B.J. Hawkins, 2007. What determines the magnitude of carbon cycle-climate feedbacks?, Global Biogeochem. Cycles, 21, GB2012.

Mauney, J.R., B.A. Kimball, and P.J. Pinter, et al., 1994. Growth and yield of cotton in response to a free-air carbon-dioxide enrichment (FACE) environment. Agricultural and Forest Meteorology, 70: 49-67.

McLaughlin, M.J., A.M. Alston, and J.K. Martin, 1988. Phosphorus cycling in wheat pasture rotations. III. Organic phosphorus turnover and phosphorus cycling. Australian Journal of Soil Research, 26: 343-353.

Medek, D.E., J. Schwartz, and S.S. Myers, 2017. Estimated Effects of Future Atmospheric $\mathrm{CO}_{2}$ Concentrations on Protein Intake and the Risk of Protein Deficiency by Country and Region. Environ Health Perspect., 125:087002.

Medlyn, B.E., et al., 2015. Using ecosystem experiments to improve vegetation models, Nat. Clim. Chang., 5: 528-534, doi:10.1038/ nclimate2621.

Melandri, G., H. AbdElgawad, D. Riewe, et al., 2020a. Biomarkers for grain yield stability in rice under drought stress. Journal of Experimental Botany, 71: 669-683.

Melandri, G., A. Prashar, S.R. McCouch, et al., 2020b. Association mapping and genetic dissection of drought-induced canopy temperature differences in rice. Journal of Experimental Botany, 71. 
Mi, G.H., F.J. Chen, Q.P. Wu, N.W. Lai, L.X. Yuan, and F.S. Zhang, 2010. Ideotype root architecture for efficient nitrogen acquisition by maize in intensive cropping systems. Science China Life Sciences, 53: 1369-1373

Middendorf, B.J., P.V.V. Prasad, and G.M. Pierzynsk, 2020. Setting research priorities for tackling climate change. Journal of Experimental Botany, 71: 480-489.

Mishra, R., R.K. Joshi, and K. Zhao, 2018. Genome editing in rice: Recent advances, challenges, and future implications. Front Plant Sci., 9.

Mitterbauer, E., M. Enders, J. Bender, M. Erbs, A. Habekuß, B. Kilian, F. Ordon, and H.-J. Weigel, 2017. Growth response of 98 barley (Hordeum vulgare L.) genotypes to elevated $\mathrm{CO}_{2}$ and identification of related quantitative trait loci using genome-wide association studies. Plant Breed, 136:483-497

Moebius, B.N., E.H.M. Van, R.R. Schindelbeck, O.J. Idowu, D.J. Clune, and J.E. Thies, 2007. Evaluation of laboratory measured soil properties as indicators of soil physical quality. Soil Sci., 172:895-912

Moog, P.R., T.A. van der Kooij, W. Bruggemann, J.W. Schiefelbein, and P.J. Kuiper, 1995. Responses to iron deficiency in Arabidopsis thaliana: the Turbo iron reductase does not depend on the formation of root hairs and transfer cells. Planta., 195:505-513

Moorhead, D.L., and A.E. Linkins, 1997. Elevated $\mathrm{CO}_{2}$ alters belowground exoenzyme activities in tussock tundra. Plant and Soil, 189: 321-329.

Moraes, T.F., and W.C. Paxton, 2000. Purification and characterization of phosphoenolpyruvate carboxylase from Brassica napus (rapeseed) suspension cell cultures. European Journal of Biochemistry, 267: 4465-4476.

Mortensen, L.M., 1994. Effects of elevated $\mathrm{CO}_{2}$ concentrations on growth and yield of eight vegetable species in a cool climate. Sci., Hortic., 58:177-185

Mungai, L.M., S. Snapp, J.P. Messina, R. Chikowo, A. Smith, E. Anders, R.B. Richardson, and G. Li, 2016. Smallholder farms and the potential for sustainable intensification. Front Plant Sci., 7: 1720.

Munyanziza, E., H.K. Kehri, and D.J. Bagyaraj, 1997. Agricultural intensification, soil biodiversity and agro-ecosystem function in the tropics: the role of mycorrhiza in crops and trees. Appl. Soil Ecol., 6: 77-85

Murgia, I., P. Arosio, D. Tarantino, and C. Soave, 2012. Biofortification for combating 'hidden hunger' for iron. Trends Plant Sci., 17: 47-55.

Myers, S.S., M.R. Smith, S. Guth, C.D. Golden, B. Vaitla, N.D. Mueller, A.D. Dangour, and P. Huybers, 2017. Climate Change and Global Food Systems: Potential Impacts on Food Security and Undernutrition. Annu Rev Public Health, 38:259-277.

Myers, S.S., K.R. Wessells, I. Kloog, A. Zanobetti, and J. Schwartz, 2015. Effect of increased concentrations of atmospheric carbon dioxide on the global threat of zinc deficiency: a modelling study. Lancet Glob Health, 3:e639-e645

Myers, S.S., A. Zanobetti, I. Kloog, P. Huybers, A.D.B. Leakey, A.J. Bloom, E. Carlisle, H.L.H. Dietterich, G. Fitzgerald, T. Hasegawa, N.M. Holbrook, R.L. Nelson, M.J. Ottman, V. Raboy, Sakai, K.A. Sartor, J. Schwartz, S. Seneweera, M. Tausz, and Y. Usui, 2014. Increasing $\mathrm{CO}_{2}$ threatens human nutrition. Nature, 510:139-142.

Nacry, P., G. Canivenc, B. Muller, A. Azmi, H. Van Onckelen, M. Rossignol, and P. Doumas, 2005. A role for auxin redistribution in the responses of the root system architecture to phosphate starvation in Arabidopsis. Plant Physiology, 138: 2061-2074.

Nadira, U.A., I.M. Ahmed, J. Zeng, N. Bibi, S. Cai, F.B. Wu, and G.P. Zhang, 2014b. The changes in physiological and biochemical traits of Tibetan wild and cultivated barley in response to low phosphorus stress. Soil Sci. Plant Nutr., 60:1-11

Nadira, U.A., I.M. Ahmed, B. Zhu, J. Zeng, S. Cai, F.B. Wu, and G.P. Zhang, 2014a. Difference in response to low phosphorus stress among Tibetan wild barley genotypes. J. Food Agric. Environ., 12:408-414

Nakandalage, N., and S. Seneweera, 2018. Chapter 12 - Micronutrients Use Efficiency of Crop-Plants Under Changing Climate. In: Hossain MA, Kamiya T, Burritt DJ, Phan Tran L-S, Fujiwara T (eds) Plant Micronutrient Use Efficiency. Academic Press Nakashima K, Ito Y, Yamaguchi- 
Shinozaki K, 2009. Transcriptional regulatory networks in response to abiotic stresses in Arabidopsis and grasses. Plant Physiol., 149: 88-95.

Navas, M.-L. and E. Garnier, 2002. Plasticity of whole plant and leaf traits in Rubia peregrina in response to light, nutrient and water availability.Acta Oecologica, 23(6): 375-383.

Nelson, G.C., M.W. Rosegrant, J. Koo, R. Robertson, T. Sulser, T. Zhu, C. Ringler, S. Msangi, A. Palazzo, M. Batka, M. Magalhaes, R. Valmonte-Santos, M. Ewing, and D. Lee, 2009. Climate Change Impact on Agriculture and Costs of Adaptation. International Food Policy Research Institute, Washington, DC.

Neocleous. D., A. Koukounaras, A. Siomos, and M. Vasilakakis, 2014. Assessing the salinity effects on mineral composition and nutritional quality of green and red "baby" lettuce. J. Food Qual. $37: 1-8$.

Neumann, G., and V. Ro"mheld, 1999. Root excretion of carboxylic acids and protons in phosphorusdeficient plants. Plant and Soil, 211: 121-130.

Newbery, R.M., J. Wolfenden, T.A. Mansfield, and A.F. Harrison, 1995. Nitrogen, phosphorus and potassium uptake and demand in Agrostis capillaris: the influence of elevated $\mathrm{CO}_{2}$ and nutrient supply. New Phytologist, 130: 565-574.

Newton, A.C., S.N. Johnson, and P.J. Gregory, 2011. Implications of climate change for diseases, crop yields and food security. Euphytica., 179:3-18.

Nezhadahmadi, A., Z.H. Prodhan, and G. Faruq, 2013. Drought Tolerance in Wheat, Sci. World, J: 112

Nie, M., C. Bell, M.D. Wallenstein, and E. Pendall, 2015. Increased plant productivity and decreased microbial respiratory $\mathrm{C}$ loss by plant growth-promoting rhizobacteria under elevated $\mathrm{CO}_{2}$. Sci. Rep., 5:9212

Nie, M., M. Lu, J. Bell, S. Raut, and E. Pendall, 2013. Altered root traits due to elevated $\mathrm{CO}_{2}$ : a metaanalysis. Global Ecology and Biogeography, 22: 1095-1105.

Niinemets, U. and F. Valladares, 2004. Photosynthetic acclimation to "simultaneous and interacting environmental stresses along natural light gradients: optimality and constraints," Plant Biology, 6(3): 254-268.

Niu, Y., R. Chai, H. Dong, H. Wang, C. Tang, and Y. Zhang, 2012. Effect of elevated $\mathrm{CO}_{2}$ on phosphorus nutrition of phosphatedeficient Arabidopsis thaliana (L.) Heynh under different nitrogen forms. J. Exp. Bot., 64:355-367.

Niu, Y.F., R.S. Chai, H.F. Dong, H. Wang, C.X. Tang, and Y.S. Zhang, 2013a. Effect of elevated $\mathrm{CO}_{2}$ on phosphorus nutrition of phosphate-deficient Arabidopsis thaliana (L.) Heynh under different nitrogen forms. Journal of Experimental Botany, 64: 355-367.

Niu, Y.F., R.S. Chai, G.L. Jin, H. Wang, C.X. Tang, and Y.S. Zhang, 2012. Responses of root architecture development to low phosphorus availability: a review. Ann. Bot., 112: 391-408

Niu, Y.F., C.W. Jin, G.L. Jin, Q.Y. Zhou, X.Y. Lin, C.X. Tang, and Y.S. Zhang, 2011. Auxin modulates the enhanced development of root hairs in Arabidopsis thaliana (L.) Heynh. under elevated $\mathrm{CO}_{2}$. Plant, Cell and Environment, 34: 1304-1317.

Noack, S.R., R.J. Smernick, T.M. McBeath, R.D. Armstrong, and M.J. Mclaughlin, 2014. Assessing crop residue phosphorus speciation using chemical fractionation and solution 31P nuclear magnetic resonance spectroscopy. Talanta, 126: 122-129.

Nongpiur, R.C., S.L. Singla-Pareek, A. Pareek, 2020. The quest for 'osmosensors' in plants. Journal of Experimental Botany, 71: 595-607.

Norby, R.J., M.F. Cotrufo, P. Ineson, E.G. O'Neill, and J.G. Canadell, 2001. Elevated $\mathrm{CO}_{2}$, litter chemistry, and decomposition: a synthesis. Oecologia, 127: 153-165.

Norby, R.J., C.A. Gunderson, S.D. Wullschleger, E.G. O'Neill, and M.K. McCracken, 1992. Productivity and compensatory responses of yellow-poplar trees in elevated $\mathrm{CO}_{2}$. Nature, 357: 322-324.

Norby, R.J., E.G. O’Neill, W.G. Hood, and R.J. Luxmoore, 1987. Carbon allocation, root exudation and mycorrhizal colonization of Pinusechinata seedlings grown under $\mathrm{CO}_{2}$ enrichment. Tree Physiology, 3: 203-210.

Norisada, M., T. Motoshige, K. Kojima, and T. Tange, 2006. Effects of phosphate supply and elevated $\mathrm{CO}_{2}$ on root acid phosphatase activity in Pinus densiflora seedlings. J Plant Nutr Soil Sc., 169:274-279. 
Nowak, R.S., D.S. Ellsworth, and S.D. Smith, 2004. Functional responses of plants to elevated atmospheric $\mathrm{CO}_{2}$-do photosynthetic and productivity data from FACE experiments support early predictions? New Phytologist, 162: 253-280.

Noya, I., S. González-García, J. Bacenetti, M. Fiala, and M.T. Moreira, 2018. Environmental impacts of the cultivation-phase associated with agricultural crops for feed production. J. Clean. Prod., 172: 3721-3733

Nuruzzaman, M., H. Lambers, M.D.A. Bolland, and E.J. Veneklaas, 2006. Distribution of carboxylates and acid phosphatase and depletion of different phosphorus fractions in the rhizosphere of a cereal and three grain legumes. Plant and Soil, 281: 109-120.

Nutan, K.K., R.S. Rathore, A.K. Tripathi, M. Mishra, A. Pareek, and S.L. Singla- Pareek, 2020a. Integrating dynamics of yield traits in rice in response to environmental changes. Journal of Experimental Botany, 71: 490-506.

Nutan, K.K., S.L. Singla-Pareek, and A. Pareek, 2020b. The Saltol QTL-localized transcription factor OsGATA8 plays an important role in stress tolerance and seed development in Arabidopsis and rice. Journal of Experimental Botany, 71: 684-698.

Oberson, A., D.K. Friesen, I.M. Rao, S. Bu“hler, and E. Frossard, 2001. Phosphorus transformations in an Oxisol under contrasting land-use systems: the role of the soil microbial biomass. Plant and Soil, 237: 197-210.

Oh, S.J. et al., 2009. Overexpression of the transcription factor AP37 in rice improves grain yield under drought conditions. Plant Physiol., 150: 1368-1379

Olanrewaju, O.S., B.R. Glick, and O.O. Babalola, 2017. Mechanisms of action of plant growth promoting bacteria. World J. Microbiol. Biotechnol., 33:197.

Olesen, J.E., and M. Bindi, 2002. Consequences of climate change for European agricultural productivity, land use and policy. Eur. J. Agron., 16: 239-262.

Olesen, J.E., M. Trnka, K.C. Kersebaum, A. Skjelvåg, B. Seguin, P. Peltonen-Sainio, F. Rossi, J. Kozyra, and F. Micale, 2011. Impacts and adaptation of European crop production systems to climate change. Eur. J. Agron, 34: 96-112.

Ou, W., X. Mao, C. Huang, W. Tie, Y. Yan, Z. Ding, C. Wu, Z. Xia, W. Wang, and S. Zhou, 2018. Genome-wide identification and expression analysis of the KUP family under abiotic stress in cassava (Manihot esculenta Crantz). Front. Physiol., 9: 17.

O'Mara, F.P., 2012. The role of grasslands in food security and climate change. Ann. Bot., 110:12631270.

Ottman, M.J., B.A. Kimball, P.J. Pinter, et al., 2001. Elevated $\mathrm{CO}_{2}$ increases sorghum biomass under drought conditions. New Phytologist, 150: 261-273.

Otto, I.M., D. Reckien, C.P. Reyer, R. Marcus, V. Le Masson, L. Jones, A. Norton, and O. Serdeczny, 2017. Social vulnerability to climate change: A review of concepts and evidence. Reg. Environ. Chang., 17: 1651-1662.

Pachauri, R.K., M.R. Allen, V.R. Barros, J. Broome, W. Cramer, R. Christ, J.A. Church, L. Clarke, Q. Dahe, and P. Dasgupta, 2014. Climate Change Synthesis Report; Contribution of Working Groups I, II and III to the Fifth Assessment Report of the Intergovernmental Panel on Climate Change; IPCC: Geneva, Switzerland.

Palacios, C.J., A. Grandis, V.J. Carvalho, A. Salatino, and M.S. Buckeridge, 2019. Isolated and combined effects of elevated $\mathrm{CO}_{2}$ and high temperature on the whole-plant biomass and the chemical composition of soybean seeds. Food Chem., 275:610-617.

Pandey, P., Y. Ge, V. Stoerger, and J.C. Schnable, 2017. High throughput in vivo analysis of plant leaf chemical properties using hyperspectral imaging. Front Plant Sci., 8:1348.

Pandey R, Lal MK, Vengavasi K, 2018. Differential response of hexaploid and tetraploid wheat to interactive effects of elevated [ $\left.\mathrm{CO}_{2}\right]$ and low phosphorus. Plant Cell Rep 37(9):1231-1244

Pandey, R., G. Zinta, H. AbdElgawad, A. Ahmad, V. Jain, and I.A. Janssens, 2015. Physiological and molecular alterations in plants exposed to high $\left[\mathrm{CO}_{2}\right]$ under phosphorus stress. Biotechnol. Adv., 33:303 - 316.

Pang, J., M.H. Ryan, H. Lambers, and K.H. Siddique, 2018. Phosphorus acquisition and utilization in crop legumes under global change. Curr Opin Plant Biol 45:248-254. 
Pang, J., M.H. Ryan, and M. Tibbett, et al., 2010. Variation in morphological and physiological parameters in herbaceous perennial legumes in response to phosphorus supply. Plant and Soil, 331: 241-255.

Pang, J., J.-G. Zhu, Z.-B. Xie, G. Liu, Y.-L. Zhang, G.-P. Chen, Q. Zeng, and L. Cheng, 2006. A new explanation of the $\mathrm{N}$ concentration decrease in tissues of rice (Oryza sativa L.) exposed to elevated atmospheric $\mathrm{CO}_{2}$. Environ. Exp. Bot., 57:98-105.

Parajuli, R., G. Thoma, and M.D. Matlock, 2018. Environmental sustainability of fruit and vegetable production supply chains in the face of climate change: A review. Sci Total Environ., 650: 2863-2879.

Parmesan C., 2006. Ecological and evolutionary responses to recent climate change," Annual Review of Ecology, Evolution, and Systematics, 37: 637-669.

Parvin, S., S. Uddin, S. Tausz-Posch, R. Armstrong, G. Fitzgerald, and M. Tausz, 2019. Grain mineral quality of dryland legumes as affected by elevated $\mathrm{CO}_{2}$ and drought: a FACE study on lentil (Lens culinaris) and faba bean (Vicia faba). Crop Pasture Science, 70:244-253.

Pastor, A.V., A. Palazzo, P. Havlik, H. Biemans, Y. Wada, M. Obersteiner, P. Kabat, and F. Ludwig, 2019. The global nexus of food-trade-water sustaining environmental flows by 2050 . Nature Sustainability, 13: 1.

Paterson, E., J.M. Hall, E.A.S. Rattray, B.S. Griffiths, K. Ritz, and K. Killham, 1997. Effect of elevated $\mathrm{CO}_{2}$ on rhizosphere carbon flow and soil microbial processes. Global Change Biology, 3: 363377.

Patterson, L.A., B. Lutz, and M.W. Doyle, 2013. Climate and direct human contributions to changes in mean annual stream flow in the South Atlantic, USA. Water Resources Research, 49: 72787291.

Paulose, B., S. Chhikara, J. Coomey, H.I. Jung, O. Vatamaniuk, and O.P. Dhankher, 2013. A $\gamma$-glutamyl cyclotransferase protects Arabidopsis plants from heavy metal toxicity by recycling glutamate to maintain glutathione homeostasis. The Plant Cell, 25: 4580-4595.

Pe'ret, B., M. Clement, L. Nussaume, and T. Desnos, 2011. Root developmental adaptation to phosphate starvation: better safe than sorry. Trends Plant Sci., 16:442-450

Pe'rez-Torres, C.A., J. Lo'pez-Bucio, A. Cruz-Ramı'rez, et al., 2008. Phosphate availability alters lateral root development in Arabidopsis by modulating auxin sensitivity via a mechanism involving the TIR1 auxin receptor. The Plant Cell, 20: 3258-3272.

Pendall, E., S. Bridgham, P.J. Hanson, et al., 2004.Below-ground process responses to elevated $\mathrm{CO}_{2}$ and temperature: a discussion of observations, measurement methods, and models. New Phytol., 162(2):311-322.

Peng, X., L.L. Ye, C.H. Wang, H. Zhou, and B. Sun, 2011. Temperature- and duration-dependent rice straw-derived biochar: characteristics and its effects on soil properties of an Ultisol in southern China. Soil and Tillage Research, 112: 159-166.

Pérez-Jiménez, M., M. Hernández-Munuera, M.C. Piñero, G. López Ortega, and F.M. Del Amor, 2017a. $\mathrm{CO}_{2}$ effects on the waterlogging response of 'Gisela 5' and 'Gisela 6' (Prunus cerasusx Prunus canescens) sweet cherry (Prunus avium) rootstocks. J Plant Physiol., 213:178-187.

Pérez-Jiménez, M., M. Hernández-Munuera, M.C. Piñero Zapata, G. López-Ortega, and F.M. Del Amor, 2017b. Two minuses can make a plus: waterlogging and elevated $\mathrm{CO}_{2}$ interactions in sweet cherry (Prunus avium) cultivars. Physiol Plant, 161: 257-272.

Pérez-Jiménez, M., M.C. Piñero, and F.M. Del Amor, 2019. Heat shock, high $\mathrm{CO}_{2}$ and nitrogen fertilization effects in pepper plants submitted to elevated temperatures. Sci. Hortic., 244:322329.

Pérez-López, U., J. Miranda-Apodaca, M. Lacuesta, A. Mena-Petite, and A. Muñoz-Rueda, 2015. Growth and nutritional quality improvement in two differently pigmented lettuce cultivars grown under elevated $\mathrm{CO}_{2}$ and/or salinity. Sci Hortic., 195: 56-66.

Petretto, G.L., P.P. Urgeghe, D. Massa, and S. Melito, 2019. Effect of salinity (NaCl) on plant growth, nutrient content, and glucosinolate hydrolysis products trends in rocket genotypes. Plant Physiol Biochem.

Petropoulos, S.A., E. Levizou, G. Ntatsi, Â. Fernandes, K. Petrotos, K. Akoumianakis, L. Barros, and I.C. Ferreira, 2017. Salinity effect on nutritional value, chemical composition and bioactive compounds content of Cichorium spinosum L. Food Chem., 214:129 - 136. 
Philippot, L., J.M. Raaijmakers, P. Lemanceau, and W.H. van der Putten, 2013. Going back to the roots: the microbial ecology of the rhizosphere. Nat. Rev. Microbiol. 11: 789-799

Piao, S., et al., 2013. Evaluation of terrestrial carbon cycle models for their response to climate variability and to $\mathrm{CO}_{2}$ trends, Glob. Chang. Biol., 19: 2117-2132,

Pigliucci, M., C.J. Murren, and C.D. Schlichting, 2006. Phenotypic plasticity and evolution by genetic assimilation. Journal of Experimental Biology, 209(12): 2362-2367.

Pilbeam, D.J., 2015. Breeding crops for improved mineral nutrition under climate change conditions. J. Exp. Bot., 66:3511-3521.

Pitts, R.J., A. Cernac, and M. Estelle, 1998. Auxin and ethylene promote root hair elongation in Arabidopsis. The Plant Journal, 16: 553-560.

Playán, E., and L. Mateos, 2006. Modernization and optimization of irrigation systems to increase water productivity. Agric. Water Manag., 80: 100-116.

Poorter, H., Y. Van Berkel, R. Baxter, J. Den Hertog, P. Dijkstra, R.M. Gifford, K.L. Griffin, C. Roumet, J. Roy, and S.C. Wong, 1997. The effect of elevated $\mathrm{CO}_{2}$ on the chemical composition and construction costs of leaves of 27 C3 species. Plant Cell Environ., 20:472-482.

Poorter, H., 1998. Do slow-growing species and nutrient-stressed plants respond relatively strongly to elevated $\mathrm{CO}_{2}$ ? Global Change Biology, 4: 693-697.

Poorter, H., U. Niinemets, A. Walter, F. Fiorani, and U. Schurr, 2010. A method to construct doseresponse curves for a wide range of environmental factors and plant traits by means of a metanalyses of phenotypic data," Journal of Experimental Botany, 61(8): 2043-2055.

Poorter, H., and M.-L. Navas, 2003. Plant growth and competition at elevated $\mathrm{CO}_{2}$ : On winners, losers and functional groups. The New Phytologist, 157: 175-198.

Porfirio, L.L., D. Newth, J.J. Finnigan, and Y. Cai, 2018. Economic shifts in agricultural production and trade due to climate change. Palgrave Communications, 4:111.

Poursarebani, N., T. Nussbaumer, H. Simkova, J. Safar, H. Witsenboer, J. van Oeveren, J. Dolezel, K.F. Mayer, N. Stein, and T. Schnurbusch, 2014. Whole-genome profiling and shotgun sequencing delivers an anchored, gene-decorated, physical map assembly of bread wheat chromosome 6A. Plant J., 79: 334-347.

Pradhan, G.P., P.V. Prasad, A.K. Fritz, M.B. Kirkham, and B.S. Gill, 2012. Effects of drought and high temperature stress on synthetic hexaploid wheat. Funct. Plant Biol., 39: 190-198.

Pre'vost, D., A. Bertrand, C. Juge, and F.P. Chalifour, 2010. Elevated $\mathrm{CO}_{2}$ induces difference in nodulation of soybean depending on bradyrhizobial strain and method of inoculation. Plant and Soil, 331: 115-127.

Pretty, J., T.G. Benton, Z.P. Bharucha, L.V. Dicks, C.B. Flora, H.C.J. Godfray, D. Goulson, S. Hartley, N. Lampkin, C. Morris, G. Pierzynski, P.V.V. Prasad, J. Reganold, J. Rockström, P. Smith, P. Thorne, and S. Wratten, 2018. Global assessment of agricultural system redesign for sustainable intensification. Nat. Sustain, 1(8):441-446.

Price T.D., A. Qvarnstrom, and D.E. Irwin, 2003. The role of phenotypic plasticity in driving genetic evolution. Proceedings of the Royal Society B: Biological Sciences, 270): 1433- 1440.

Prior, J., I. Connon, E. McIntyre, J. Adams, T. Capon, J. Kent, C. Rissel, L. Thomas, S. Thompson, and H. Westcott, 2018. Built environment interventions for human and planetary health: integrating health in climate change adaption and mitigation. Public Health Res. Pract., 28(4): e2841831

Priya, M., L. Sharma, R. Kaur, H. Bindumadhava, R.M. Nair, K.H.M. Siddique, and H. Nayyar, 2019. GABA ( $\gamma$-aminobutyric acid), as a thermo-protectant, to improve the reproductive function of heat-stressed mungbean plants. Scientific Reports, 9: 7788.

Qadir, M., Th.M. Boers, S. Schubert, A. Ghafoor, and G. Murtaza, 2003. Agricultural water management in water-starved countries: Challenges and opportunities. Agric. Water Manag., 62: $165-185$.

Qafoku, N.P., 2014. Overview of different aspects of climate change effects on soils. Richland, WA: Pacific Northwest National Laboratory. Retrieved from https://www.pnnl.gov/main/

Qiao, Y., S. Miao, Q. Li, J. Jin, X. Luo, and C. Tang, 2019. Elevated $\mathrm{CO}_{2}$ and temperature increase grain oil concentration but their impacts on grain yield differ between soybean and maize grown in a temperate region. Sci. Total Environ., 666:405- 413. 
Radhapriya, P., A. Ramachandran, and P. Palani, 2018. Indigenous plant growth-promoting bacteria enhance plant growth, biomass, and nutrient uptake in degraded forest plants. 3 Biotech, 8: 154.

Rafiq, M.H., R. Ahmad, A. Jabbar, H. Munir, and M. Hussain, 2017. Wheat productivity responses in the rice-based system under different no-till techniques and nitrogen sources. Environ Sci Pollut R 24:21797-21806. Ramzani PMA, Khalid M, Naveed M, Ahmad R, Shahid M, 2016. Iron biofortification of wheat grains through integrated use of organic and chemical fertilizers in $\mathrm{pH}$ affected calcareous soil. Plant Physiol. Biochem. 104:284-293.

Raghothama, K.G., 1999. Phosphate acquisition. Ann Rev Plant Physiol Plant Mol. Biol. 50:665-693.

Rahaman, M.M., M.R. Shourov, and M.N. Akram, 2016. Production of rice versus groundwater depletion in Bangladesh during 1988-2014. In: Proceedings of Conference on water security and climate change: challenges and opportunities in Asia. Asian Institute of Technology, Bangkok, Thailand. Berlin: Springer.

Ramaekers, L., R. Remans, I.M. Rao, M.W.V. Blair and J. Erleyden, 2010. Strategies for improving phosphorus acquisition efficiency of crop plants.Field Crops Research, 117: 169-176.

Randall, P.J., J.E. Hayes, P.J. Hocking, and A.E. Richardson, 2001. Root exudates in phosphorus acquisition by plants. In: N Ae, J Arihara, K Okada, A Srinivasan, eds. Plant nutrient acquisition - new concepts for field professionals. Springer: Tokyo, 71-100.

Rasheed, R., M. Iqbal, M.A. Ashraf, I. Hussain, F. Shafiq, A. Yousaf, and A. Zaheer, 2018. Glycine betaine counteracts the inhibitory effects of waterlogging on growth, photosynthetic pigments, oxidative defence system, nutrient composition, and fruit quality in tomato. J. Hortic.Sci. Biotechnol., 93:385-391.

Ray, D.K., J.S. Gerber, G.K. MacDonald, and P.C. West, 2015. Climate variation explains a third of global crop yield variability. Nat. Commun. 6: 5989.

Reckling, M., T.F. Döring, G. Bergkvist, F. Chmielewski, F. Stoddard, C. Watson, S. Seddig, and J. Bachinger, 2018. Grain legume yield instability has increased over 60 years in long-term field experiments as measured by a scale-adjusted coefficient of variation. Asp. Appl. Biol., 138: $15-20$.

Reef, R., M.C. Ball, I.C. Feller, and C.E. Lovelock, 2010. Relationship between RNA: DNA ratio, growth and elemental stoichiometry in mangrove trees. Functional Ecology, 24: 1064-1072.

Reich, B.R., S.E. Hobbie, T. Lee, et al., 2006. Nitrogen limitation constrains sustainability of ecosystem response to $\mathrm{CO}_{2}$. Nature, 440: 922-925.

Rellán-Álvarez, R., S. Andaluz, J. Rodríguez-Celma, G. Wohlgemuth, G. Zocchi, A. ÁlvarezFernández, O. Fiehn, A.F. López-Millán, and J. Abadía, 2010. Changes in the proteomic and metabolic profiles of Beta vulgaris root tips in response to iron deficiency and resupply. BMC Plant Biol 10:1-15. https://doi. org/10.1186/1471-2229-10-120

Reynolds, W.D., B.T. Bowman, C.F. Drury, C.S. Tan, and X. Lu, 2002. Indicators of good soil physical quality: density and storage parameters. Geoderma., 110:131-146

Rho, H., S.L. Dotty, and S.H. Kim, 2020. Endophytes alleviate the elevated $\mathrm{CO}_{2}$ - dependent decrease in photosynthesis in rice, particularly under nitrogen limitation. Journal of Experimental Botany, 71: 707-718.

Richardson, A.E., P.J. Hocking, R.J. Simpson, and T.S. George, 2009. Plant mechanisms to optimize access to soil phosphorus. Crop and Pasture Science, 60: 124-143.

Richardson, A.E., 2001. Prospects for using soil microorganisms to improve the acquisition of phosphorus by plants. Australian Journal of Plant Physiology, 28: 897-906.

Richardson, A.E., J.P. Lynch, P.R. Ryan, E. Delhaize, F.A. Smith, S.E. Smith, P.R. Harvey, M.H. Ryan, E.J. Veneklass, H. Lambers, A. Oberson, R.A. Culvenor, and R.J. Simpson, 2011. Plant and microbial strategies to improve the phosphorus efficiency of agriculture. Plant Soil, 349: 121156

Richardson, K.J., K.H. Lewis, P.K. Krishnamurthy, C. Kent, Wiltshire, and H.M. Hanlon, 2018. Food security outcomes under a changing clima A.J.te: Impacts of mitigation and adaptaion on vulnerability to food insecurity. Clim. Chang., 147: 327-341.

Robin, A., G. Vansuyt, P. Hinsinger, J.M. Meyer, J.F. Briat, and P. Lemanceau, 2008. Chapter 4 Iron Dynamics in the Rhizosphere: Consequences for Plant Health and Nutrition. Academic Press, ADV AGRON. 
Rodríguez-Celma, J., G. Lattanzio, D. Villarroya, E. GutierrezCarbonell, L. Ceballos-Laita, J. Rencoret, A. Gutiérrez, J.C. Del Río, M.A. Grusak, A. Abadía, J. Abadía, and A.-F. López-Millán, 2016. Effects of Fe deficiency on the protein profiles and lignin composition of stem tissues from Medicago truncatula in absence or presence of calcium carbonate. J. Proteome, 140: 1-12.

Rogelj, J., M. Den Elzen, N. Höhne, T. Fransen, H.Fekete, H. Winkler, R. Schaeffer, F. Sha, K. Riahi, and M.P. Meinshausen, 2016. Agreement climate proposals need a boost to keep warming well below 2 _C. Nature, 534: 631.

Rogers, H.H., S.A. Prior, and E.G. Oneill, 1992. Cotton root and rhizosphere responses to free-air $\mathrm{CO}_{2}$ enrichment. Critical Reviews in Plant Sciences, 11: 251-263.

Rogers, H.H., G.B. Runion, and S.V. Krupa, 1994. Plant responses to atmospheric $\mathrm{CO}_{2}$ enrichment with emphasis on roots and the rhizosphere. Environmental Pollution, 83: 155-189.

Rosenzweig, C., J. Elliott, D. Deryng, A.C. Ruane, C. Müller, A. Arneth, K.J. Boote, C. Folberth, M. Glotter, and N. Khabarov, 2014. Assessing agricultural risks of climate change in the $21 \mathrm{st}$ century in a global gridded crop model intercomparison. Proc. Natl. Acad. Sci. USA, 111: $3268-3273$.

Ruf, F., G. Schroth, and K. Doffangui, 2015. Climate change, cocoa migrations and deforestation in West Africa: What does the past tell us about the future? Sustain. Sci. 10: 101-111.

Rustioni, L., D. Grossi, L. Brancadoro, and O. Failla, 2017. Characterization of iron deficiency symptoms in grapevine (Vitis spp.) leaves by reflectance spectroscopy. Plant Physiol. Biochem., 118:342-347.

Sabir, A., and G. Sari, 2019. Zinc pulverization alleviates the adverse effect of water deficit on plant growth, yield and nutrient acquisition in grapevines (Vitis vinifera L.). Sci Hortic., 244: 61-67.

Saeed, M., A.A. Dahab, G. Wangzhen, and Z. Tianzhen, 2012. A cascade of recently discovered molecular mechanisms involved in abiotic stress tolerance of plants. Omics., 16:188-199.

Saha, S., D. Chakraborty, V.K. Sehgal, and M. Pal, 2015. Potential impact of rising atmospheric $\mathrm{CO}_{2}$ on quality of grains in chickpea (Cicer arietinum L.). Food Chem., 187:431-436

Saini, H., and D. Aspinall, 1981. Effect of water deficit on sporogenesis in wheat (Triticum aestivum L.). Ann. Bot. 48: 623-633.

Saini, H., and D. Aspinall, 1982. Abnormal sporogenesis in wheat (Triticum aestivum L.) induced by short periods of high temperature. Ann. Bot. 49: 835-846.

Sakurai, G., T. Lizumi, M. Nishimon, and M. Yokozawa, 2014. How much as the increase in atmospheric $\mathrm{CO}_{2}$ directly affected past soybean production. Scientific Reports, 4: 4978

Salvador, S.M.P., D. Torri, L. Borselli, and J. Poesen, 2008. Climate effects on soil erodibility. Earth Surface Processes and Landforms, 33:1082-1097

Sanchez-G' omez D., F. Valladares, and M.A. Zavala, 2006. Functional ' traits and plasticity in response to light in seedlings of four Iberian forest tree species," Tree Physiology, 26(11): $1425-1433$.

Santelia, D., V. Vincenzetti, E. Azzarello, et al., 2005. MDR-like ABC transporter AtPGP4 is involved in auxin mediated lateral root and root hair development. FEBS Letters, 579: 5399-5406.

Sarker U, MT Islam, and S Oba, 2018. Salinity stress accelerates nutrients, dietary fiber, minerals, phytochemicals and antioxidant activity in Amaranthus tricolor leaves. PLoS One 13: e0206388.

Sarker, U., and S. Oba, 2018. Response of nutrients, minerals, antioxidant leaf pigments, vitamins, polyphenol, flavonoid and antioxidant activity in selected vegetable amaranth under four soil water content. Food Chem., 252:72-83.

Sattar, S., M.A. Maqsood, and S. Hussain, Rahmatullah., 2011. Internal and external phosphorus requirements of maize genotypes on typic Calciargid. Communication in Soil Science and Plant Analysis, 42: 184-193.

Scagel, C.F., J. Lee, and J.N. Mitchell, 2019. Salinity from $\mathrm{NaCl}$ changes the nutrient and polyphenolic composition of basil leaves. Ind Crop Prod 127:119-128.

Schachtman, D.P., R.J. Reid, and S.M. Ayling, 1998. Phosphorus uptake by plants: from soil to cell. Plant Physiology, 116: 447-453.

Scharpenseel, H.W., M. Schomaker, and A. Ayoub, 1990. Soils on a warmer Earth: Effects of expected climate change on soil processes, with emphasis on the Tropics and SubTropics. Elsevier, Amsterdam., 273. 
Scheben, A., Y. Yuan, and D. Edwards, 2016. Advances in genomics for adapting crops to climate change. Curr. Plant Biol., 6: 2-10.

Scheiner, S.M. and C.J. Goodnight, 1984. The comparison of phenotypic plasticity and genetic variation in populations of the grass Danthonia spicata.Evolution, 38: 845-855.

Schewe, J., S.N. Gosling, C. Reyer, et al., 2019. State-of-the-art global models underestimate impacts from climate extremes. Nature Communications, 10: 1005.

Schiefelbein, J.W., 2000. Constructing a plant cell. The genetic control of root hair development. Plant Physiology, 124: 1525-1531.

Schlenker, W., and M.J. Roberts, 2009. Nonlinear temperature effects indicate severe damages to US crop yields under climate change. Proc. Natl. Acad. Sci. USA 106: 15594-15598.

Schlichting, C.D., 2002. Phenotypic plasticity in plants," Plant Species Biology, 17(2-3): 85-88.

Schmidhuber, J., and F.N. Tubiello, 2007. Global food security under climate change. Proc. Natl. Acad. Sci. USA, 104: 19703-19708.

Schofield, E.J., J.K. Rowntree, E. Paterson, and R.W. Brooker, 2018. Temporal dynamism of resource capture: a missing factor in ecology?. Trends Ecol., E33: 277-286

Sgherri, C., U. Pérez-López, F. Micaelli, J. Miranda-Apodaca, A. MenaPetite, A. Muñoz-Rueda, and M.F. Quartacci, 2017. Elevated $\mathrm{CO}_{2}$ and salinity are responsible for phenolics-enrichment in two differently pigmented lettuces. Plant Physiol. Biochem., 115:269-278.

Shabani, G., M. Ardakani, M. Chaichi, J. Friedel, and K. Khavazi, 2015. Effect of Different Fertilizing Treatments on Nutrient Uptake in Annual Medic (Medicago scutellata cv. Robinson) under Irrigated and Dry Farming Systems. J. Agric. Sci. Technol., 17: 299-310.

Shahane, A.A., Y.S. Shivay, R. Prasanna, and D. Kumar, 2019. Improving water and nutrient use efficiency in rice by changing crop establishment methods, application of microbial inoculations, and Zn fertilization. Global challenges (Hoboken, NJ) 3, 1800005.

Shahbaz, M., and M. Ashraf, 2013. Improving salinity tolerance in cereals. Crit. Rev. Plant Sci., 32:237-249.

Sharma, L., M. Priya, N. Kausha, K. Bhandhari, S. Chaudhary, O.P. Dhankher, P.V. Vara Prasad, K.H.M. Siddique, and H. Nayyar, 2020. Plant growth-regulating molecules as thermoprotectants: functional relevance and prospects for improving heat tolerance in food crops. Journal of Experimental Botany, 71: 569-594.

Shen, J.B., L.X. Yuan, J.L. Zhang, et al., 2011. Phosphorus dynamics: from soil to plant. Plant Physiology, 156: 997-1005.

Sheoran, I.S., and H.S. Saini, 1996. Drought-induced male sterility in rice: Changes in carbohydrate levels and enzyme activities associated with the inhibition of starch accumulation in pollen. Sex. Plant Reprod., 9: 161-169.

Shimono, H., T. Konno, H. Sakai, and R. Sameshima, 2012. Interactive Effects of Elevated Atmospheric $\mathrm{CO}_{2}$ and Waterlogging on Vegetative Growth of Soybean (Glycine max (L.) Merr.). Plant Prod. Sci., 15:238-245.

Sicher ,R.C., and J.Y. Barnaby, 2012. Impact of carbon dioxide enrichment on the responses of maize leaf transcripts and metabolites to water stress. Physiol Plant, 144:238-253.

Signorelli, S., J. Shaw, D. Hermawaty, Z. Wang, P. Verboven, J.A. Considine, and M.J. Considine, 2020. The initiation of bud burst in grapevine features dynamic regulation of the apoplastic pore size. Journal of Experimental Botany, 71: 719-729.

Silva, J.F., T.R. Silva, I.E.C. Escobar, A.C.R. Fraiz, J.W.M. dos Santos, T.R. do Nascimento, J.M.R. dos S.J.W.P Santos, R.F. de Melo, and D. Signor, 2018. Screening of plant growth promotion ability among bacteria isolated from field-grown sorghum under different managements in Brazilian drylands. World J Microbiol Biotechnology, 34:186.

Sinclair, T.R., C.B. Tanner, and J.M. Bennett, 1983. Water-use efficiency in crop production. Bio. Science, 34: 36-40.

Singh, S.K., G. Badgujar, V.R. Reddy, D.H. Fleisher, and J.A. Bunce, 2013. Carbon dioxide diffusion across stomata and mesophyll and photo-biochemical processes as affected by growth $\mathrm{CO}_{2}$ and phosphorus nutrition in cotton. J. Plant Physiol., 170:801-813.

Singh, S.K., and V.R. Reddy, 2014. Combined effects of phosphorus nutrition and elevated carbon dioxide concentration on chlorophyll fluorescence, photosynthesis, and nutrient efficiency of cotton. J Plant Nutr Soil SC., 177: 892-892-902 
Singh, S.K., and V.R. Reddy, 2018. Co-regulation of photosynthetic processes under potassium deficiency across $\mathrm{CO}_{2}$ levels in soybean: mechanisms of limitations and adaptations. Photosynth Res. 137:183-200

Skene, K.R., 2000. Pattern formation in cluster roots: some developmental and evolutionary considerations. Ann. Bot. 85: 901-908.

Smethurst, C.F., T. Garnett, and S. Shabala, 2005. Nutritional and chlorophyll fluorescence responses of lucerne (Medicago sativa) to waterlogging and subsequent recovery. Plant Soil, 270:31- 45.

Song, C., F.I.V. Ballantyne, and V.H. Smith, 2014. Enhanced dissolved organic carbon production in aquatic ecosystems in response to elevated atmospheric $\mathrm{CO}_{2}$. Biogeochemistry, 118: 49-60.

Specht, J.E., D.J. Hume, and S.V. Kumudini, 1999. Soybean yield potential—a genetic and physiological perspective. Crop Science, 39: 1560-1570.

Spencer, W.E., J. Teeri, and R.G. Wetzel, 1994. Acclimation of photosynthetic phenotype to environmental heterogeneity. Ecology, 75(2): 301-314.

Spohn, M., and Y. Kuzyakov, 2013. Phosphorus mineralization can be driven by microbial need for carbon. Soil Biology and Biochemistry, 61: 69-75.

Spreitzer, R.J.S., and M.E. Rubisco, 2002. Structure, regulatory interactions, and possibilities for a better enzyme. Annu. Rev. Plant Biol. 53: 449-475.

Srivastava, A.K., A. Shankar, A.K.N. Chandran, M. Sharma, K.H. Jung, P. Suprasanna, and G.K. Pandey, 2020. Emerging concepts of potassium homeostasis in plants. Journal of Experimental Botany, 71: 608-619.

Staddon, P.L., R. Gregersen, and I. Jakobsen, 2004. The response of two Glomus mycorrhizal fungi and a fine endophyte to elevated atmospheric $\mathrm{CO}_{2}$, soil warming and drought. Global Change Biology, 10:1909-1921.

Steffens, D., B. Hutsch, T. Eschholz, T. Losak, and S. Schubert, 2005. Water logging may inhibit plant growth primarily by nutrient deficiency rather than nutrient toxicity. Plant Soil Environ.

Stewart, Z.P., G.M. Pierzynski, B.J. Middendorf, and P.V.V. Prasad, 2020. Approaches to improve soil fertility in Sub-Sahara Africa. Journal of Experimental Botany, 71: 632-641.

Stitt, M., and A. Krapp, 1999. The interaction between elevated carbon dioxide and nitrogen nutrition: the physiological and molecular background. Plant, Cell and Environment, 22: 583-621.

Sto"cklin, J., and C. Ko"rner, 1999. Interactive effects of elevated $\mathrm{CO}_{2}, \mathrm{P}$ availability and legume presence on calcareous grassland: results of a glasshouse experiment. Functional Ecology, 13: 200-209.

Sublett, W., T. Barickman, and C. Sams, 2018. Effects of elevated temperature and potassium on biomass and quality of dark red 'Lollo Rosso' lettuce. Hortic., 4:11.

Sulpice, R., 2020. Closing the yield gap: can metabolomics be of help. Journal of Experimental Botany, 71: 461-464.

Sultan, S.E., 2000. Phenotypic plasticity for plant development, function and life history. Trends in Plant Science, 5(12): 537-542,

Suzuki, N., R.M. Rivero, V. Shulaev, E. Blumwald, and R. Mittler, 2014. Abiotic and biotic stress combinations. New Phytol., 203: 32-43.

Svistoonoff, S., A. Creff, M. Reymond, C. Sigoillot-Claude, L. Ricaud, A. Blanchet, L. Nussaume, T. Desnos, 2007. Root tip contact with low-phosphate media reprograms plant root architecture. Nat. Genet., 39: 792-796

Svoboda, N., M. Strer, and J. Hufnagel, 2015. Rainfed winter wheat cultivation in the North German Plain will be water limited under climate change until 2070. Environ. Sci. Eur., 27: 29.

Szabolcs, I., 1990. Impact of climate change on soil attributes: Influence on salinization and alkalinization. In Developments in soil science, (20): 61-69). Amsterdam, the Netherlands: Elsevier.

Tang, C., C.D.A. McLay, and L. Barton, 1997. A comparison of proton excretion of twelve pasture legumes grown in nutrient solution. Australian Journal of Experimental Agriculture, 37: 56370.

Tani, E., E. Abraham, D. Chachalis, and I. Travlos, 2017. Molecular, genetic and agronomic approaches to utilizing pulses as cover crops and green manure into cropping systems. Int. J. Mol. Sci., 18:1202. 
Tarafdar, J.C., and N. Claassen, 2001. Comparative efficiency of acid phosphatase originated from plant and fungal sources. Journal of Plant Nutrition and Soil Science, 164: 279-282.

Tarafdar, J.C., 1995. Effect of vesicular-arbuscular mycorrhizal and phosphatase producing fungal inoculation on growth and nutrition of white clover supplied with organic phosphorus. Folia Microbiological, 40: 327-332.

Taranto, F., A. Nicolia, S. Pavan, P. De Vita, and N D’Agostino, 2018. Biotechnological and digital revolution for climate-smart plant breeding. Agronomy, 8: 277.

Tarekegne, A., A. Bennie, and M. Labuschagne, 2000. Effects of soil waterlogging on the concentration and uptake of selected nutrients in wheat genotypes differing in tolerance. The eleventh regional wheat workshop for eastern, central and southern Africa, Addis Abeba, Ethiopia, Addis Ababa.

Tarnawski, S., and M. Aragno, 2006. The influence of elevated $\mathrm{CO}_{2}$ on diversity, activity and biogeochemical function of rhizosphere and soil bacterial communities. In: Nösberger J, Long $\mathrm{SP}$, et al., editors. Managed ecosystems and $\mathrm{CO}_{2}$ case studies, processes and perspectives. Ecological studies Series, Berlin: Springer, 187: 393-409.

Taub, D.R., and X. Wang, 2008. Why are Nitrogen Concentrations in Plant Tissues Lower under Elevated $\mathrm{CO}_{2}$ ? A Critical Examination of the Hypotheses. J. Integr. Plant Biol. 50:1365-1374.

Tebaldi, C., and D. Lobell, 2018. Estimated impacts of emission reductions on wheat and maize crops. Clim. Chang., 146, 533-545.

Thimm, O., B. Essigmann, S. Kloska, T. Altmann, and T.J. Buckhout, 2001. Response of Arabidopsis to Iron Deficiency Stress as Revealed by Microarray Analysis. Plant Physiol., 127: 1030-1043.

Thomas, J.M.G., K.J. Boote, L.H. Allen, M. Gallo-Meagher, J.M. Davis, 2003. Elevated Temperature and Carbon Dioxide Effects on Soybean Seed Composition and Transcript Abundance. Crop Sci., 43:1548 - 1557.

Tian, Q.Y., X.X. Zhang, Y. Gao, et al., 2013. Wheat genotypes differing in aluminum tolerance differ in their growth response to $\mathrm{CO}_{2}$ enrichment in acid soils. Ecology and Evolution, 3: 1440-1448.

Ticconi, C.A., and S. Abel, 2004. Short on phosphate: plant surveillance and countermeasures. Trends Plant Sci., 9:548-555

Toreti, A., S. Bassu, A. Ceglar, and M. Zampieri, 2019. Climate Change and Crop Yields. In: Ferranti P, Berry EM, Anderson JR (eds) Encyclopedia of Food Security and Sustainability. Elsevier, Oxford .

Treseder, K.K., 2004. A meta-analysis of mycorrhizal responses to nitrogen, phosphorus, and atmospheric $\mathrm{CO}_{2}$ in field studies. New Phytologist, 164: 347-355.

Tubiello, F.N., M. Donatelli, C. Rosenzweig, and C.O. Stockle, 2000. Effects of climate change and elevated $\mathrm{CO}_{2}$ on cropping systems: Model predictions at two Italian locations. Eur. J. Agron., 13: $179-189$.

Uhde-Stone, C., G. Gilbert, J.M.F. Johnson, R. Litjens, K.E. Zinn, S.J. Temple, C.P. Vance, and D.L. Allan, 2003. Acclimation of white lupin to phosphorus deficiency involves enhanced expression of genes related to organic acid metabolism. Plant and Soil, 248: 99-116.

Ukkola, A.M., I.C. Prentice, T.F. Keenan, A.I.J.M. van Dijk, N.R. Viney, R.B. Myneni, and J. Bi, 2015. Reduced streamflow in water-stressed climates consistent with $\mathrm{CO}_{2}$ effects on vegetation, Nat. Clim. Chang., 6: 75-78,

Ulmasov, T., J. Murfett, G. Hagen, and T.J. Guilfoyle, 1997. Aux/1AA proteins repress expression of reporter genes containing natural and highly active synthetic auxin response elements. Plant Cell, 9: 1963-1971

Valladares F., D. Sanchez-Gomez, and M.A. Zavala, 2006. Quantitative estimation of phenotypic plasticity: bridging the gap between the evolutionary concept and its ecological applications.Journal of Ecology, 94(6): 1103-1116.

Valladares F., E. Gianoli, and J.M. Gomez, 2007. Ecological limits to ' plant phenotypic plasticity. New Phytologist, 176(4): 749-763.

Valladares F., E. Martinez-Ferri, L. Balaguer, E. Perez-Corona, and E. Manrique, 2000. Low leaf-level response to light and nutrients in Mediterranean evergreen oaks: a conservative resource-use strategy. New Phytologist, 148(1): 79-91.

Valladares F., J. Chico, I. Aranda et al., 2002. The greater seedling high-light tolerance of Quercus robur over Fagus sylvatica is linked to a greater physiological plasticity. Trees-Structure and Function, 16(6): 395-403. 
Valladares F., L. Balaguer, E. Martinez-Ferri, E. Perez-Corona, and E. Manrique, 2002. Plasticity, instability and canalization: Is the phenotypic variation in seedlings of sclerophyll oaks consistent with the environmental unpredictability of Mediterranean ecosystems. New Phytologist, 156(3): 457-467.

Van Ginkel, J.H., A. Gorissen, and D. Polci, 2000. Elevated atmospheric carbon dioxide concentration: effects of increased carbon input in a Lolium perenne soil on microorganisms and decomposition. Soil Biology and Biochemistry, 32: 449-456.

Van Kleunen, M. and M. Fischer, 2005. Constraints on the evolution of adaptive phenotypic plasticity in plants," New Phytologist, 166(1): 49-60.

Van Velthuizen, H., 2007. Mapping Biophysical Factors That Influence Agricultural Production and Rural Vulnerability; Food and Agriculture Organization: Rome, Italy.

Vasconcelos, M., T. Clemente, and M. Grusak, 2014. Evaluation of constitutive iron reductase (AtFRO2) expression on mineral accumulation and distribution in soybean (Glycine max. L). Front. Plant Sci., 5.

Vasconcelos, M.W., W. Gruissem, and N.K. Bhullar, 2017. Iron biofortification in the 21st century: setting realistic targets, overcoming obstacles, and new strategies for healthy nutrition. Curr. Opin. Biotechnol., 44:8-15

Vaughan, M.M., A. Block, S.A. Christensen, L.H. Allen, and E.A. Schmelz, 2018. The effects of climate change associated abiotic stresses on maize phytochemical defenses. Phytochem. Rev., 17: $37-49$.

Velu, G., C. Guzman, S. Mondal, J.E. Autrique, J. Huerta, and R.P. Singh, 2016. Effect of drought and elevated temperature on grain zinc and iron concentrations in CIMMYT spring wheat. J. Cereal. Sci., 69:182-186.

Veneklaas, E.J., H. Lambers, J. Bragg, et al., 2012. Opportunities for improving phosphorus-use efficiency in crop plants. New Phytologist, 195: 306-320

Veresoglou, S.D., G. Menexes, and M.C. Rillig, 2012. Do arbuscular mycorrhizal fungi affect the allometric partition of host plant biomass to shoots and roots? A meta-analysis of studies from 1990 to 2010. Mycorrhiza, 22: 227-235.

Vestergren, J., A.G. Vincent, P. Jansson, et al., 2012. High-resolution characterization of organic phosphorus in soil extracts using 2D 1H-31P NMR correction spectroscopy. Environmental Science and Technology, 46: 3950-3956.

Via, S. and R. Lande, 1987. Evolution of genetic variability in a spatially heterogeneous environment: effects of genotype environment interaction. Genetical Research, 49(2): 147-156.

Via, S., R. Gomulkiewicz, G. De Jong, S.M. Scheiner, C.D. Schlichting, and P.H. Van Tienderen, 1995. Adaptive phenotypic plasticity: consensus and controversy. Trends in Ecology and Evolution, 10(5): 212-217.

Vicente, R., R. Martínez-Carrasco, P. Pérez, and R. Morcuende, 2018. New insights into the impacts of elevated $\mathrm{CO}_{2}$, nitrogen, and temperature levels on the regulation of $\mathrm{C}$ and $\mathrm{N}$ metabolism $\mathrm{n}$ durum wheat using network analysis. New Biotechnol., 40: 192-199.

Viswanath, T., D. Pal, and T.J. Purakayastha, 2010. Elevated $\mathrm{CO}_{2}$ reduces rate of decomposition of rice and wheat residues in soil. Agriculture, Ecosystems and Environment, 139: 557-564.

Von Caemmerer, S. and J.R. Evans, 2010. Enhancing C3 photosynthesis. Plant Physiol., 154, 589-592

Vu, D.T., R.D. Armstrong, P.W.G. Sale, and C. Tang, 2010. Phosphorus availability for three crop species as a function of soil type and fertilizer history. Plant and Soil, 337: 497-510.

Vu, D.T., C. Tang, and R.D. Armstrong, 2008. Changes and availability of P fractions following 65 years of P application to a calcareous soil in a Mediterranean climate. Plant and Soil 304: 2133.

$\mathrm{Vu}$, J.C., and L.H.J. Allen, 2009. Stem juice production of the C4 sugarcane (Saccharum officinarum) is enhanced by growth at double-ambient $\mathrm{CO}_{2}$ and high temperature. J Plant Physiol., 166:1141-1151.

Waitt, D. E. and D.A. Levin, 1998. Genetic and phenotypic correlations in plants: a botanical test of Cheverud's conjecture. Heredity, 80(3): 310-319.

Wand, S.J.E., G.F. Midgley, M.H. Jones, and P.S. Curtis, 1999. Responses of wild C4 and C3 grass (Poaceae) species to elevated atmospheric $\mathrm{CO}_{2}$ concentration: a meta-analytic test of current theories and perceptions. Global Change Biology, 5: 723-741. 
Wang, A., S.K. Lam, X. Hao, F.Y. Li, Y. Zong, H. Wang, and P. Li, 2018a. Elevated $\mathrm{CO}_{2}$ reduces the adverse effects of drought stress on a high-yielding soybean (Glycine max (L.) Merr.) cultivar by increasing water use efficiency. Plant Physiol Biochem., 132: 660-665.

Wang, G.-X., Y.-F. Bai, and J.-X. Liao, 2004. Effects of elevated $\mathrm{CO}_{2}$ concentration on growth, water use, yield and grain quality of wheat under two soil water levels. Agric Ecosyst Environ., 104:493-507

Wang, J., T. Zhu, H. Ni, H. Zhong, X. Fu, and J. Wang, 2013. Effects of elevated $\mathrm{CO}_{2}$ and nitrogen deposition on ecosystem carbon fluxes on the Sanjiang plain wetland in Northeast China. PLOS one, 8: e66563

Wang, Y., X. Hu, Z. Hou, J. Ning, and Z. Zhang, 2018b. Discrimination of nitrogen fertilizer levels of tea plant (Camellia sinensis) based on hyperspectral imaging. J. Sci. Food Agric., 98:46594664.

Wang, Z., and B. Huang, 2004. Physiological recovery of Kentucky bluegrass from simultaneous drought and heat stress. Crop Sci., 44: 1729-1736.

Wasaki, J., A. Rothe, A. Kania, et al., 2005. Root exudation, phosphorus acquisition, and microbial diversity in the rhizosphere of white lupine as affected by phosphorus supply and atmospheric carbon dioxide concentration. Journal of Environmental Quality, 34: 2157-2166.

Wasaki, J., R. Yonetani, S. Kuroda, T. Shinano, J. Yazaki, F. Fujii, K. Shimbo, K. Yamamoto, K. Sakata, and T. Sasaki, 2003. Transcriptomic analysis of metabolic changes by phosphorus stress in rice plant roots. PLANT CELL ENVIRON, 26: 1515-1523.

Watt, M., and J.R. Evans, 1999. Linking development and determinacy with organic acid efflux from proteoid roots of white lupin grown with low phosphorus and ambient or elevated atmospheric $\mathrm{CO}_{2}$ concentration. Plant Physiology, 120: 705-716.

Watts-Williams, S.J., F. Andrew Smith, and I Jakobsen, 2019. Soil phosphorus availability is a driver of the responses of maize (Zea mays) to elevated $\mathrm{CO}_{2}$ concentration and arbuscular mycorrhizal colonisation. Symbiosis, 77:73-82.

Wei, X., M. Liu, S. Wang, and M. Jiang, 2018. Seed morphological traits and seed element concentrations of an endangered tree species displayed contrasting responses to waterlogging induced by extreme precipitation. Flora, 246-247:19-25.

Weigelt, A. and P. Jolliffe, 2003. Indices of plant competition. Journal of Ecology, 91(5): 707-720.

Weil, R.R., and F. Magdoff, 2004. Significance of soil organic matter to soil quality and health. In: Magdoff F, Weil RR. (eds.), Soil organic matter in sustainable agriculture. CRC press, Florida, $1-43$.

Weisskopf, L., E. Abou-mansour, N. Fromin, N. Tomasi, D. Santelia, I. Edelkott, G. Neumann, M. Aragno, R. Tabacchi, and E. Martinoia, 2006. White lupin has developed a complex strategy to limit microbial degradation of secreted citrate required for phosphate acquisition. Plant, Cell and Environment, 29: 919-927.

Wen, Z., H. Li, J. Shen, and Z. Rengel, 2017. Maize responds to low shoot P concentration by altering root morphology rather than increasing root exudation. Plant Soil, 416: 377-389.

Wenzel, C.L., A.E. Ashford, and B.A. Summerell, 1994. Phosphate- solubiliZing bacteria associated with proteoid roots of seedlings of waratah [Telopea speciossima (Sm.) R.Br.]. New Phytologist, 128: 487-496.

Wesseler, J., and D. Zilberman, 2014. The economic power of the Golden Rice opposition. Environ Dev Econ., 19:724-742.

Wheeler, T., and J. Von Braun, 2013. Climate change impacts on global food security. Science, 341: 508-513.

Whitehead, S.J., S.J.M. Caporn, and M.C. Press, 1997. Effects of elevated $\mathrm{CO}_{2}$, nitrogen and phosphorus on the growth and photosynthesis of two upland perennials: Calluna vulgaris and Pteridium aquilinum. New Phytologist, 135: 201-211.

Wijewardana, C., K.R. Reddy, and N. Bellaloui, 2019. Soybean seed physiology, quality, and chemical composition under soil moisture stress. FOOD CHEM, 278: 92-92-100.

Winkel, T., J.-F. Renno, and W. Payne, 1997. Effect of the timing of water deficit on growth, phenology and yield of pearl millet (Pennisetum glaucum (L.) R. Br.) grown in Sahelian conditions. J. Exp. Bot. 48: 1001-1009. 
Wissuwa, M., G. Gamat, and A.M. Ismail, 2005. Is root growth under phosphorus deficiency affected by source or sink limitations? J. Exp. Bot., 56:1943-1950.

Wolf, J., 1996. Effects of nutrient supply (NPK) on spring wheat response to elevated atmospheric $\mathrm{CO}_{2}$. Plant and Soil, 185: 113-123.

Wungrampha, S., R. Joshi, R.S. Rathore, S.L. Singla-Pareek, and A.P. Govindjee, 2019. $\mathrm{CO}_{2}$ uptake and chlorophyll a fluorescence of Suaeda fruticosa grown under diurnal rhythm and after transfer to continuous dark. Photosynth Res., 142: 211.

$\mathrm{Xu}, \mathrm{M} ., \mathrm{Z}$. He, Y. Deng, et al., 2013. Elevated $\mathrm{CO}_{2}$ influences microbial carbon and nitrogen cycling. BMC Microbiology, 13: 124.

Xu, Z.Z., and G.S. Zhou, 2006. Combined effects of water stress and high temperature on photosynthesis, nitrogen metabolism and lipid peroxidation of a perennial grass Leymus chinensis. Planta., 224: 1080-1090.

Xue, Y., H. Xia, P. Christie, Z. Zhang, L. Li, and C. Tang, 2016. Crop acquisition of phosphorus, iron and zinc from soil in cereal/ legume intercropping systems: a critical review. Ann. BotLondon, 117:363-377

Yang, L., Y. Wang, G. Dong, H. Gu, J. Huang, J. Zhu, H. Yang, G. Liu, and Y. Han, 2007. The impact of free-air $\mathrm{CO}_{2}$ enrichment (FACE) and nitrogen supply on grain quality of rice. Field Crop Res., 102:128-140

Yang, L.X., Y.L. Wang, J.Y. Huang, et al., 2007. Seasonal changes in the effects of free-air $\mathrm{CO}_{2}$ enrichment (FACE) on phosphorus uptake and utilization of rice at three levels of $\mathrm{N}$ fertilization. Field Crops Research, 102: 141-150.

Yao, Z., X. Zheng, C. Liu, S. Lin, Q. Zuo, and K. Butterbach- Bahl, 2017. Improving rice production sustainability by reducing water demand and greenhouse gas emissions with biodegradable films. Scientific Reports 7, 39855. Ye H, Song L, Schapaugh WT, et al., 2020. The importance of slow canopy wilting in drought tolerance in soybean. Journal of Experimental Botany 71, 642-652.

Yeo, A., 1999. Predicting the interaction between the effects of salinity and climate change on crop plants. Scientia Horticulturae, 78: 159-174.

Yilmaz, O., K. Kahraman, R. Ozgur, B. Uzilday, I. Turkan, and L. Ozturk, 2017a. Growth performance and antioxidative response in bread and durum wheat plants grown with varied potassium treatments under ambient and elevated carbon dioxide. Environ. Exp. Bot., 137:26-35.

Yilmaz, O., K. Kahraman, and L. Ozturk, 2017b. Elevated carbon dioxide exacerbates adverse effects of $\mathrm{Mg}$ deficiency in durum wheat. Plant Soil, 410:41-50.

Yu, J., H. Du, M. Xu, and B. Huang, 2012. Metabolic responses to heat stress under elevated atmospheric $\mathrm{CO}_{2}$ concentration in a cool-season grass species. J. Am. Soc. Hortic. Sci., 10.21273/ JASHS.137.4.221, 137:221-228

Yu, J., L. Sun, N. Fan, Z. Yang, and B. Huang, 2015. Physiological factors involved in positive effects of elevated carbon dioxide concentration on Bermudagrass tolerance to salinity stress. Environ. Exp. Bot., 115:20-27.

Yuhui, W., Y. Denghua, W. Junfeng, D. Yi, and S. Xinshan, 2017. Effects of elevated $\mathrm{CO}_{2}$ and drought on plant physiology, soil carbon and soil enzyme activities. Pedosphere, 27:846-855

Zaehle, S., P. Friedlingstein, and A.D. Friend, 2010. Terrestrial nitrogen feedbacks may accelerate future climate change. Geophysical Research Letters, 37, L01401.

Zafar, S.A., S.S. Zaidi, Y. Gaba, S.N. Singla-Pareek, O. Parkash Dhankher, X. Li, S. Mansoor, and A. Pareek, 2020. Engineering abiotic stress tolerance via CRISPR-Cas mediated genome editing. Journal of Experimental Botany, 71: 470-479.

Zaghdoud, C., M. Carvajal, A. Ferchichi, and M.-B.M. Del Carmen, 2016. Water balance and Nmetabolism in broccoli (Brassica oleracea L. var. Italica) plants depending on nitrogen source under salt stress and elevated $\mathrm{CO}_{2}$. Sci. Total Environ., 571: 763-771

Zaghdoud, C., C. Mota-Cadenas, M. Carvajal, B. Muries, A. Ferchichi, and M.C. Martínez- Ballesta, 2013. Elevated $\mathrm{CO}_{2}$ alleviates negative effects of salinity on broccoli (Brassica oleracea L. var Italica) plants by modulating water balance through aquaporins abundance. Environ. Exp. Bot., 95:15-24. 
Zak, D.R., K.S. Pregitzer, P.S. Curtis, J.A. Teeri, R. Fogel, and D.L. Randlett, 1993. Elevated atmospheric $\mathrm{CO}_{2}$ and feedback between carbon and nitrogen cycles. Plant and Soil, 151: 105117.

Zavaleta, E.S., M.R. Shaw, N.R. Chiariello, B.D. Thomas, E.E. Cleland, C.B. Field, and H.A. Mooney, 2003. Grassland responses to three years of elevated temperature, $\mathrm{CO}_{2}$, precipitation, and $\mathrm{N}$ deposition. Ecological Monographs, 73: 585-604.

Zeng, N., Z. Yang, Z. Zhang, L. Hu, and L. Chen, 2019. Comparative Transcriptome Combined with Proteome Analyses Revealed Key Factors Involved in Alfalfa (Medicago sativa) Response to Waterlogging Stress. Int. J. Mol. Sci., 20:1359.

Zhang, F., J. Shen, J. Zhang, Y. Zuo, L. Li, and X. Chen, 2010. Rhizosphere processes and management for improving nutrient use efficiency and crop productivity: implications for China. Advances in Agronomy, 107: 1-32.

Zhang, G., T. Zhang, J. Liu, J. Zhang, and C. He, 2018. Comprehensive analysis of differentially expressed genes reveals the molecular response to elevated $\mathrm{CO}_{2}$ levels in two sea buckthorn cultivars. Gene, 660:120-127.

Zhang, H.J., P.W. Barlow, and B.G. Forde, 1999. Dual pathways for regulation of root branching by nitrate. Proc Natl Acad Sci USA, 96:6529-6534

Zhang, Y., X.M. Chen, C.C. Zhang, G.X. Pan, and X.H. Zhang, 2014. Availability of soil nitrogen and phosphorus under elevated $\left[\mathrm{CO}_{2}\right]$ and temperature in the Taihu Lake region, China. Journal of Plant Nutrition and Soil Science, 177: 343-348.

Zhang, C., R.J. Simpson, C.M. Kim, N. Warthmann, E. Delhaize, L. Dolan, M.E. Byrne, Y. Wu, and P.R. Ryan, 2018. Do longer root hairs improve phosphorus uptake? Testing the hypothesis with transgenic Brachypodium distachyon lines overexpressing endogenous RSL genes. New Phytol., 217: 1654-1666.

Zhao, X., S.L. Liu, C. Pu, X.Q. Zhang, J.F. Xue, R. Zhang, Y.Q. Wang, R. Lal, H.L. Zhang, and F. Chen, 2016. Methane and nitrous oxide emissions under no-till farming in China: a metaanalysis. Glob. Chang Biol., 22:1372-1384.

Zhao, X.Z., G.-X. Wang, Z.X. Shen, H. Zhang, and Q. M-Q, 2006. Impact of elevated CO 2 concentration under three soil water levels on growth of Cinnamomum camphora. J Zhejiang Univ Sci B., 7: 283-290

Zhao, C., B. Liu, S. Piao, X.Wang, D.B. Lobell, Y. Huang, M. Huang, Y. Yao, S. Bassu, and P. Ciais, 2017. Temperature increase reduces global yields of major crops in four independent estimates. Proc. Natl. Acad. Sci. USA. 114: 9326-9331.

Zheng, H., T. Cheng, D. Li, X. Yao, Y. Tian, W. Cao, and Y. Zhu, 2018. Combining Unmanned Aerial Vehicle (UAV)-Based Multispectral Imagery and Ground-Based Hyperspectral Data for Plant Nitrogen Concentration Estimation in Rice. Front Plant Sci., 9:936.

Zheng, X., B. Chen, G. Lu, and B. Han, 2009. Overexpression of a NAC transcription factor enhances rice drought and salt tolerance. Biochem. Biophys. Res. Commun. 379: 985-989.

Zhu, H., H. Liu, Y. Xu, and Y. Guijun, 2018a. UAV-based hyperspectral analysis and spectral indices constructing for quantitatively monitoring leaf nitrogen content of winter wheat. Appl. Opt., 57:7722-7732

Zhu, X., F. Song, S. Liu, F. Liu, and X. Li, 2018b. Arbuscular mycorrhiza enhances nutrient accumulation in wheat exposed to elevated $\mathrm{CO}_{2}$ and soil salinity. J. Plant Nutr. Soil Sc., $181: 836-846$

Zhu, X.G., E. de Sturler, and S.P. Long, 2007. Optimizing the distribution of resources between enzymes of carbon metabolism can dramatically increase photosynthetic rate: a numerical simulation using an evolutionary algorithm. Plant Physiol., 145: 513-526.

Zhu, X.G., S.P. Long, and D.R. Ort, 2010. Improving photosynthetic efficiency for greater yield. Annu. Rev. Plant Biol., 61: 235-261

Zhu, C., L. Bortesi, C. Baysal, R.M. Twyman, R. Fischer, T. Capell, S. Schillberg, and P. Christou, 2017. Characteristics of genome editing mutations in cereal crops. Trends Plant Sci., 22: 38 52.

Ziervogel, G., and P.J. Ericksen, 2010. Adapting to climate change to sustain food security. Wiley Interdisciplinary Reviews: Climate Change, 1: 525-540 
Zinselmeier, C., M.E. Westgate, J.R. Schussler, and R.J. Jones, 1995. Low water potential disrupts carbohydrate metabolism in maize (Zea mays L.) ovaries. Plant Physiol., 107: 385-391.

Ziska, L.H., and J.A. Bunce, 2007. Predicting the impact of changing $\mathrm{CO}_{2}$ on crop yields: some thoughts on food. New Phytol., 175:607-618

Zocchi, G., 2006. Metabolic changes in iron stressed dicotiledoneus plants. In: Barton LL, Abadía J (eds) Iron Nutrition in Plants and Rizospheric Microorganisms. Springer, Dordrecht, The Netherlands.

Zocchi, G., P. De Nisi, M. Dell'Orto, L. Espen, and P.M. Gallina, 2007. Iron deficiency differently affects metabolic responses in soybean roots. J. Exp. Bot., 58(5):993-1000.

Zong, Y.-Z., and Z.P. Shangguan, 2014. Nitrogen Deficiency Limited the Improvement of Photosynthesis in Maize by Elevated $\mathrm{CO}_{2}$ under Drought. J. Integr. Agric. 13:73-81.

Zunzunegui M., F. Ain-Lhout, M.C.D. Barradas, L. Alvarez- ' Cansino, M.P. Esquivias, and F. Garc'1a Novo, 2009. Physiological, morphological and allocation plasticity of a semi-deciduous shrub.Acta Oecologica, 35(3): 370-379.

Zunzunegui M., M.C.D. Barradas, F. Ain-Lhout, L. AlvarezCansino, M.P. Esquivias, and F.G. Novo, 2011. Seasonal physiological plasticity and recovery capacity after summer stress in Mediterranean scrub communities. Plant Ecology, 212(1): 127-142. 